\title{
(ब)
}

AUTARQUIA ASSOCIADA À UNIVERSIDADE DE SÃO PAULO

\section{EFEITOS DA RADIAÇÃO IONIZANTE NAS PROPRIEDADES DE COMPÓSITOS DE POLIAMIDA 6 COM DIÓXIDO DE SILÍCIO COLOIDAL (AEROSIL ${ }^{\circledR}$ )}

\author{
Camila Almeida Amorim
}

Dissertação apresentada como parte dos requisitos para obtenção do Grau de Mestre em Ciências na Área de Tecnologia Nuclear - Aplicações

Orientador:

Prof. Dr. Leonardo Gondim de Andrade e Silva 
INSTITUTO DE PESQUISAS ENERGÉTICAS E NUCLEARES

Autarquia associada à Universidade de São Paulo

\title{
EFEITOS DA RADIAÇÃO IONIZANTE NAS PROPRIEDADES DE COMPÓSITOS DE POLIAMIDA 6 COM DIÓXIDO DE SILÍCIO COLOIDAL (AEROSIL ${ }^{\circledR}$ )
}

\author{
Camila Almeida Amorim
}

Dissertação apresentada como parte dos
requisitos para obtenção do Grau de
Mestre em Ciências na Área
de Tecnologia Nuclear-Aplicações
Orientador:

Prof. Dr. Leonardo Gondim de Andrade e Silva

Versão Corrigida

Versão Original disponível no IPEN

São Paulo

2017 
Dedico o presente trabalho aos meus pais Ubiranam de Almeida Amorim e Jose Alves Amorim pelos ensinamentos e apoio incondicional dados a mim, à minha irmã Suelen Almeida Amorim, ao meu irmão Douglas Almeida Amorim por me aguentarem nos momentos difíceis e a minha tia Marlene Alves Amorim por sempre encorajar-me com palavras de estímulo. 


\section{AGRADECIMENTOS}

Ao meu orientador Prof. Dr. Leonardo Gondim de Andrade e Silva pela oportunidade, pelos ensinamentos, conversas e pelo incentivo em adquirir conhecimentos e por toda ajuda no desenvolvimento do trabalho.

Ao Instituto de Pesquisas Energéticas e Nucleares IPEN-CNEN/SP pelo suporte para o desenvolvimento do trabalho de mestrado.

A Profa. Dra. Luci Diva Brocado Machado pela contribuição na realização deste trabalho.

Ao Prof. Dr. Rafael Traldi Moura do Departamento de Mecatrônica e Sistemas Mecânicos da Escola Politécnica da USP pela sua contribuição para realização deste trabalho, pela sua paciência, ensinamentos e pelo interesse no trabalho.

Ao Prof. Dr. Edvaldo Luis Rossini do Centro Universitário Fundação Santo André, pelo apoio e incentivo.

Ao Prof. Dr. Waldir Ferro pelo fornecimento dos materiais utilizados neste trabalho.

Ao Prof. Julio Harada e ao aluno de iniciação cientifíca lan Trolles Cavalcante por toda ajuda técnica na realização deste trabalho.

Aos secretários Marcos Cardoso e Cláudia Regina Nolla do Centro de Tecnologia da Radiação - IPEN pelo auxílio dado a mim e pela amizade.

Aos engenheiros Elizabeth Somessari Ribeiro, Carlos Gaia da Silveira, ao Dr. Nelson Minoru Omi do Centro de Tecnologia das Radiações - IPEN pela gentileza e auxílio no processamento por irradiação das amostras.

À Comissão Nacional de Energia Nuclear - CNEN pela bolsa de mestrado concedida.

À Dra. Amanda Cristina Ramos Koike pela ajuda dada em minha jornada, pela parceria nos momentos bons e nos difíceis também, e pela contribuição na parte estrutural do trabalho, mas principalmente pela sua amizade.

Aos meus amigos e colegas MSc. Jorge Sales, Jessica Lanzoni Moura, Pedro Zandonadi e Victor Cruz pela ajuda técnica e fornecimento da matéria prima deste trabalho. 
À Profa. Dra. Sonia Heilman, a MSc. Ana Paula Funari do CTR e a MSc. Luana dos Santos Andrade da UFABC por toda sua ajuda com o trabalho, pela sua amizade e pelos momentos únicos proporcionados por suas pessoas.

Aos amigos do CTR, Regiane Martins, Dra. Angélica Barbezan, MSc. Bruna Saporito Teixeira, Jaqueline J. Souza, Luiza Ferreira, Juliana, MSc. Luciana Vieira de Santana e MSc. Djalma Batista Dias.

Aos amigos e colegas do laboratório GMSIE da Escola Politécnica da Universidade de São Paulo, Vinicius Cruz, Herinque Ramos, Bruno Mussulini, Vitor Hartmann, Pouria Ataabadi, MSc. Ouronon Marie R. Beugre, Victor Siqueira Chaim, Mohammad Shaterzadeh, Miguel Calle, Dr. Leonardo Mazzariol, Decio de Moura Rinaldi, Prof. Dr. Marcílio Alves e Profa. Dra. Larissa Driemeier por toda ajuda no aprendizado e momentos de descontração.

Aos amigos americanos, Kathy Ellis MacKintosh, Jeremiah Alisson, Jefferson Rotta, Kyle Harrer e sua esposa e a minha grande amiga brasileira Debora Harrer por toda a ajuda com tradução dos trabalhos e dos artigos para a língua inglesa.

As minhas grandes amigas Lara Neres Diniz, Jessica Luiza Moura da Hora e Tássia Souza Barreto, por todo apoio e ajuda na tradução dos trabalhos e dos artigos para a língua inglesa.

À todos que não foram citados, mas que de alguma forma colaboraram para a realização deste trabalho. 
"A vída não é fácíl para nenhum de nós. Temos que ter persístêncía e, acíma de tudo, confíança em nós mesmos.” Marie Curie 


\section{RESUMO}

AMORIM, Camila A. Efeitos da radiação ionizante nas propriedades de compósitos de poliamida $6 \mathrm{com}$ dióxido de silício coloidal (AEROSIL ${ }^{\circledR}$ ). 2017. 91 p. Dissertação (Mestrado em Tecnologia Nuclear) - Instituto de Pesquisas Energéticas e Nucleares - IPEN-CNEN/SP. São Paulo

Os polímeros têm sido usados em áreas diferentes, como indústrias automotivas, eletrônicas e de construção civil. A poliamida 6 (PA 6) é um dos principais plásticos de engenharia com aplicações em diversas áreas produtivas, devido as suas propriedades térmicas, mecânicas e a estabilidade dimensional. O objetivo principal deste trabalho foi estudar a potencialidade do uso do dióxido de silício coloidal $\left(\mathrm{SiO}_{2}\right)$ como carga em substituição ao talco, estudando o efeito da radiação ionizante em suas propriedades. $\mathrm{O} \mathrm{SiO}_{2}$ é uma substância amorfa com baixa densidade que tem potencial para ser usado como carga mineral em substituição ao talco na matriz da resina de PA 6. Atualmente o talco é a carga mineral mais utilizada pelas indústrias, por isto vem sofrendo redução de suas reservas ao longo dos anos. Este estudo foi desenvolvido a partir da preparação de um "masterbeach" de PA $6 \mathrm{com} \mathrm{SiO}_{2}$. Posteriormente, este "masterbeach" foi fracionado em diferentes porcentagens em uma matriz de PA 6. Os corpos de prova das amostras foram processados em uma extrusora dupla rosca, injetados e irradiados no acelerador de elétrons para estudar o efeito da radiação ionizante no compósito de PA 6 com diferentes porcentagens de $\mathrm{SiO}_{2}$. Assim sendo, as propriedades destes compósitos foram analisadas e comparadas com as propriedades das amostras de PA6 com talco. Os resultados mostraram que a utilização do $\mathrm{SiO}_{2}$ como carga para a poliamida 6 é tecnicamente viável, uma vez que suas propriedades foram semelhantes ao compósito de PA 6 com talco. A irradiação dos compósitos estudados apresentou melhorias principalmente nas propriedades térmicas e mecânicas.

Palavras chave: poliamida 6, talco, $\mathrm{SiO}_{2}$ 


\begin{abstract}
AMORIM, Camila A. Ionizing radiation effects on polyamide 6 composites with colloidal silicon dioxide (AEROSIL ${ }^{\circledR}$ ). 2017. 91 p. Dissertação (Mestrado em Tecnologia Nuclear) - Instituto de Pesquisas Energéticas e Nucleares - IPENCNEN/SP. São Paulo

Polymers have been used in different fields, such as automotive, civil construction and electronics industries. Polyamide 6 (PA 6) is one of the main engineering plastics with several productive applications areas. By the same token, there was an interest in improving their thermal, mechanical and dimensional stability properties. The main objective of this work was to study the potentiality of colloidal silicon dioxide such as filler. According to literature, $\mathrm{SiO}_{2}$ is an amorphous substance with low density. In addition, this material has the potential to be used as a mineral filler to replace the talc in the PA 6 resin matrix. Therefore, $\mathrm{SiO}_{2}$ load was compared to the mineral filler talc which is currently used by industries. Consequently, their reservations are decreasing all over the years. Indeed, these studies were developed from colloidal silicon dioxide with PA 6 the masterbatch elaboration. In addition, the masterbatch was fractionated in different percentages in a PA 6 matrix. It is important to emphasize that all samples were injected and irradiated by an electrons accelerator. Furthermore, the effect of ionizing radiation on the $\mathrm{PA} 6$ composite in different $\mathrm{SiO}_{2}$ percentages was studied. In short, radiation interacts with the polymer by transferring energy to a polymer chain causing modifications that are interfering with its properties. Thus, the mechanical and thermal properties of these composites were measured. In this manner, the irradiation composite studied in that research brought improvements in the thermal and mechanical properties evaluated. In conclusion, results have shown that the use of colloidal silicon dioxide in polyamide 6 composite is technically feasible load to replace talc.
\end{abstract}

Key words: polyamide 6 , talc, $\mathrm{SiO}_{2}$ 


\section{SUMÁRIO}

Página

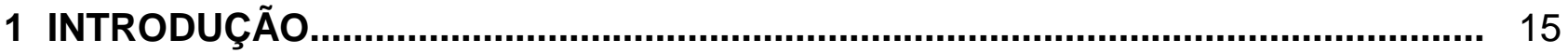

2 OBJETIVO................................................................................................................ 17

2.1 Objetivo geral....................................................................................................... 17

2.2 Objetivos específicos....................................................................................... 17

3 REVISÃO DE LITERATURA................................................................................. 18

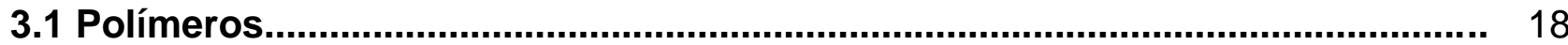

3.2 Poliamidas.......................................................................................................... 20

3.2.1 Propriedades das poliamidas................................................................ 21

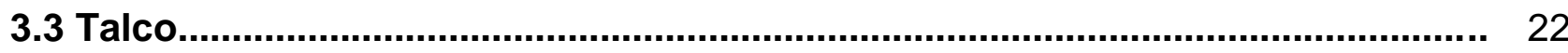

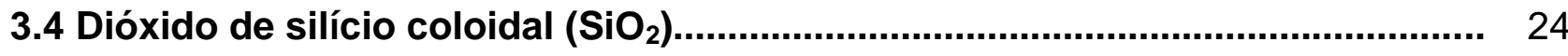

3.5 Radiação ionizante.......................................................................................... 27

3.6 Caracterização de polímeros................................................................................ 29

3.7 Termogravimetria............................................................................................... 30

3.8 Calorimetria exploratória diferencial (DSC) e análise térmica diferencial 31

(DTA).

3.9 Espectroscopia de absorção no infravermelho por transformada de Fourier (FTIR).

3.10 Difração de raios $X$.

3.11 Microscopia eletrônica de varredura (MEV) e técnica por espectroscopia por energia dispersiva (EDS).

3.12 Resistência à tração

3.12.1 Modelo de Bergsntrom - Boyce ............................................................

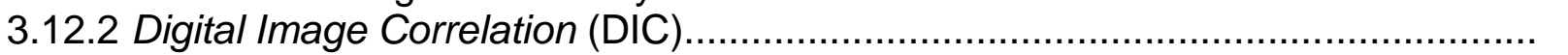

3.13 Análise de densidade.......................................................................................

4 MATERIAIS E MÉTODOS................................................................................... 40

4.1 Matéria prima utilizada......................................................................................... 40

4.2 Preparação das amostras para análise.......................................................... 40

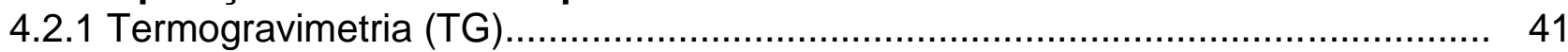

4.2.2 Calorimetria exploratória diferencial (DSC) .................................................. 42

4.2.3 Espectroscopia de absorção no infravermelho por transformada de Fourier 42

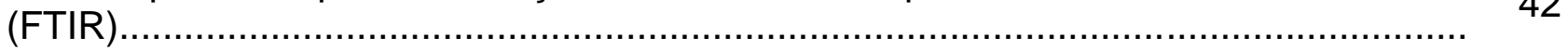

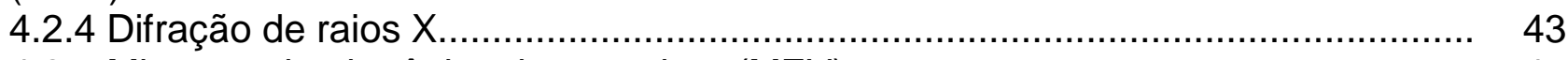

4.2.5 Microscopia eletrônica de varredura (MEV) ............................................. 45

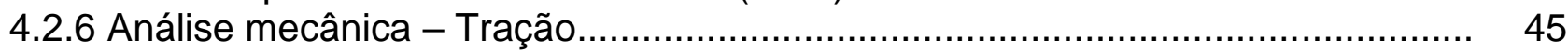

4.3 Irradiações das amostras................................................................................ 47

4.4 Densidade............................................................................................................ 48

5 RESULTADOS E DISCUSSÃO............................................................................... 49

5.1 Calorimetria exploratória diferencial e termogravimetria do 49

5.2 Termogravimetria........................................................................................... 52

5.3 Calorimetria exploratória diferencial (DSC).................................................. 59

5.4 Espectroscopia de absorção no infravermelho por transformada de Fourier (FTIR).. 64 


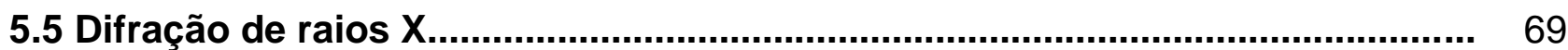

5.6 Microscopia eletrônica de varredura (MEV)....................................................... 74

5.6.1 Microscopia eletrônica de varredura das cargas.............................................. 74

5.6.2 Microscopia eletrônica de varredura das amostras........................................... 75

5.7 Análise de densidade.................................................................................. 77

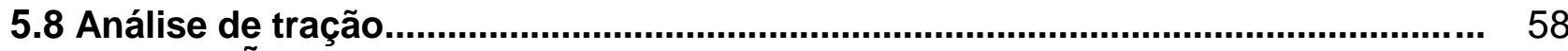

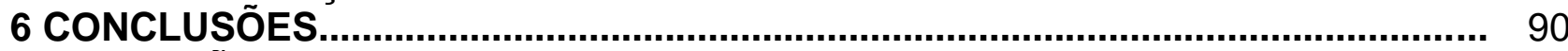

7 SUGESTÕES PARA TRABALHOS FUTUROS.................................................. 92

REFERÊNCIAS BIBLIOGRÁFICAS.................................................................. 93

APÊNDICE A - Arruma dados parte 1 .................................................................. 97

APÊNDICE B - Arruma dados parte 2 ................................................................. 98

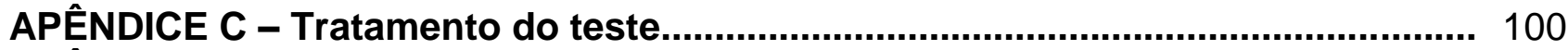

APÊNDICE D - Faz gráfico CP1 e CP2 …......................................................... 105 


\section{LISTA DE FIGURAS}

Página

FIGURA 1 - Tipos de moléculas poliméricas: a) linear; b) ramificada; c) com ramificações em estrela; d) escalar; e) graftizada ou enxertada; f) semi-escalar;

g) com ligações cruzadas ou reticulada

FIGURA 2 - Esquema representativo das estruturas das poliamidas 6 e 6.6

FIGURA 3 - Dependência do tamanho da partícula com a transparência da dispersão

FIGURA 4 - Dissociação dos grupos silanóis na superfície das partículas de $\mathrm{SiO}_{2} 26$

FIGURA 5 - Espectro eletromagnético da radiação

FIGURA 6 - Diagrama de um equipamento para termogravimetria

FIGURA 7 - Comportamento esquemático da resistência dos polímeros em função da velocidade de carregamento e da umidade

FIGURA 8 - Modelos proposto por Bersgtrom

FIGURA 9 - Equipamento de TGA da TA Instruments

FIGURA 10 - Equipamento de DSC Perkin Elmer marca Perkin Elmer

FIGURA 11 - Espectrômetro marca Perkin Elmer

FIGURA 12 - Equipamento de Difração de raios X Bruker D8 Advance

FIGURA 13 - Microscópio eletrônico de varredura JEOL

FIGURA 14 - Instron modelo 3339 
FIGURA 16 - Curvas de DSC do masterbatch de PA 6 com $13 \%$ de $\mathrm{SiO}_{2}$

FIGURA 17 - Curvas de DSC do masterbatch de PA 6 com $13 \%$ de $\mathrm{SiO}_{2}$

FIGURA 18 - Curvas TG de compósitos de PA 6 com carga de $\mathrm{SiO}_{2}$ e carga de

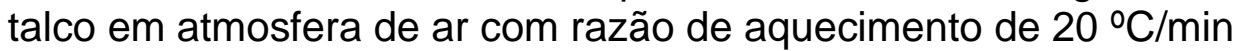

FIGURA 19 - Curvas TG de compósitos irradiados e não irradiados de PA 6 com $1 \%$ de $\mathrm{SiO}_{2}$ em atmosfera de ar com razão de aquecimento de $20 \stackrel{\circ}{\circ} \mathrm{C} / \mathrm{min}$

FIGURA 20 - Curvas TG de compósitos irradiados e não irradiados de PA 6 com $3 \%$ de $\mathrm{SiO} 2$ em atmosfera de ar com razão de aquecimento de $20 \stackrel{\circ}{\circ} / \mathrm{min}$

FIGURA 21 - Curvas TG de compósitos irradiados e não irradiados de PA 6 com $6 \%$ de $\mathrm{SiO}_{2}$ em atmosfera de ar com razão de aquecimento de $20 \stackrel{\circ}{\circ} / \mathrm{min}$

FIGURA 22 - Curvas TG de compósitos irradiados e não irradiados de PA 6 com $1 \%$ de talco em atmosfera de ar com razão de aquecimento de $20 \stackrel{\circ}{\circ} / \mathrm{min}$

FIGURA 23 - Curvas TG de compósitos irradiados e não irradiados de PA 6 com $3 \%$ de talco em atmosfera de ar com razão de aquecimento de $20 \stackrel{\circ}{\circ} / \mathrm{min}$

FIGURA 24 - Curvas TG de compósitos irradiados e não irradiados de PA 6 com $6 \%$ de talco em atmosfera de ar com razão de aquecimento de $20 \stackrel{\circ}{\circ} / \mathrm{min}$

FIGURA 25 - Curvas TG de compósitos irradiados e não irradiados de PA 6 com $10 \%$ de talco em atmosfera de ar com razão de aquecimento de $20 \stackrel{\circ}{\circ} / \mathrm{min}$

FIGURA 26 - Curvas de DSC de compósitos irradiados e não irradiado de PA 6 com $1 \%$ de $\mathrm{SiO}_{2}$

FIGURA 27 - Curvas de DSC de compósitos irradiados e não irradiado de PA 6 com $1 \%$ de $\mathrm{SiO}_{2}$

FIGURA 28 - Curvas de DSC de compósitos irradiados e não irradiado de PA 6 com $1 \%$ de $\mathrm{SiO}_{2}$

FIGURA 29 - Curvas de DSC de compósitos irradiados e não irradiado de PA 6 com $3 \%$ de $\mathrm{SiO}_{2}$

FIGURA 30 - Curvas de DSC de compósitos irradiados e não irradiado de PA 6 com $3 \%$ de $\mathrm{SiO}_{2}$

FIGURA 31 - Curvas de DSC de compósitos irradiados e não irradiado de PA 6 com $3 \%$ de $\mathrm{SiO}_{2}$

FIGURA 32 - Curvas de DSC de compósitos irradiados e não irradiado de PA 6 com $6 \%$ de $\mathrm{SiO}_{2}$ 
FIGURA 33 - Curvas de DSC de compósitos irradiados e não irradiado de PA 6 com $6 \%$ de $\mathrm{SiO}_{2}$

FIGURA 34 - Curvas de DSC de compósitos irradiados e não irradiado de PA 6 com $6 \%$ de $\mathrm{SiO}_{2}$

FIGURA 35 - - Espectros de FTIR de compósitos irradiados e não irradiado de $\mathrm{PA} 6 \mathrm{com} 1 \%$ de $\mathrm{SiO}_{2}$

FIGURA 36 - Espectros de FTIR de compósitos irradiados e não irradiado de PA 6 com $3 \%$ de $\mathrm{SiO}_{2}$

FIGURA 37 - Espectros de FTIR de compósitos irradiados e não irradiado de PA 6 com $6 \%$ de $\mathrm{SiO}_{2}$

FIGURA 38 - Espectros de FTIR de compósitos irradiados e não irradiado de PA 6 com $1 \%$ de talco

FIGURA 39 - Espectros de FTIR de compósitos irradiados e não irradiado de PA $6 \mathrm{com} 3 \%$ de talco

FIGURA 40 - Espectros de FTIR de compósitos irradiados e não irradiado de PA $6 \operatorname{com} 6 \%$ de talco

FIGURA 41 - Espectros de FTIR de compósitos irradiados e não irradiado de PA 6 com $10 \%$ de talco

FIGURA 42 - Espectros DRX (intensidade) de compósitos não irradiado e irradiados de PA $6 \mathrm{com} 1 \%$ de $\mathrm{SiO}_{2}$

FIGURA 43 - Espectros DRX (intensidade) de compósitos não irradiado e irradiados de PA 6 com $3 \%$ de $\mathrm{SiO}_{2}$

FIGURA 44- Espectros DRX (intensidade) de compósitos não irradiado e irradiados de PA 6 com $6 \%$ de $\mathrm{SiO}_{2}$

FIGURA 45 - Espectros DRX (intensidade) de compósitos não irradiado e irradiados de PA 6 com $1 \%$ de talco

FIGURA 46 - Espectros DRX (intensidade) de compósitos não irradiado e irradiados de PA 6 com $3 \%$ de talco

FIGURA 47 - Espectros DRX (intensidade) de compósitos não irradiado e irradiados de PA 6 com $6 \%$ de talco

FIGURA 48 - Espectros DRX (intensidade) de compósitos não irradiado e irradiados de PA 6 com $10 \%$ de talco 
FIGURA 50 - Micrografias dos compósitos irradiados e não irradiados de PA 6 com $6 \%$ de $\mathrm{SiO}_{2}$ e com $10 \%$ de talco

FIGURA 51 - Gráficos de EDS do compósito não irradiado de PA 6 com $6 \%$ de $\mathrm{SiO}_{2}$ e PA 6 com $6 \%$ talco e irradiado

FIGURA 52 - Quadro com as análises de densidade

FIGURA 53 - Curvas de deformação de Green e coeficiente de Poisson de compósitos não irradiados de PA 6 com $1 \%$ de $\mathrm{SiO}_{2} \mathrm{CP} 1$

FIGURA 54 - Curvas de deformação de Green e coeficiente de Poisson de compósitos irradiados com 200 kGy de PA 6 com $1 \%$ de $\mathrm{SiO}_{2} \mathrm{CP} 1$

FIGURA 55 - Curvas de deformação de Green e coeficiente de Poisson dos compósitos não irradiados de PA 6 com $10 \%$ de talco CP1

FIGURA 56 - Curvas de deformação de Green e coeficiente de Poisson dos compósitos irradiados com 200 kGy de PA 6 com $10 \%$ de talco CP1

FIGURA 57 - Deformação logarítmica (a) e alongamento (b) dos compósitos não irradiados de PA 6 com $1 \%$ de $\mathrm{SiO}_{2} \mathrm{CP} 1$

FIGURA 58 - Deformação logarítmica (a) e alongamento (b) dos compósitos não irradiados de PA 6 com $1 \%$ de $\mathrm{SiO}_{2} \mathrm{CP} 2$

FIGURA 59 - Deformação logarítmica (a) e alongamento (b) dos compósitos irradiados com $200 \mathrm{kGy}$ de PA 6 com $1 \%$ de $\mathrm{SiO}_{2} \mathrm{CP} 1$

FIGURA 60 - Deformação logarítmica (a) e alongamento (b) dos compósitos irradiados com 200 kGy de PA 6 com $1 \%$ de SiO2 CP2

FIGURA 61 - Deformação logarítmica (a) e alongamento (b) dos compósitos não irradiados de PA 6 com $10 \%$ de talco CP1

FIGURA 62 - Deformação logarítmica (a) e alongamento (b) dos compósitos não irradiados de PA 6 com $10 \%$ de talco CP2

FIGURA 63 - Deformação logarítmica (a) e alongamento (b) dos compósitos irradiados com $200 \mathrm{kGy}$ de PA 6 com $10 \%$ de talco CP1

FIGURA 64 - Deformação logarítmica (a) e alongamento (b) dos compósitos irradiados com 200 kGy de PA 6 com $10 \%$ de talco CP2

FIGURA 65 - Comparação das curvas CP1 e CP2 dos compósitos de PA 6 com $1 \%$ de SiO2 não irradiados e irradiados. 
FIGURA 66 - Comparação das curvas CP1 e CP2 dos compósitos de PA 6 com $6 \%$ de $\mathrm{SiO} 2$ não irradiados e irradiados.

FIGURA 67 - Comparação das curvas CP1 e CP2 dos compósitos de PA 6 com $10 \%$ de talco2 não irradiados e irradiados. 


\section{INTRODUÇÃo}

Nos últimos anos os materiais plásticos têm sido aplicados em diversos setores, como na produção de embalagens, construção civil, eletroeletrônicos e na indústria automotiva. O termo polímero é hoje em dia é considerado muito mais coerente para a definição desse tipo de material (PLATSHOW, 2002).

Os polímeros são classificados como termofixos, borrachas, fibras e termoplásticos (plásticos). São macromoléculas caracterizadas por sua estrutura química, interações intra e intermoleculares e por seu tamanho. Há muito tempo a humanidade tem estado em contato com materiais plásticos, por meio de produtos que são encontrados na natureza como: a resina do pinheiro, o asfalto, 0 âmbar, a cera de abelha entre outros, ou os polímeros sintéticos como os termoplásticos, sendo os mais utilizados os polipropilenos (PP), os polietilenos (PE), as poliamidas (PA), os poli (cloreto de vinila) (PVC), entre outros (SPINACÉ, 2005).

As poliamidas, pioneiras na aplicação à engenharia, apresentam propriedades como resistência a temperaturas elevadas, combinação adequada entre tenacidade e rigidez e facilidade de processamento. São classificadas como termoplásticos semicristalinos de fácil processabilidade e diferenciadas por números que indicam a quantidade de átomos de carbono nas unidades monoméricas originais. A polimerização de poliamidas derivadas de aminoácidos ou lactamas são designadas por um único número poliamida 6 (PA 6), enquanto que as preparadas pela reação de diaminas e ácido são designadas por dois números poliamida 66 (PA 66), em que o primeiro representa a diamina e o segundo o ácido (WIEBECK e HARADA, 2005).

O talco é utilizado bastante como carga e reforço na produção de diversas peças por ser um mineral monoclínico raramente cristalizado. Sabe-se que os depósitos de talco dos estados do Ceará e Piauí, relacionados no ANUÁRIO MINERAL BRASILEIRO (2001), deixaram de constar como reservas em 1986, em razão dos parâmetros de economicidade, tecnologia, mercado, qualidade do minério e tamanho dos depósitos. 
O dióxido de silício coloidal (Si-O-OH) é uma sílica pirogênica (fumed) submicroscópica obtida a partir de uma hidrólise e chama a $1.000 \stackrel{\circ}{\mathrm{C}}$ e tem por nome comercial AEROSIL ${ }^{\circledR}$ sendo fabricado pela Degussa desde 1942 (MINATTI, 2009). A natureza química do $\mathrm{SiO}_{2}$ confere a capacidade de reter a umidade (AMADO, 2014). À medida que a temperatura e a concentração de $\mathrm{SiO}_{2}$ aumentam, diminui então a umidade residual dos extratos, bem como a higroscopicidade otimizando condições de secagem (VASCONCELOS et al., 2005).

Segundo EVORA et al., (2002), ao irradiar um material polimérico a modificação permanente na estrutura físico-química dos polímeros é dada por meio do efeito da radiação ionizante, pois a mesma ao interagir com os polímeros transfere energia aos átomos da cadeia polimérica. Essas modificações são reticulação e cisão das cadeias poliméricas, que são processos simultâneos e concorrentes, cuja predominância de um ou outro depende principalmente da dose de radiação, com que foi tratado o material.

Em razão da crescente utilização da poliamida no mercado nacional e suas aplicações, pretende-se avaliar neste estudo o efeito da radiação ionizante nas propriedades de compósitos de PA 6 com carga de dióxido de silício coloidal $\left(\mathrm{SiO}_{2}\right)$ incorporadas em diferentes formulações e comparar os resultados com os compósitos de PA 6 com talco, com o propósito de usar o dióxido de silício coloidal em substituição ao talco que é a carga mineral atualmente mais utilizada. 


\section{OBJETIVO}

\subsection{Objetivo geral}

Preparar os compósitos de PA 6 com diferentes porcentagens de $\mathrm{SiO}_{2}$ ( $1 \%, 3 \%, 6 \%$ ) e os compósitos de PA 6 com talco em diferentes porcentagens ( $1 \%, 3 \%, 6 \%$ e $10 \%)$.

\subsection{Objetivos específicos}

Irradiar os compósitos de PA $6 \mathrm{com} \mathrm{SiO}_{2}$ em diferentes porcentagens.

Irradiar os compósitos de PA 6 com talco em diferentes porcentagens.

Caracterizar os compósitos de PA 6 com $\mathrm{SiO}_{2}$ em diferentes porcentagens.

Caracterizar os compósitos de PA 6 com talco em diferentes porcentagens.

Comparar os resultados da caracterização de ambos os compósitos mencionados anteriormente. 


\section{REVISÃO DE LITERATURA}

\subsection{Polímeros}

Polímero é uma molécula de longas cadeias formada por um processo de ligação de monômeros devido ao fornecimento de calor ou pressão, conhecido como polimerização (MOURA, 2013).

Segundo CALLISTER, 2002 a cristalinidade dos polímeros pode ser definida como o empacotamento das cadeias moleculares de tal modo a produzir uma matriz atômica ordenada. Assim, as estruturas cristalinas podem ser especificadas em termos de células unitárias. Desta maneira, o estado cristalino pode existir nos materiais poliméricos.

O grau de cristalinidade pode variar desde completamente amorfo até quase $95 \%$ cristalino. Também se pode dizer que o grau de cristalinidade depende da taxa de resfriamento do polímero durante a solidificação e da própria configuração da cadeia, pois quando um polímero está se solidificando, o mesmo, está passando de um estado no qual as cadeias estão entrelaçadas ou embaraçadas, necessitando de um tempo de resfriamento grande o suficiente para que as cadeias se alinhem (CALLISTER, 2002).

Os polímeros podem ser classificados como termofixos/termorrígidos e termoplásticos. Os termofixos são polímeros produzidos por uma reação química e podem se tornarem flexíveis acima da temperatura de transição vítrea $(\mathrm{Tg})$, porém sem se fundir. Para temperaturas acima da $\mathrm{Tg}$ as ligações cruzadas podem ser quebradas e o material sofrer como consequência uma degradação (CANEVAROLO JUNIOR, 2002).

Os polímeros termoplásticos são formados por macromoléculas ligadas entre si por forças relativamente fracas como van der Waals. Quando aquecidos tornam-se flexíveis devido à quebra das ligações intermoleculares, atingindo o estado líquido viscoso acima da temperatura de transição vítrea. Eles apresentam uma faixa grande de aplicações por possuírem diversas propriedades como: o fato de serem moldáveis à quente, isolante térmico e elétrico, densidade baixa, resistência ao impacto e custo baixo. Portanto, o consumo dos polímeros vem crescendo no mundo e também no Brasil (CANEVAROLO JUNIOR, 2002; SPINACÉ, 2005). 
Os plásticos são sólidos à temperatura ambiente quando estão em seu estado final, e quando aquecidos acima da temperatura de "amolecimento" tornam-se fluidos e passíveis para serem moldados, sendo que, a definição de plástico é um termo comum para qualquer substância que pode ser moldada por meio da ação do calor e pressão (SOARES, 2002).

Os polímeros possuem unidades químicas unidas por ligações covalentes, que se repetem ao longo da cadeia e podem apresentar varrições quanto à forma. Também apresentam diferenças fundamentais no comportamento físico e físicoquímico, pois quando os meros são ligados entre si formando um fio, a cadeia é linear; quando as unidades estão conectadas de forma tridimensional (formando uma rede), o polímero é reticulado, ou seja, apresenta ligações cruzadas. A outra forma é quando uma cadeia possui ramificações laterais, pois o polímero é chamado de ramificado ou não linear. Na Figura 1 são mostrados os principais tipos de arranjos dos meros (AKCELRUD, 2007).

Figura 1 - Tipos de moléculas poliméricas: a) linear; b) ramificada; c) com ramificações em estrela; d) escalar; e) graftizada ou enxertada; f) semi-escalar; g) com ligações cruzadas ou reticulada

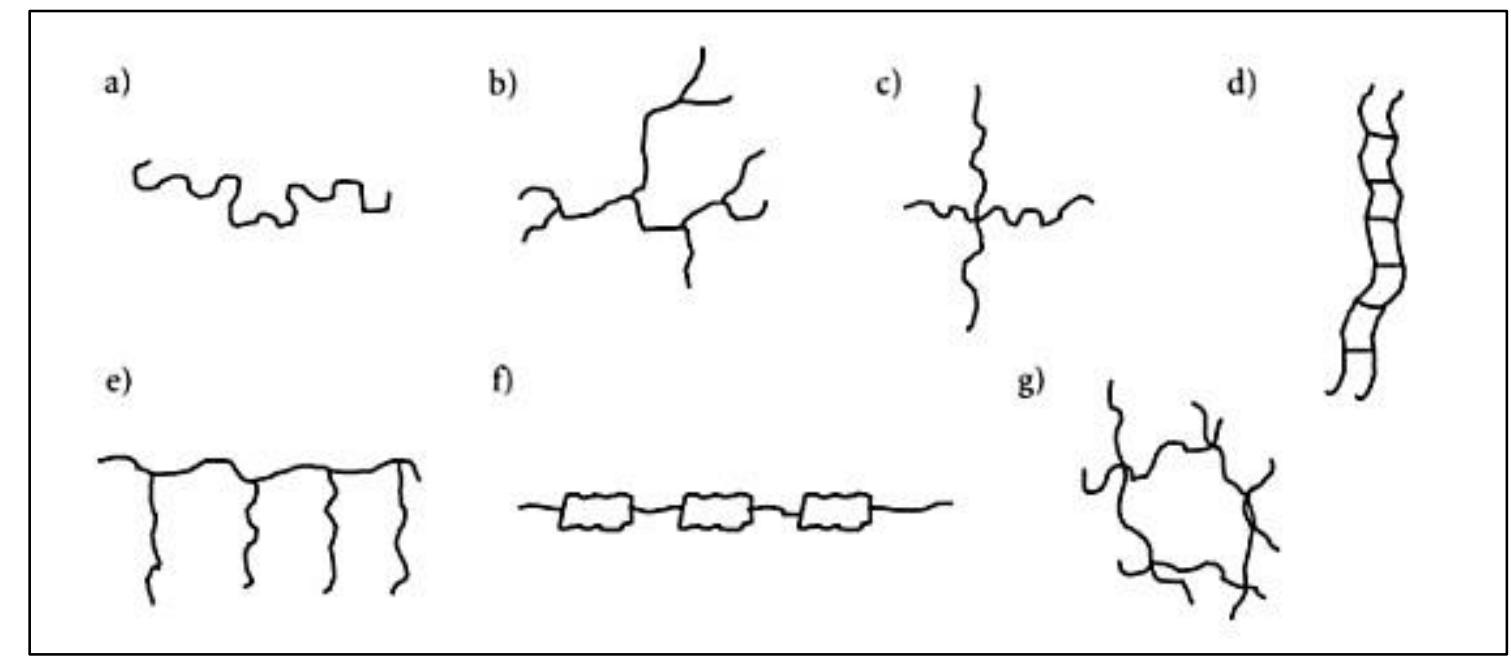

Fonte: AKCELRUD, 2007. 
De acordo com HEMAIS (2003) a indústria de polímeros no Brasil passou a existir formalmente após a instalação de petroquímicas na década de $70 \mathrm{com}$ a instalação dos polos petroquímicos. No Brasil cerca de 90.000 t/ano plástico de engenharia e embalagens alimentícia de poliamidas são responsável pelo abastecimento total do mercado brasileiro e na América do Sul este valor chega a ser cerca de 100.000 t/ano de poliamidas no setor industrial. Portanto, por permitir flexibilidade maior de projeto e economia na produção, sendo a densidade do plástico baixa é essencial para a redução do consumo de combustíveis, uma vez que a substituição de materiais diversos por cerca de 100 quilos de plástico, em um carro pesando 1 tonelada, trará uma economia de combustível de 7,5\% (HEMAIS, 2003).

\subsection{Poliamidas}

Segundo FERRO (2006), as poliamidas de maior importância comercial são as PA 6 e PA 66, cujas estruturas são mostradas na Figura 2. A PA 6 é obtida a partir da caprolactama, um composto orgânico responsável pelos 6 átomos de carbono e a PA 66 é obtida a partir do hexametileno diamina e ácidos dibásicos. $\mathrm{Na}$ PA 66, os responsáveis pelos 12 átomos de carbono são o hexametileno diamina e o ácido adípico, conforme mostrado na Figura 2 (WIEBECK e HARADA, 2005; SIMIELLI, 2010). 
Figura 2 - Esquema representativo das estruturas das poliamidas 6 e 66

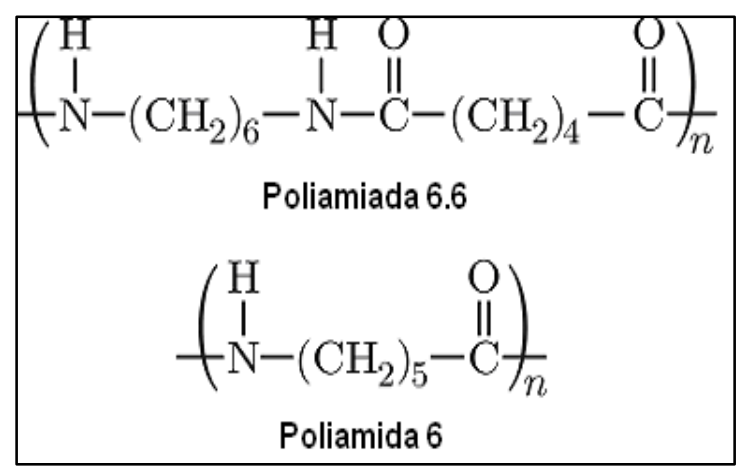

Fonte: WIEBECK e HARADA, 2005.

A poliamida 6 ou nylon 6 como encontradas no mercado, está entre os plásticos de engenharia mais importantes, a mesma é caracterizada por ser um polímero semicristalino e com grau de cristalinidade elevado. Também é possível utilizá-las de diferentes maneiras sendo a substituição de metais em componentes uma das aplicações mais utilizadas, pois a poliamida 6 possui propriedades mecânicas, químicas e físicas excelentes (EVORA, 2002).

\subsubsection{Propriedades das poliamidas}

A PA é caracterizada por uma combinação de resistência, elasticidade, dureza e resistência à abrasão alta e suas propriedades mecânicas boa que são mantidas até $150 \stackrel{\circ}{\circ}$ desde que estabilizada ao calor. A dureza e a flexibilidade são mantidas em temperaturas baixas. Além de propriedades mecânicas adequadas, a PA tem resistência química boa, sendo dissolvida em temperatura ambiente apenas em fenóis, cresol, ácido fórmico e (BILLMEYER, 1984).

As PA 6 e PA 66 possuem grupos amida polares (CONH) espaçados regularmente ao longo da cadeia que cristalizam com atração intermolecular alta, possuindo segmentos de cadeia alifáticos que conferem uma certa flexibilidade na região amorfa. Outra característica é que polímeros são tenazes acima de suas temperaturas de transição vítrea (WIEBECK e HARADA, 2005). 
As poliamidas de unidades repetitivas mais curtas (maior número de ligações de hidrogênio), tal como no caso de PA 6 e PA 66, apresentam valores de absorção de água elevados, sendo estes valores ainda maior em temperaturas altas (BILLMEYER, 1984). A presença de água funciona como plastificante do polímero, separando as cadeias moleculares e diminuindo a cristalinidade e a temperatura de transição vítrea $\left(T_{g}\right)$ do polímero, resultando em uma redução da rigidez e resistência à fluência das poliamidas, por outro lado, aumenta-se a resistência ao impacto e a tenacidade dos mesmos (WIEBECK e HARADA, 2005).

A $T_{g}$ da PA 66 seca é da ordem de $50 \stackrel{\circ}{\circ}$, com absorção normal de umidade este valor é reduzido para, aproximadamente, abaixo da temperatura ambiente. Isto influi na cinética de cristalização pós-moldagem, que prossegue muito lentamente, resultando em efeitos de encolhimento pós-moldagem que irão estabilizar somente num período não inferior a dois anos. No caso de PA 6 este efeito negativo é menos marcante (WIEBECK e HARADA, 2005).

A resistência ao intemperismo das poliamidas pode ser melhorada pela aditivação ou pigmentação. Na área elétrica, sua utilização é restrita às frequências baixas em razão dos seus grupos polares (BILLMEYER, 1984).

Pode-se destacar que juntos os nylons 6 e 66 são responsáveis pela maior parte da produção de poliamidas que incluem os nylons $610,11,12$, entre outros, sendo ainda $12 \%$ da produção total de produção das poliamidas para aplicações em peças plásticas, sendo o consumo anual de poliamida na América do Sul em torno de 110.000 t/ano de PA 6 e PA 66, sendo o Brasil responsável pelo consumo de 24.000 t/ano (WIEBECK e HARADA, 2005; SIMIELLI, 2010).

\subsection{Talco}

O talco é um mineral monoclínico raramente cristalizado, de estrutura lamelar fibrosa ou compacta, de dureza baixa, translúcido e com densidade em torno de $2,7 \mathrm{~g} / \mathrm{cm}^{3}$. É um filossilicato de magnésio hidratado com fórmula estrutural $\mathrm{Mg}_{3}\left(\mathrm{Si}_{4} \mathrm{O}_{10}\right)(\mathrm{OH})_{2}$ ou $3 \mathrm{MgO}_{4} 4 \mathrm{SiO}_{2} \cdot \mathrm{H}_{2} \mathrm{O}$, constituindo-se de $31,7 \% \mathrm{MgO}$, $63,5 \%$ de $\mathrm{SiO}_{2}$ e $4,8 \%$ de $\mathrm{H}_{2} \mathrm{O}$, traços de níquel, ferro e cobalto em sua estrutura. As suas propriedades o torna muito utilizado na área industrial, 
possuindo resistência ao choque térmico alto, leveza e teor de umidade baixo, poder de absorção de óleo e graxa alto, condutividade térmica, elétrica e inércia química baixa (PINHEIRO, 1973).

Segundo CAMPOS (2001), a maior parte da produção de talco destina-se às indústrias de produtos minerais não metálicos; indústria de papel e papelão; indústria da borracha; indústria química; indústria de produtos farmacêuticos e veterinários; indústria de perfumarias; sabões e velas; indústria de matérias plásticas; indústria têxtil e indústria de produtos alimentícias. No estado da Bahia os depósitos de talco encontrados possuem qualidade alta, sendo destinado na maior parte para indústrias farmacêuticas e de cosméticos.

De acordo com os dados apresentados pelo ANUÁRIO MINERAL BRASILEIRO (2001), as reservas de talco oficialmente encontradas no Brasil são da ordem de 91 milhões de toneladas, das quais $65,4 \%$ são medidas, $17,5 \%$ indicadas e $17,1 \%$ inferidas. Os estados da Bahia (48,0 \%), Paraná $(29,0 \%)$ e São Paulo (14,3 \%) respondem juntos por $91,3 \%$ da produção brasileira de talco e pirofilita. Da mesma forma, a produção é concentrada também em poucas empresas, sendo que as três maiores empresas nacionais produtoras responderam em 2013 por $74,0 \%$ de toda a produção brasileira.

No entanto, no relatório do DEPARTAMENTO NACIONAL DE PRODUÇÂO MINERAL (2015) foi mostrado que $99,3 \%$ da produção nacional de talco concentra-se em 5 estados a saber, em números redondos, Paraná $(27,2 \%)$, Bahia (51,9 \%), São Paulo (16,9 \%), Rio Grande do Norte (8 \%) e Minas Gerais (2 $\%$ ). Cabe destacar que a produção potiguar, concentrada no Grupo Elizabeth, iniciou-se em 2006/2007, também foi constatado que a produção brasileira de talco e pirofilita atingiram 400.000 toneladas (DNPM, 2015), respondendo por cerca de $5 \%$ da produção mundial.

A granulometria do talco é muito importante, como também, o grau de pureza e a cor do produto. As especificações, das propriedades físico-químicas necessárias variam com a destinação industrial do talco (MONTE et al., 2003). O talco tem grande parte da sua produção anual empregada nas indústrias de cerâmica, inseticidas, tintas, borrachas, papel, têxtil, cosméticos, isolantes térmicos, moldes de fundições, polidores de cereais, polidores de calçados, entre outras. 


\subsection{Dióxido de silício coloidal $\left(\mathrm{SiO}_{2}\right)$}

Com a expansão da economia mundial, a indústria do petróleo vem procurando atender cada vez mais, a demanda crescente, por hidrocarbonetos leves e por produtos petroquímicos básicos (CARNEIRO, 2011).

Segundo ANTON (2009) os materiais compósitos possuem densidade baixa e são facilmente produzidos por processo de fabricação de polímeros; também a incorporação de nanopartículas, em uma matriz polimérica pode melhorar as propriedades mecânicas e térmicas do polímero (AMADO, 2014).

Os particulados de $\mathrm{SiO}_{2}$ podem apresentar mono ou polidispersão no tamanho dos aglomerados, esta suspensão apresenta geralmente concentração de sólidos entre 5 e $40 \%$, densidade entre 1,3 e 2,3 ${\mathrm{g} . \mathrm{cm}^{-3}}^{-3}$, e pH entre 7 e 10,5 e suas cores de suspensões variam de transparente a branca, dependendo do tamanho e do teor das partículas (Figura 3).

Diversas são as aplicações para a sílica coloidal, destacando-se o uso desta na fabricação de moldes para peças em indústrias e de agentes em formulações para concreto (ANTON, 2009). 
Figura 3 - Dependência do tamanho da partícula com a transparência da dispersão

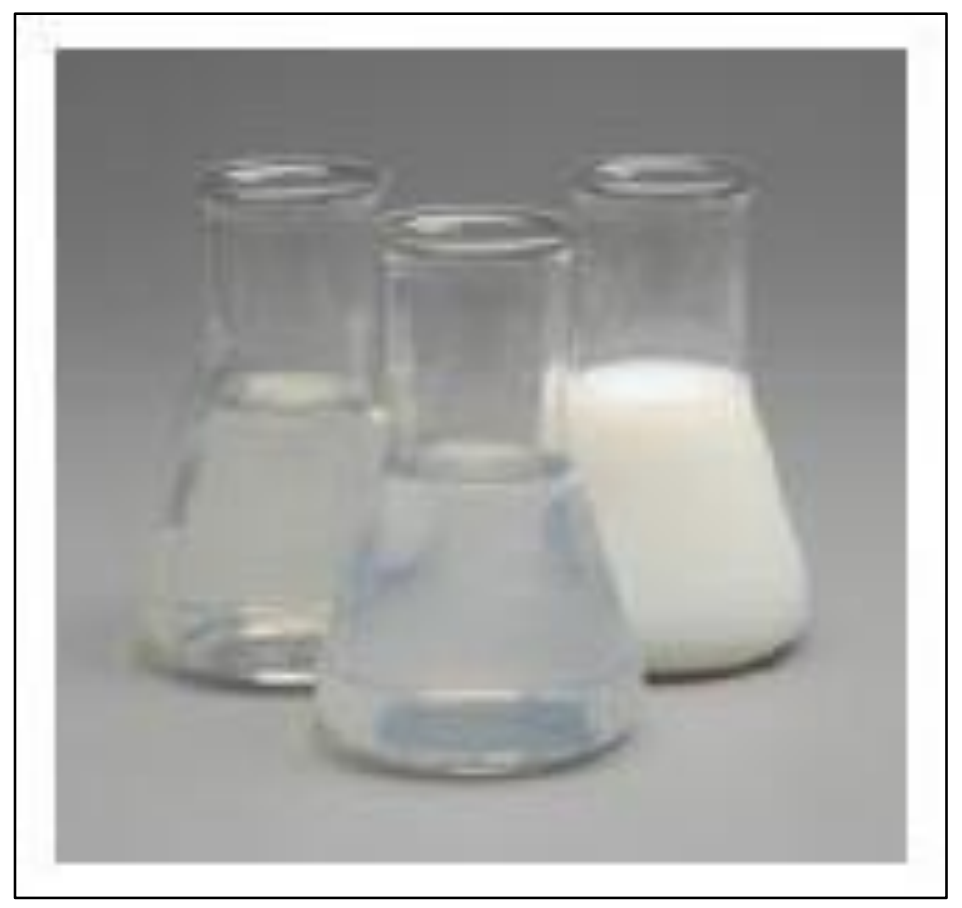

Fonte: autor da dissertação.

$\mathrm{O} \mathrm{SiO}_{2}$ possui uma densidade superficial de carga obtida pela quantidade de grupos que estão na superfície negativamente carregados. $\mathrm{O} \mathrm{pH}$ e a força iônica do meio aquoso favorecem a dissociação dos grupos silanóis da superfície da sílica Figura. 4 liberando prótons para o meio aquoso e criando uma superfície sólida negativamente carregada (MOURA, S., 2003). 
Figura 4 - Dissociação dos grupos silanóis na superfície das partículas de $\mathrm{SiO}_{2}$

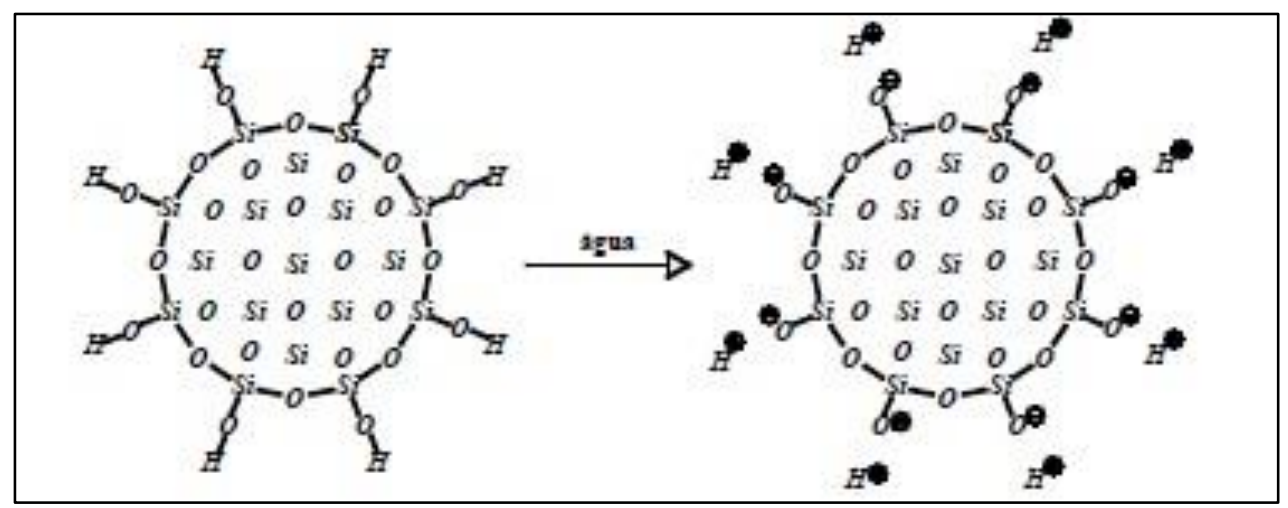

Fonte: IONASHIRO, 2004.

Existem diversos tipos de Aerosi $^{\circledR}$ que são utilizados para diversos fins, cujas áreas superficiais podem variar entre $50 \mathrm{~m}^{2} / \mathrm{g}$ e $380 \mathrm{~m}^{2} / \mathrm{g}$ e a média de tratamento de partícula pode variar de $7 \mathrm{~nm}$ a $40 \mathrm{~nm}$, sendo possível observar que vários grupos podem estar ligados quimicamente à superfície da sílica, alterando suas características superficiais e deixando as partículas hidrofílicas ou hidrofóbicas (MINATTI, 2009).

A força de ligação das sílicas coloidais é bastante influenciada pela reatividade da solução, sendo os sais solúveis comumente utilizados como gelificante, que ao serem adicionados liberam íons (cátions e ânions) que são atraídos para a superfície negativa das partículas, neutralizando parte da carga e diminuindo a repulsividade (MAGLIANO, 2010).

Um aspecto importante da sílica coloidal é que em razão do tamanho nanométrico de suas partículas, a área superficial elevada resultante aumenta a reatividade do sistema e proporciona um considerável progresso no desenvolvimento de resistência mecânica com o aumento da temperatura de queima (SANTOS, 2011).

Segundo MAGLIANO (2010) suspensões com área superficial alta apresentam tempo curto para formação do gel (tempo de gel) e aumentam o poder ligante da estrutura, entretanto, potencializam a retração durante a secagem gerando tensões internas que podem causar trincas. Dois fatores são responsáveis pela reatividade das soluções: a) tamanho médio de partícula, sendo este o fator principal, e b) a concentração de sólidos. 


\subsection{Radiação ionizante}

A energia que se propaga a partir de uma fonte emissora através de qualquer meio é chamada de radiação e pode ser classificada como energia em trânsito. Pode ser apresentada em forma de partícula atômica ou subatômica energéticas tais como partículas alfa, elétrons, pósitrons, prótons, nêutrons, entre outros. Sendo produzidas em aceleradores de partículas ou em reatores, e também as partículas alfa, os elétrons e os pósitrons são emitidas espontaneamente de núcleos dos átomos radioativos (OKUNO, 2013).

Existem dois tipos de radiação a ionizante e a não ionizante as quais caracterizam-se pela frequência, comprimento de onda e nível energético, produzindo assim efeitos físicos e biológicos diferentes (FATOR DE SEGURANÇA, 2004). A radiação não ionizante é o tipo de radiação que não possui energia suficiente para ionizar os átomos ou as moléculas com as quais interage. Uma das mais importantes características desta radiação é a sua frequência, cuja escala é muito grande, como é possível verificar no espectro eletromagnético, mostrado na Figura 5 (PAULINO, 2001). 
Figura 5 - Espectro eletromagnético da radiação

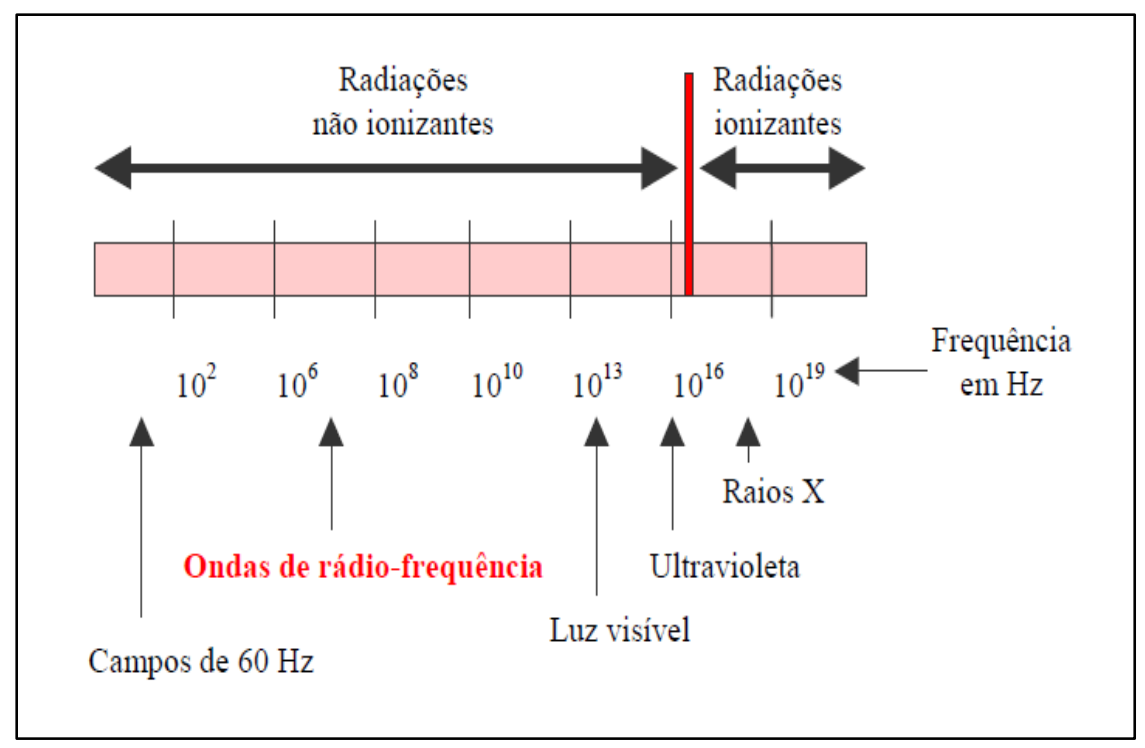

Fonte: OKUNO, 2013.

A radiação ionizante pode ser considerada como a energia que é transportada por qualquer um dos diversos tipos de partículas, sendo superior a energia de ligação dos elétrons de um átomo com o seu núcleo. Esta energia retira elétrons dos átomos ou moléculas com os quais interagem, criando íons ou moléculas ionizadas, deste modo é caracterizada por ter energia superior à energia de ligação dos elétrons, sendo a sua energia suficiente para arrancar elétrons dos seus níveis orbitais (JIN et al., 2010; NOUAILHETAS, 2011). As radiações provêm de fontes radioativas naturais ou artificiais. As fontes internas de radiação incluem os radionuclídeos presentes no corpo humano, como o potássio-40 (VELUDO, 2011).

Nos polímeros as moléculas ao serem irradiadas liberam elétrons de energia alta e provocam ionização. Assim, o elétron primário causa a ionização de outras moléculas produzindo mais elétrons, sendo que uma parte das interações da radiação com o material polimérico pode também resultar diretamente em transferência de energia, que não é suficiente para causar ionização, mas resulta diretamente em um estado eletronicamente excitado. Assim, as moléculas que se encontram no estado excitado decaem para o estado fundamental emitindo fosforescência e fluorescência ou por meio de reações químicas, por quebra 
heterolítica da ligação produzindo íons, ou por quebra homolítica de ligações, favorecendo a formação de radicais, onde ocorrerá o processo de reticulação (EVORA et al., 2002).

De acordo com ANDRADE (2011) a radiação ionizante em polímeros vem crescendo cada vez mais, pois a interação da radiação com os polímeros resulta na formação de moléculas ionizadas e moléculas excitadas que posteriormente se combinam ou dissociam para produzir radicais livres, que por sua vez têm uma participação importante nas reações químicas que ocorrem nos polímeros irradiados.

A vantagem desses polímeros modificados por esse processo permite grandes possibilidades de modificações em suas propriedades, minimizando ou evitando o uso de solventes, iniciadores ou aditivos potencialmente tóxicos, além de que essa aplicação pode ser utilizada tanto para os não modificados, como também com os não termoplásticos e os termofixos, onde existe viabilidade econômica do processo desde o custo de produção do polímero, incluindo qualidade, armazenamento e transporte (EVORA, 2001).

\subsection{Caracterização de polímeros}

Quando se caracteriza polímeros busca-se medir as propriedades físico-químicas do material irradiado, por meio de ensaios que seguem normas de padrão internacional e que descrevem as mudanças ocorridas no material sem irradiar comparando-os com os materiais irradiados.

Neste trabalho foram estudadas as propriedades térmicas e mecânicas e morfológicas dos compósitos não irradiados e irradiados de PA 6 com $\mathrm{SiO}_{2}$ e com talco em diferentes porcentagens. A caracterização estrutural foi outro ponto avaliado utilizando a técnica de difração de raios $X(D R X)$ e a morfologia foi avaliada por microscopia eletrônica de varredura (MEV). 


\subsection{Termogravimetria}

A termogravimetria é uma técnica que acompanha a perda ou ganho de massa da amostra em função do tempo ou temperatura, enquanto que a termogravimetria derivada (DTG) é um arranjo matemático, no qual a derivada da variação de massa em relação ao tempo $(\mathrm{dm} / \mathrm{dt})$ é registrada em função da temperatura ou tempo (IONASHIRO, 2004).

O equipamento utilizado na termogravimetria é composto basicamente pela termobalança, podendo mudar de configuração de um fabricante para outro, porém os fundamentos de todos eles são os mesmos. Os principais componentes da termobalança são: forno, suporte de amostra e sensor de temperatura, balança registradora, programador de temperatura do forno, sistema registrador e controle da atmosfera do forno. Na Figura 6 é mostrado um diagrama de um equipamento de termogravimetria genérico (IONASHIRO, 2004).

Figura 6 - Diagrama de um equipamento para termogravimetria

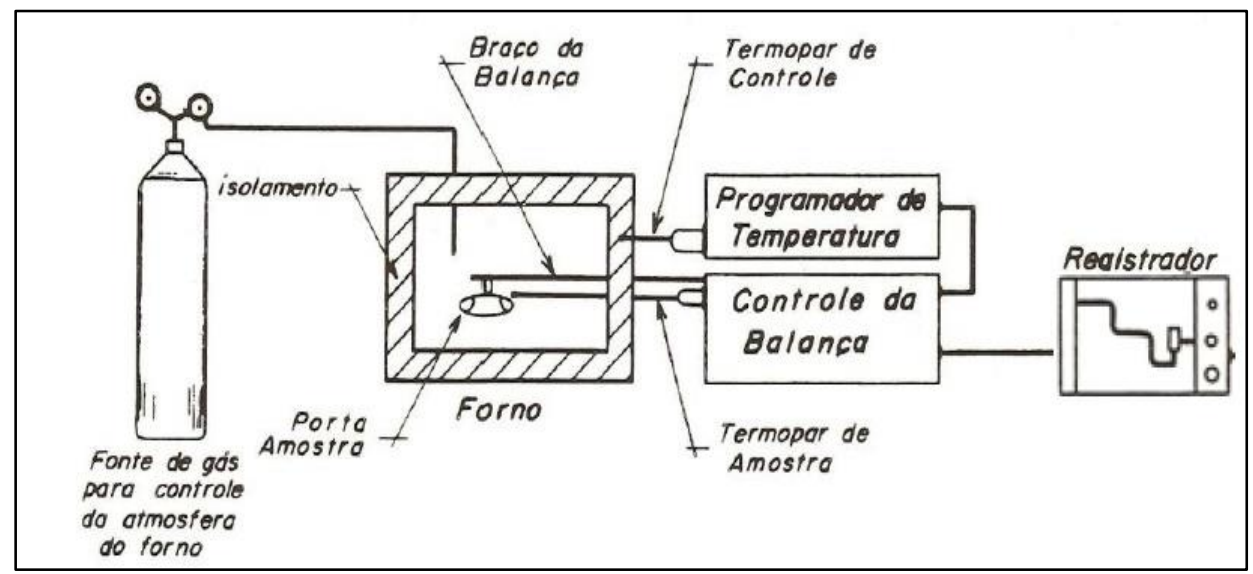

Fonte: AKCELRUD, 2007. 
Em geral a razão de aquecimento pode atingir $1{ }^{\circ} \mathrm{C} \min ^{-1}$ até $100 \stackrel{\circ}{\circ} \min ^{-1}$ dependendo do fabricante. A temperatura final vai depender do forno, podendo chegar a, até, $2000 \stackrel{\circ}{ } \mathrm{C}$. A sensibilidade é da ordem de $0,1 \mu \mathrm{g}$, geralmente com capacidade de até $1 \mathrm{~g}$ (IONASHIRO, 2004).

\subsection{Calorimetria exploratória diferencial (DSC) e análise térmica diferencial (DTA)}

Define-se como calorimetria exploratória diferencial (DSC) como uma técnica termoanalítica, na qual as variações de entalpia da amostra são monitoradas em relação a um material de referência termicamente inerte enquanto ambas são submetidas a uma programação controlada de temperatura (BROWN, 1988).

Por outro lado, a análise térmica diferencial (DTA) é definida com uma técnica que determina a diferença entre as temperaturas de amostra e de um material inerte, à medida que ambos vão sendo aquecidos em um forno. Todavia, as duas modalidades são aplicadas para obter os dados de calorimetria exploratória diferencial (BROWN, 1988).

A DSC é feita por fluxo de calor, o arranjo é aquele, no qual a amostra e a referência, são contidas em seus respectivos suportes e são colocadas em um disco de metal onde a troca de calor entre o forno e a amostra ocorre preferencialmente pelo disco. Já a DTA é feita pelo arranjo, no qual a amostra e a referência são mantidas na mesma temperatura, por meio de aquecedores elétricos (BROWN, 1988). 


\subsection{Espectroscopia de absorção no infravermelho por transformada de Fourier (FTIR)}

A técnica de FTIR é muito útil para a verificação de propriedades químicas e físicas dos polímeros em geral, sendo uma ferramenta utilizada na identificação de grupos funcionais e nos estudos de conformação e estrutura de macromoléculas.

Os espectrômetros por transformada de Fourier (FTIR) são equipamentos que possuem um feixe colimado proveniente de uma fonte, sendo separado em um divisor de feixes, uma parte do feixe vai para um espelho fixo e a outra para um espelho móvel. Depois da fixação, os dois feixes se encontram e sofrem uma interferência após terem percorrido distâncias diferentes devido ao percurso do espelho móvel (SKOOG et al., 2002).

O gráfico da intensidade da radiação em função do atraso (ס) é chamado de interferograma e o atraso é definido como a diferença no caminho percorrido pelos dois feixes. Considera-se a radiação como uma função cosenoidal de intensidade/frequência $\checkmark$ considerando uma relação cosenoidal da função que descreve 0 interferograma em função do atraso $I(\delta)$ versus o espectro infravermelho em função da frequência $B(v)$ tem-se a Equação 1 :

$$
I(\delta)=\int_{-\infty}^{+\infty} B(\mathrm{v}) \cos (2 \pi \delta \mathrm{v}) \mathrm{d} \delta \quad \text { Equação } 1
$$

Uma transformada de Fourier é caracterizada pela conversão da equação 1, que se encontra em função do atraso, em função da frequência, a fim de obter um espectro de frequências (Equação 2):

$$
B(\mathrm{v})=\int_{-\infty}^{+\infty} I(\delta) \cos (2 \pi \delta \mathrm{v}) \mathrm{d} \delta
$$

Equação 2

As equações 1 e 2 são chamadas de pares de Fourier e são a base de toda espectroscopia de absorção por transformada de Fourier. As vantagens no uso de instrumentos com transformada de Fourier é a eficiência de luminosidade que é obtida porque os instrumentos do equipamento possuem poucos elementos óticos e nenhuma sonda para atenuar a radiação. A técnica também se torna 
vantajosa pelo alto poder de resolução e reprodutibilidade do comprimento de onda e o fato de que todos os elementos (frequências) atingem o detector simultaneamente (PERKINS, 1987).

\subsection{Difração de raios $X$}

Esta técnica permite avaliar a obtenção do grau de cristalinidade do compósito não irradiado e irradiado por meio do estudo das estruturas cristalinas. Esse método permite a medida direta da distância entre planos paralelos de pontos do reticulado cristalino, determinando os parâmetros do mesmo. Também é possível medir os ângulos entre os planos do reticulado, por exemplo, os ângulos interaxiais de um cristal (SANCHES, 2011).

$A$ difração de raios $X$ é uma consequência de relações de fases especificas estabelecida entre duas ou mais ondas que foram dispersas pelos obstáculos. Portanto, os raios $X$ são uma forma de radiações eletromagnéticas que possuem energias elevadas e comprimentos de ondas curtos (CALLISTER, 2002).

Quando um feixe de raios $\mathrm{X}$ incide sobre um material sólido, uma fração deste feixe se dispersa, se espalha, em todas as direções pelos elétrons associados a cada átomo ou íon que se encontra na trajetória do feixe (CALLISTER, 2002).

A técnica de difração de raios $X$ é utilizada por meio de um aparelho chamado de difratômetro e é empregado de forma que uma amostra pulverizada ou policristalina que consiste em muitas partículas aleatoriamente orientadas, exposta a uma radiação X monocromática (TEIXEIRA, 2014).

Assim, cada partícula de grão é um cristal, com orientações aleatórias asseguram que pelo menos algumas partículas estejam orientadas da forma apropriada, de forma que, todos os possíveis conjuntos de planos cristalográficos estarão disponíveis para difração. Um dos principais usos da difratometria de raios $X$ está na determinação de estruturas cristalina, porém a técnica também pode ser usada para determinar orientações cristalográficas utilizados em fotografias de difração de raios X (TEIXEIRA, 2014). 


\subsection{Microscopia eletrônica de varredura (MEV) e técnica por espectroscopia por energia dispersiva (EDS)}

A microscopia eletrônica de varredura tem como principal aplicação à análise da morfologia da superfície da amostra, portanto verificou-se a morfologia da carga adicionada na PA 6. Além de informações estruturais de topografia, também puderam ser obtidas informações sobre a composição química da superfície da amostra por meio de micrografias e gráficos EDS para verificação da composição química das amostras.

Tornar visível o que for muito pequeno é a principal função de qualquer microscópio. Sabe-se que a forma mais antiga e usual é a lupa seguida do microscópio óptico (funcionamento por meio de fótons), que ilumina o objeto com luz visível ou luz ultravioleta (DEDAVID et al., 2007).

O microscópio eletrônico de varredura é um aparelho que pode fornecer rapidamente informações sobre a morfologia e identificação de elementos químicos de uma amostra sólida. Sua utilização é comum em biologia, odontologia, farmácia, engenharia, química, metalurgia, física, medicina e geologia (NAGATANI, 1987).

O microscópio eletrônico de varredura é um dos mais versáteis instrumentos disponíveis para a observação e análise de características microestruturais de objetos sólidos, pois, o mesmo, utiliza feixe de elétrons ao invés de fótons, o que permite solucionar qualquer problema de resolução relacionado com a fonte de luz branca, problema que ocorre em um microscópico óptico ou convencional (DEDAVID et al., 2007).

A técnica de microscopia eletrônica de varredura consiste em utilizar um feixe de elétrons de diâmetro pequeno para explorar a superfície da amostra, ponto a ponto, por linhas sucessivas e transmitir o sinal do detector a uma tela catódica cuja varredura está perfeitamente sincronizada com aquela do feixe incidente. Por um sistema de bobinas de deflexão, o feixe pode ser guiado de modo a varrer a superfície da amostra segundo uma malha retangular. O sinal de imagem resulta da interação do feixe incidente com a superfície da amostra (DEDAVID et al., 2007). 
O microscópio utilizado na MEV também permite a utilização da técnica de EDS (Energy-Disperse X - Ray Spectroscopy - conforme a sigla em inglês) a qual considera o princípio de que a energia de um fóton $(E)$ está relacionada com a frequência eletromagnética $(p)$ pela relação $E=h p$, em que "h" é a constante de Planck. Os fótons com energias correspondentes a todo espectro de raios $X$ atingem 0 detector de raios $X$ quase que simultaneamente, e o processo de medida é rápido, o que permite analisar os comprimentos de onda de modo simultâneo (CRUZ et al., 2006).

A análise por EDS é uma ferramenta muito importante da MEV para a caracterização de materiais metálicos e semicondutores, pois permite ao pesquisador identificar a composição de sua amostra, mesmo que qualitativamente, em pontos específicos da imagem (CRUZ et al., 2006).

\subsection{Resistência à tração}

A resistência à tração é a medida da capacidade de um material resistir às forças que tendem a puxar e separar o mesmo, antes da ruptura. Assim, esta propriedade é específica para polímeros, pois é a mais utilizada para selecionar um determinado material plástico (FERRO, 2009).

Sabe-se que a resistência à tração dos polímeros é dependente da velocidade de carregamento, temperatura e de alguns fatores ambientais, como a umidade. Na Figura 6 (a) é mostrado o efeito da velocidade de carregamento sobre a resistência. De forma que a Figura 7 (b) mostra a influência da umidade em materiais como a poliamida (MARCZAK, 2004). 
Figura 7 - Comportamento esquemático da resistência dos polímeros em função da velocidade de carregamento e da umidade

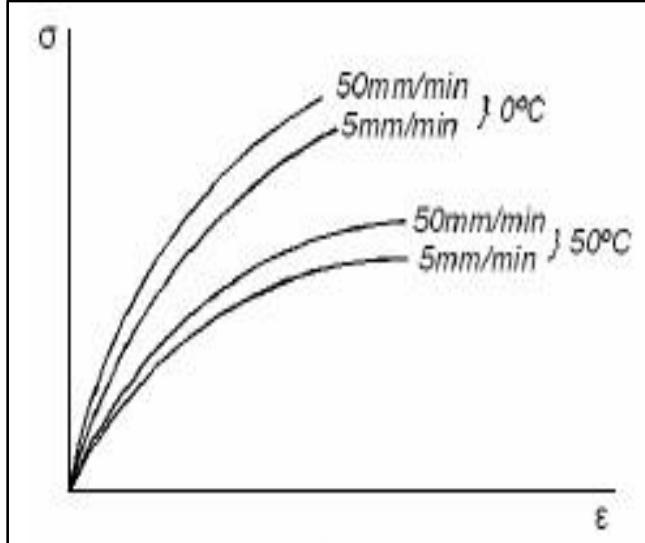

(a)

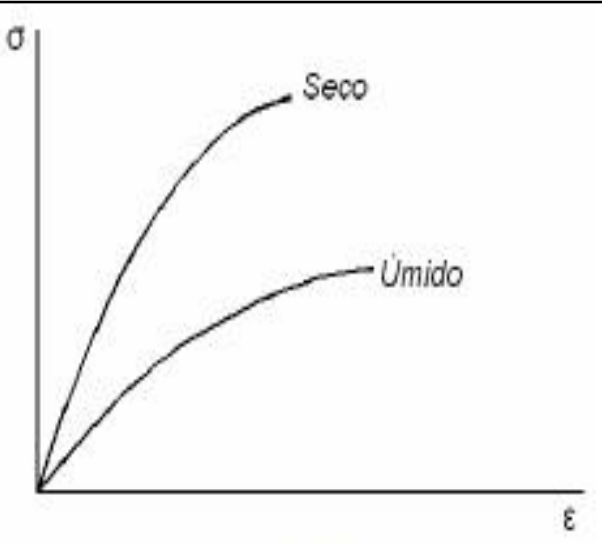

(b)

Fonte: MARCZAK, 2004.

Segundo CHAVES (1999), o comportamento mecânico de um polímero pode ser caracterizado por suas propriedades e tensão versus deformação, ou seja, a partir do momento em que se aplica uma tensão no polímero para deformá-lo até provocar sua ruptura.

A lei de Hooke é utilizada para o ensaio de tração por deformações elásticas, que ocorre no início do teste, pois acima de uma determinada tensão de escoamento o regime de escoamento muda de elástico para plástico.

Algumas regiões se deformam mais que outras e ocorre uma diminuição na área da seção transversal localizada no ponto que se origina a ruptura, durante 0 teste. A região correspondente a esta deformação é denominada de pescoço ou estricção. Devido a esta diminuição na área, a carga para deformar o material, e consequentemente também a tensão nominal, diminuem, apesar da tensão real continuar constante ou subindo (ORÉFICE et al., 2012). 


\subsubsection{Modelo de Bergsntrom - Boyce}

Um material viscoelástico possui propriedades características de sólido e fluido e a ocorrência dessas propriedades dependem em grande parte das condições do ambiente, principalmente a temperatura, e do regime do carregamento imposto ao material. Geralmente grande parte dos polímeros exibe comportamento viscoelástico na temperatura de trabalho quando um carregamento é aplicado ao longo do tempo (PAGLIOSA, 2004).

Para representar o comportamento mecânico viscoelástico o modelo de Bergstrom-Boyce foi inicialmente proposto e pode ser explicado de maneira simplificada, considerando-se um elastômero com poucas ligações cruzadas e longas cadeias entre as mesmas. Sabe-se que ao se aplicar um carregamento a altas taxas de deformação, esta cadeia se deforma de maneira semelhante ao material em torno, com a entropia da mesma caindo e, consequentemente, adicionando resistência ao material (MOURA R., 2013).

Para verificar esta teoria ensaios experimentais em borrachas naturais, com e sem aditivos mostrados na Figura 8 foram testadas para averiguação da sensibilidade à taxa de deformação, o deslocamento foi imposto ao corpo de prova em intervalos, de mesmo período de tempo, de velocidades constantes não nula e velocidade nula combinando ensaios de compressão com ensaios de relaxação (MOURA, R., 2013).

Assim, o autor concluiu que para representar o comportamento mecânico de um elastômero e sua dependência é necessário modelar uma parte de equilíbrio, independentemente da taxa de deformação ou do tempo. Esse modelo será aplicado na poliamida 6 com o intuito de avaliar o comportamento mecânico a baixíssimas taxas de deformação (MOURA, R., 2013). 
Figura 8 - Modelos proposto por Bersgtrom

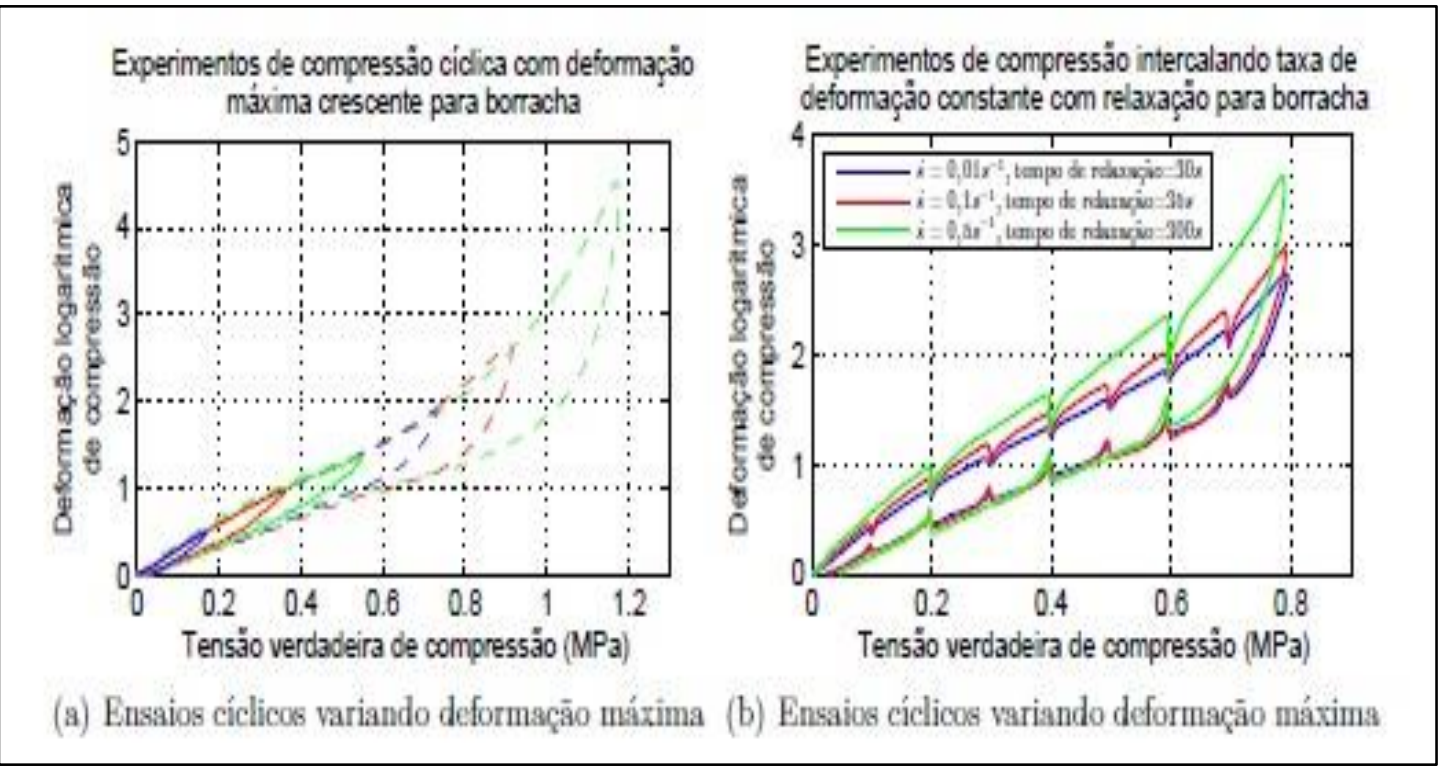

Fonte: MOURA R., 2013.

\subsubsection{Digital Image Correlation (DIC)}

A correlação de imagem digital (Digital Image Correlation), consistem em localizar o ponto A na segunda imagem pela comparação de padrões de correlação onde o Rol é a área delimitada pelo usuário. O software de Ncorr que é usado para tratamento de imagens, fornecendo arquivos.mat que pode ser aberto, por meio do software Matlab®. Os softwares contêm a deformação de Green em x, em y e xy (Equação 3), gerando imagens das fotografias sobrepostas das malhas com representação com níveis de cores em escala representando deformações axiais ou deformações transversais ou taxa de deformação axial (levando em consideração o intervalo entre uma fotografia e a seguinte (MOURA R., 2013).

$$
\varepsilon^{G}=\frac{l^{2}-l_{0}^{2}}{2 l_{0}^{2}}=\frac{1}{2}\left(\lambda^{2}-1\right) ; \quad \text { Equação } 3
$$




\subsection{Análise de densidade}

A densidade avalia o grau de uniformidade na moldagem de um produto ou na variação da cristalinidade do polímero que pode ser afetada por carga ou reforços. Esta análise consiste na avaliação da relação entre a massa e o volume de uma peça moldada que apresente no mínimo $1 \mathrm{~cm}^{3}$, com superfície livre de impurezas e gorduras e sem rugosidade (MANRICH, 2005). 


\section{MATERIAIS E MÉTODOS}

\subsection{Matéria prima utilizada}

Para execução deste estudo os corpos de prova de PA 6 pura e com talco foram disponibilizados pela empresa Rhodia Poliamida e Especialidades LTDA. Os corpos de prova do $1^{\circ}$ lote de compósitos foram preparados no laboratório de desenvolvimento da empresa Rhodia Poliamida e Especialidades LTDA. e o $2^{\circ}$ lote foi processado no Instituto de Pesquisas Energéticas e Nucleares IPENCNEN/SP. O $\mathrm{SiO}_{2}$ para os dois lotes foi adquirido da empresa Evonik Degussa do Brasil Ltda.

Primeiramente foi desenvolvido um "masterbatch" que consistiu em micronizar cerca de $10 \%$ da massa total da poliamida 6 , misturar com o óleo mineral encaplus 240 e adicionar o $\mathrm{SiO}_{2}$ aos poucos. Em seguida extrudou-se os grãos de poliamida $6 \mathrm{com}$ a mistura garantindo que o composto fosse totalmente misturado. Assim sendo, obteve-se um masterbeach $13 \%$ em $\mathrm{SiO}_{2}$ na matriz de PA 6. Todo esse processo foi realizado na empresa Cromex S/A. Posteriormente, os compósitos de PA 6 foram preparados com carga de $\mathrm{SiO}_{2}$ e com carga de talco, variando a porcentagem das cargas tanto de $\mathrm{SiO}_{2}$ como de talco

Os compósitos foram processados em uma extrusora dupla rosca ZSK30, com elementos de rosca apropriados para o processamento e homogeneização da poliamida. Posteriormente os compósitos foram injetados, em uma injetora de plásticos Romi 65R Primax seguindo a norma ISO1874-2. Após o processo de injeção eles foram mantidos em embalagens fechadas durante um período de 48 horas, em temperatura e umidade controladas $\left(23 \pm 2{ }^{\circ} \mathrm{C}\right.$ e $50 \pm 5 \%$ ), de acordo com a norma ISO / R291.

\subsection{Preparação e caracterização das amostras para análise}

Para avaliar as propriedades mecânicas, térmicas, estruturais e morfológicas os corpos de prova de PA 6 com cargas de $\mathrm{SiO}_{2}$ foram processadas com três diferentes formulações ( $1 \%, 3 \%$ e $6 \%$ ) e formulaçõs com carga de talco com (1\%, $3 \%, 6 \%$ e $10 \%)$. 
Também, foram processadas amostras de PA 6 com $10 \%$ de talco que foram os padrões de comparações com as formulações anteriores, as quais são utilizadas na indústria automobilística.

\subsubsection{Termogravimetria (TG)}

Os compósitos de PA 6 com talco e $\mathrm{SiO}_{2}$ não irradiados e irradiados foram caracterizados por termogravimetria (TG) e por termogravimetria derivada (DTG). Utilizou-se uma termobalança modelo TGA da TA Instruments, na faixa de temperatura de 20 a $600^{\circ} \mathrm{C}$, sob uma atmosfera dinâmica de ar comprimido, com vazão de $100 \mathrm{~mL} \cdot \mathrm{min}^{-1}$, razão de aquecimento de $20^{\circ} \mathrm{C} / \mathrm{min}$, em cadinho de platina e massa de amostra de aproximadamente $10 \mathrm{mg}$ (Figura 9). Antes dos ensaios, foram obtidas curvas em branco para avaliar a linha base do sistema. A calibração do equipamento TGA-51 foi realizada conforme a norma ASTM 1582-4; para verificação do sistema, sendo usado como padrão oxalato de cálcio monoidratado com pureza de 99,99 \% de procedência Merk.

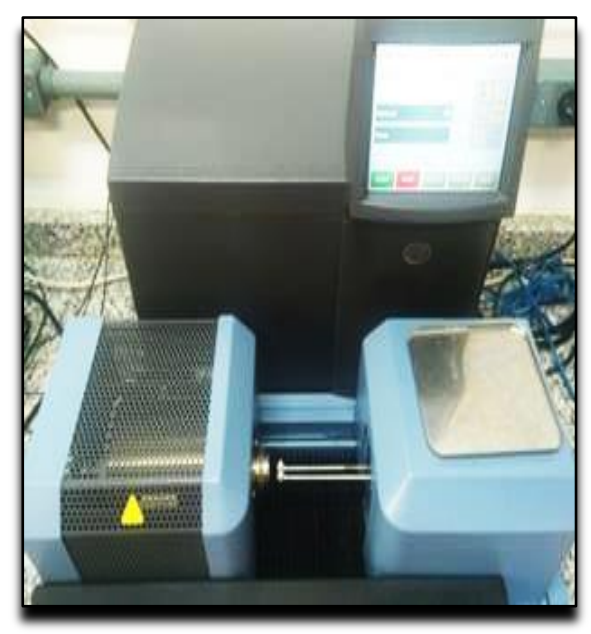

Fonte: autor da dissertação 
4.2.2 Calorimetria exploratória diferencial (DSC)

Os compósitos de PA 6 com talco e $\mathrm{SiO}_{2}$ não irradiados e irradiados foram caracterizados por calorimetria exploratória diferencial (DSC), por meio da célula DSC modelo DSC Perkin Elmer (Figura 10), sob uma atmosfera de $\mathrm{N}_{2}$, com vazão de $100 \mathrm{~mL} \cdot \mathrm{min}^{-1}$, na faixa de temperatura de 20 a $600{ }^{\circ} \mathrm{C}$, razão de aquecimento de $20{ }^{\circ} \mathrm{C} / \mathrm{min}$, em cadinho de alumínio parcialmente fechado e massa de amostra de cerca de $10 \mathrm{mg}$.

Figura 10 - Equipamento de DSC da marca Perkin Elmer

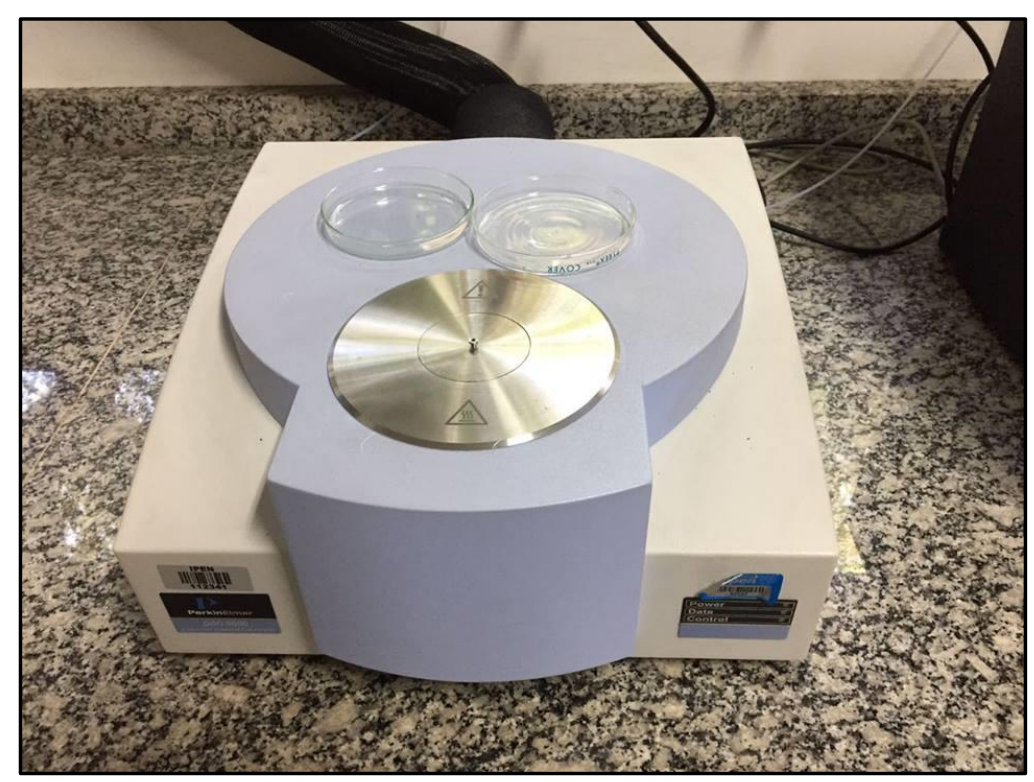

Fonte: autor da dissertação

4.2.3 Espectroscopia de absorção no infravermelho por transformada de Fourier (FTIR)

Os ensaios de espectroscopia de absorção no infravermelho por transformada de Fourrier foram realizados no espectrômetro marca Perkin Elmer (Figura 11), modelo Spectrum One, acoplado com dispositivo Universal ATR ("Sampling Acessory") no Laboratório do Centro de Tecnologia das Radiações 
(CTR) do IPEN-CNEN/SP. O equipamento possui um programa de comparação que permite correlacionar as diferenças espectrais ocorridas entre as amostras analisadas, no intervalo de 400 a $10000 \mathrm{~cm}^{-1}$ com resolução de $2 \mathrm{~cm}^{-1}$.

\section{Figura 11 - Espectrômetro marca Perkin Elmer}

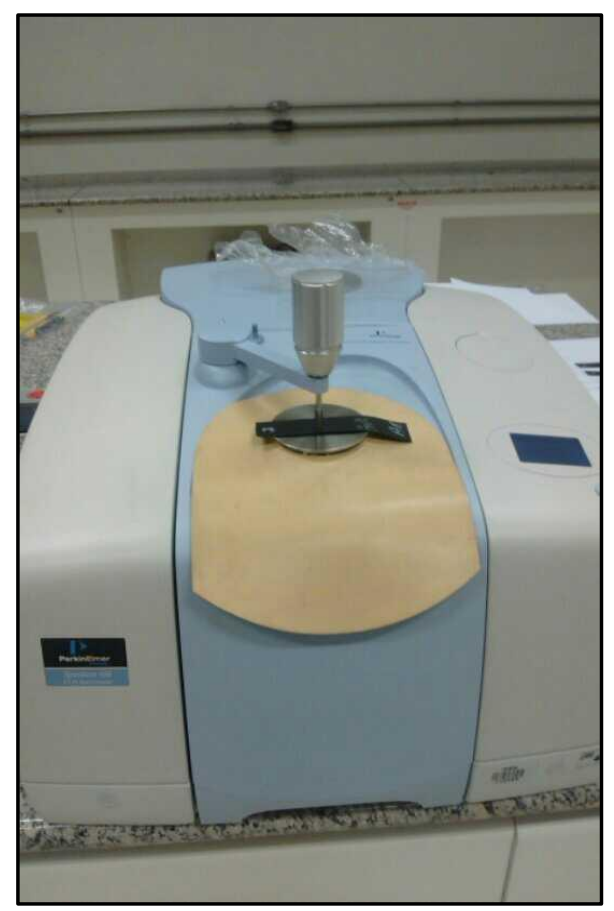

Fonte: autor da dissertação

\subsubsection{Difração de raios $X$}

Foi possível verificar os picos de $\mathrm{PA} 6$ de $\mathrm{SiO}_{2}$ e de talco com e sem radiação utilizando o equipamento de raios $X$ Bruker D8 Advance (Figura 12) do laboratório do Centro de Ciências e Tecnologia de Materiais. 
Figura 12 - Equipamento de Difração de raios X Bruker D8 Advance

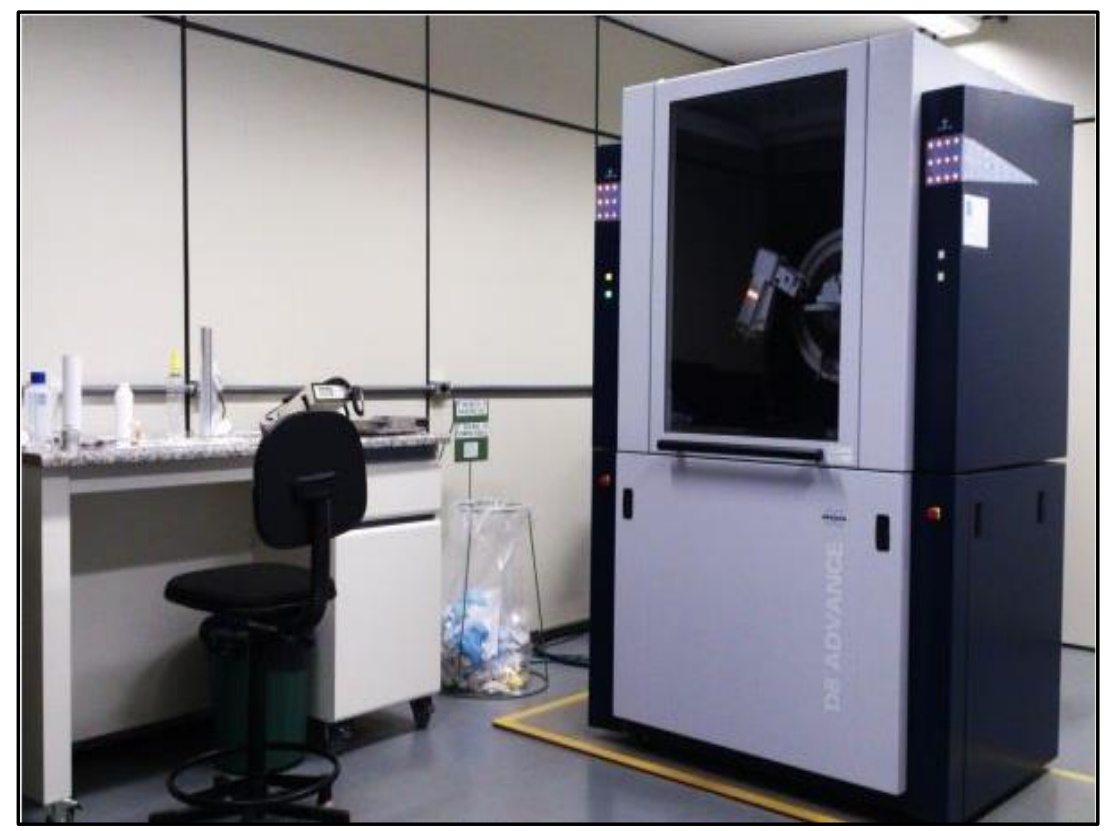

Fonte: autor da dissertação 


\subsubsection{Microscopia eletrônica de varredura (MEV)}

Realizou-se os testes de MEV em um microscópio eletrônico de varredura JEOL, modelo: JSM 6510 (filamento de tungstênio) (Figura 13 - Microscópio eletrônico de varredura JEOL da Escola de Engenharia da Universidade Presbiteriana Mackenzie).

Figura 13 - Microscópio eletrônico de varredura JEOL

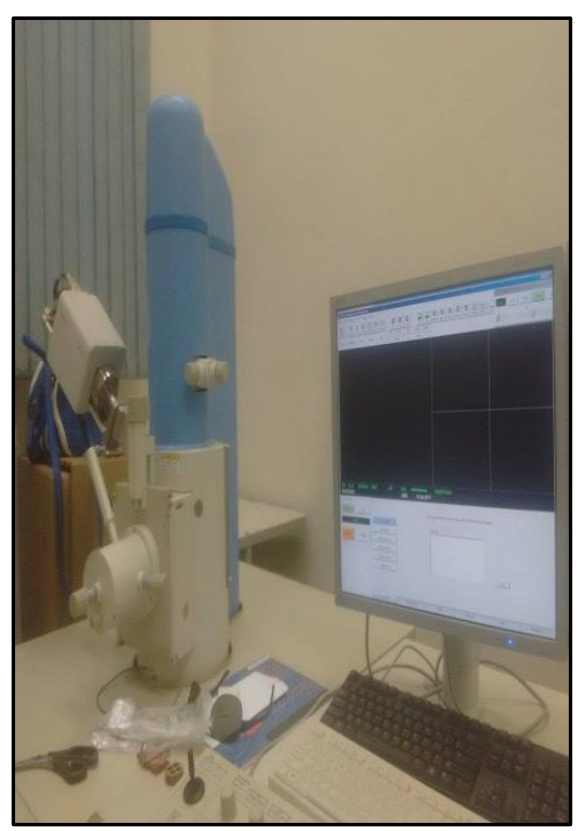

Fonte: autor da dissertação.

\subsubsection{Análise mecânica - Tração}

Foram medidas as larguras e espessuras de todas as amostras, em quatro regiões de cada corpo de prova, as quais apresentaram dimensões médias de $160 \mathrm{~mm}$ de comprimento, $13 \mathrm{~mm}$ de largura e 3,30 $\mathrm{mm}$ de espessura.

Foi utilizada tinta plástica na região do comprimento LO de cada corpo de prova. Para este trabalho foi utilizado o método de Bergstron para verificar a velocidade e o módulo de elasticidade. Os ensaios também seguiram os parâmetros da norma de tração ISO 527. 
Todos os ensaios foram executados em um equipamento denominado Máquina Universal de Ensaios Instron modelo 3339 (Figura 14), com célula de carga de $50 \mathrm{kN}$, com limite de velocidade de teste $400 \mathrm{~mm} / \mathrm{min}$ e um limite de frequência de aquisição dos resultados de $10 \mathrm{~Hz}$.

Figura 14 - Instron modelo 3339

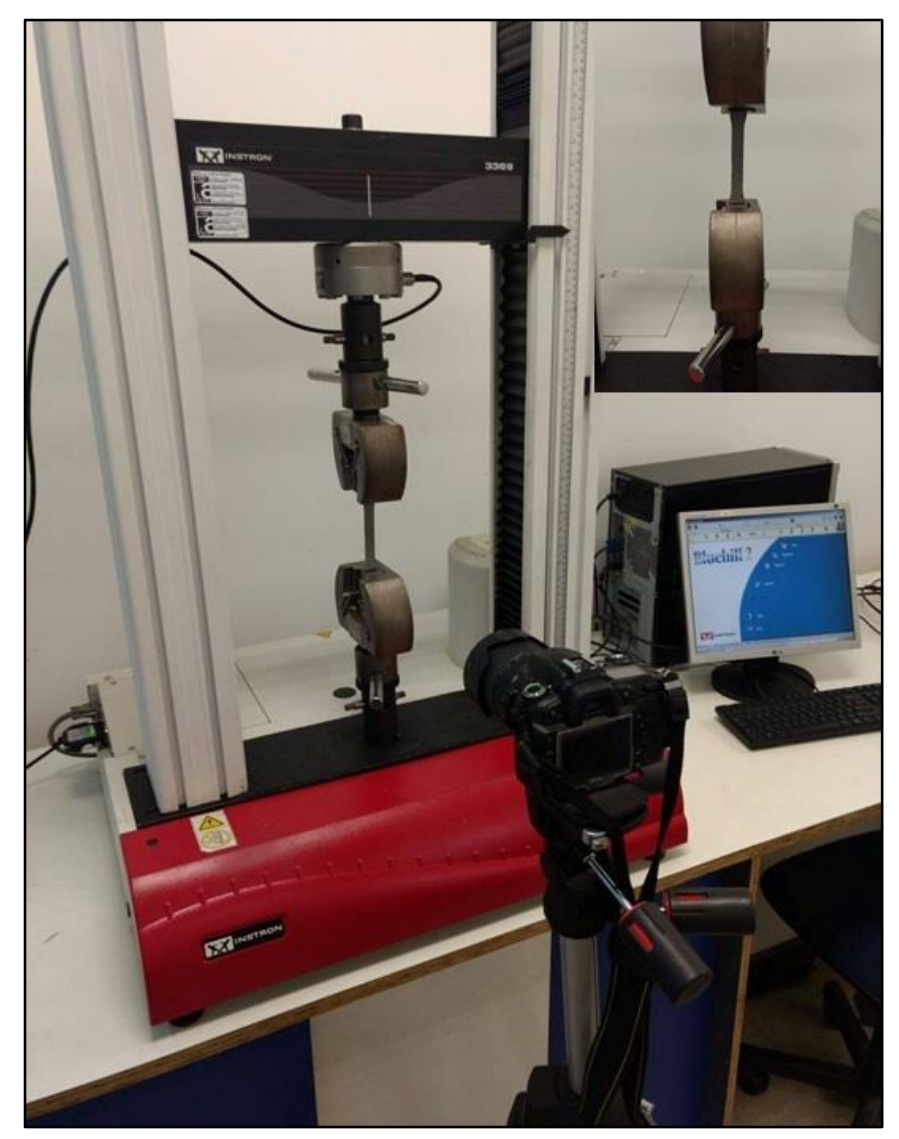

Fonte: autor da dissertação.

Este equipamento consiste basicamente de um arranjo constituído por duas travessas (uma fixa e outra móvel), uma célula de carga, um mecanismo de direcionamento, acessórios de fixação dos corpos de prova e extensômetros. Nos ensaios de tração, dispositivos de fixação dos corpos de prova (garras) foram acoplados às travessas fixa e móvel e seu funcionamento baseia-se no movimento vertical das garras, as quais possuem velocidade de 
afastamento/aproximação, respectivamente, controladas pelo operador (CANTO e PESSAN, 2004).

Para o ensaio de correlação de imagem (DIC) os corpos de prova do tipo gravata foram pintados com tinta plásticas preta e branca de forma que não alterem as propriedades mecânicas do material analisado, sendo possível calcular o deslocamento de um determinado ponto.

Por meio da função de interpolação foi possível calcular a distribuição de nível de cinza entre pixels, permitindo melhorar a acurácia para um nível de subpixel. Um dos motivos da popularização deste método é o seu custo baixo, já que na grande maioria dos casos o padrão é randomicamente aplicado por tintas pulverizadas sobre a superfície, sendo aplicada primeiro uma camada branca, seguida de uma camada preta (MOURA R., 2013).

As medições realizadas foram à deformação logarítmica (real), a deformação de Green, o coeficiente de Poisson (deformação transversal sendo proporcional a deformação longitudinal) e a tensão verdadeira.

Para medir todos esses parâmetros também foi necessário medir a espessura e largura de cada corpo de prova e calcular a área dos mesmos. Por isso os corpos de prova foram definidos como CP1 que a velocidade do teste de tração $0,075 \mathrm{~mm} / \mathrm{s}$ e CP2 que a velocidade do teste de tração foi de $0,35 \mathrm{~mm} / \mathrm{s}$ na Instron.

Em seguida os resultados do teste de tração informados pela Instron e os resultados dos dados do DIC no software ncorr, foram calculados por meio do algorítmo apresentado no apêndice $A$ deste trabalho que foi desenvolvido utilizando o software Matlab ${ }^{\circledR}$.

\subsection{Irradiações das amostras}

As amostras dos compósitos de PA 6 com as cargas de $\mathrm{SiO}_{2}$ e de talco, em diferentes proporções foram irradiadas com doses de 200, 300, e 400 kGy a uma taxa de dose de 22,40 kGy no acelerador de elétrons Dynamitron JOB 188 (Figura 15), de energia de 0,5 a 1,5 MeV e corrente de 0,1 a $25 \mathrm{~mA}$ do Centro de Tecnologia das Radiações do IPEN-CNEN/SP. 
Figura 15 - Acelerador de elétrons JOB 188

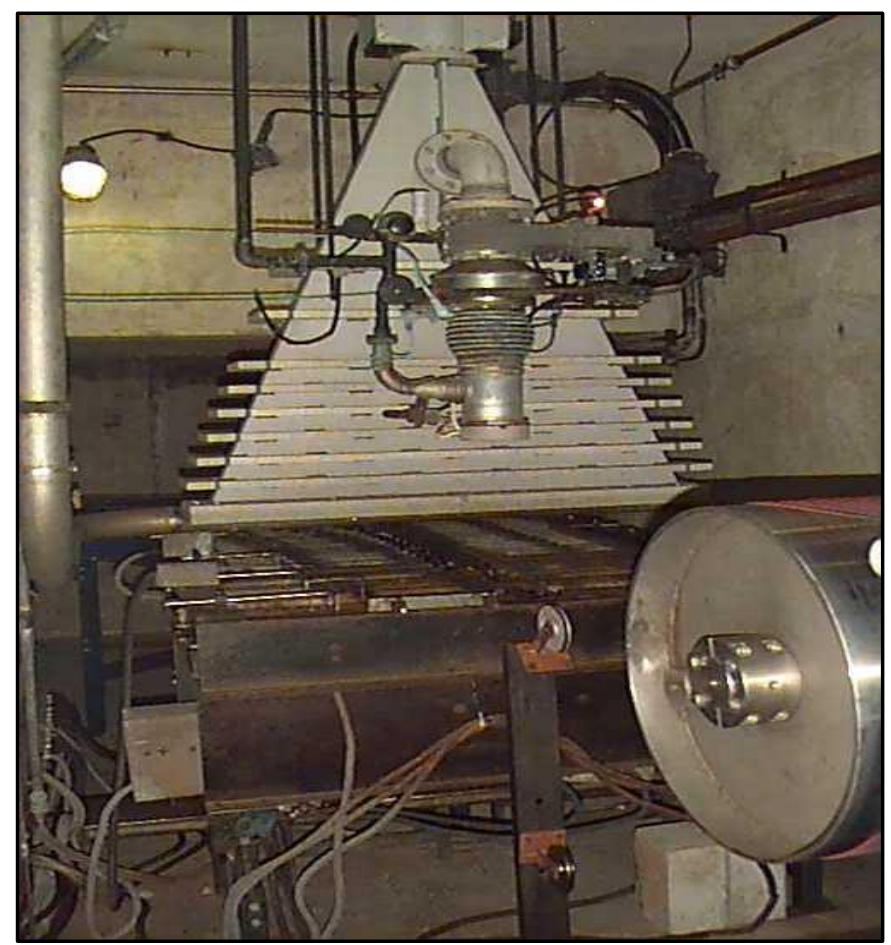

Fonte: autor da dissertação.

\subsection{Densidade}

O ensaio de densidade foi realizado em uma balança analítica de marca Kern de precisão de $\pm 0,1 \mathrm{mg}$. A análise foi realizada utilizando tetrahidrofurano liquido para imersão, em razão de a poliamida ser higroscópica.

Os corpos de prova foram injetados conforme a norma ISO 1874-2, e acondicionados em embalagem selada com bloqueio de umidade por 48 horas em temperatura e umidade controlada $\left(23 \pm 2{ }^{\circ} \mathrm{C}\right.$ e $50 \pm 5 \%$ de umidade) conforme a norma ISO/R291. Após o tempo de acondicionamento os ensaios foram realizados seguindo a norma ASTM D792-98. 


\section{RESULTADOS E DISCUSSÃO}

\subsection{Calorimetria exploratória diferencial e termogravimetria do masterbatch}

Na Figura 16 são mostradas as curvas DSC obtidas para o master de PA 6 com $13 \%$ de $\mathrm{SiO}_{2}$ submetida a sequência de ciclos de resfriamento, aquecimento e resfriamento.

Figura 16 - Curvas de DSC do masterbatch de PA 6 com $13 \%$ de $\mathrm{SiO}_{2}$

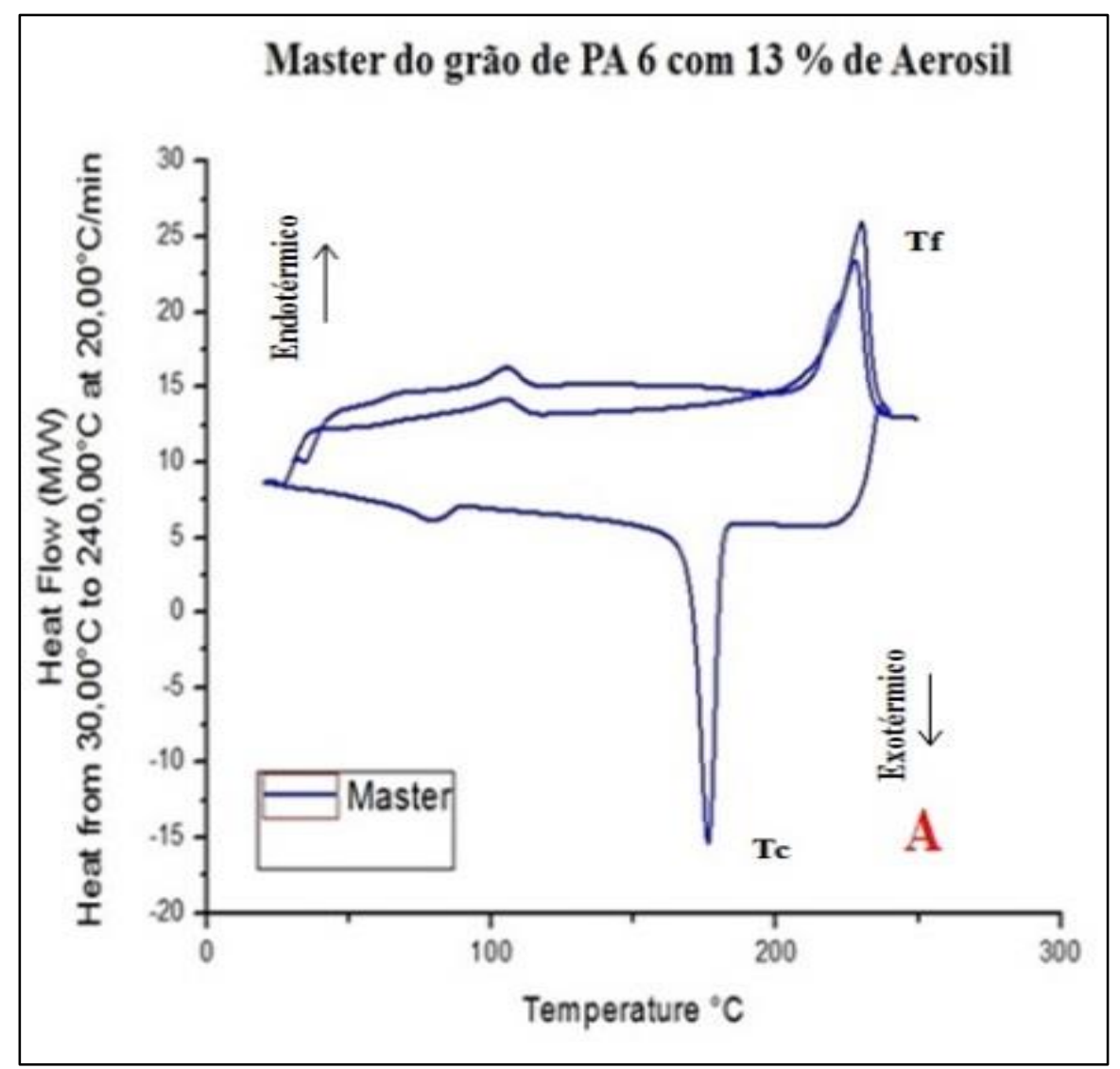

Fonte: autor da dissertação. 
Na Figura 17 é mostrada a curva termogravimétrica do masterbatch de PA 6 com $13 \%$ de $\mathrm{SiO}_{2}$.

Figura 17 - Curvas de DSC do masterbatch de PA 6 com $13 \%$ de $\mathrm{SiO}_{2}$

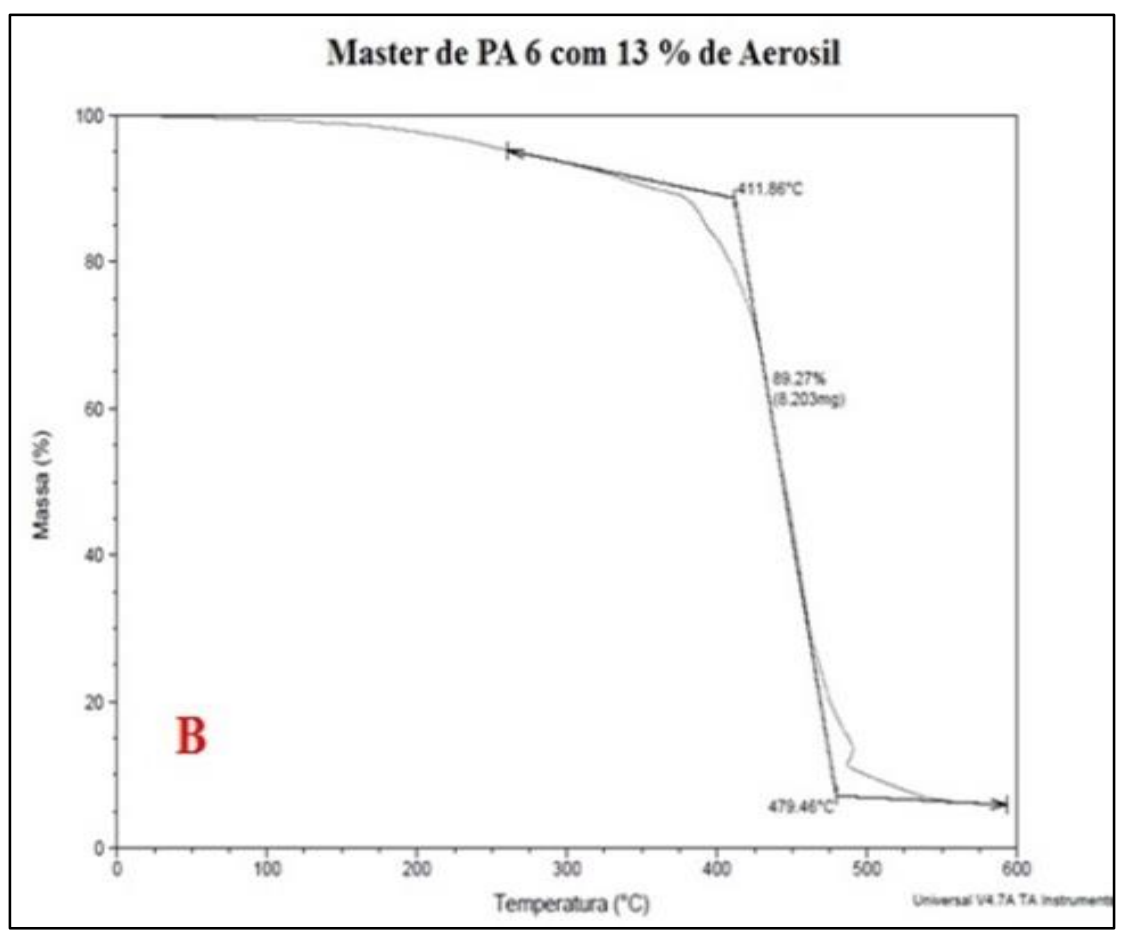

Fonte: autor da dissertação.

Primeiramente foram realizados ensaios de DSC cujos resultados estão mostrados na (Figura 16) e os resultados de TG na (Figura 17) com o masterbatch de PA 6 com $13 \%$ de $\mathrm{SiO}_{2}$, com o objetivo de obter o histórico térmico da poliamida $6 \mathrm{com} \mathrm{SiO}_{2}$ antes da obtenção dos corpos de prova.

De acordo com a (Figura 16) as amostras do máster com massa entre 10 $15 \mathrm{mg}$, em seguida foram aquecidas de $30^{\circ} \mathrm{C}$ à $240^{\circ} \mathrm{C}$ à razão de $20^{\circ} \mathrm{C} / \mathrm{min}$ em atmosfera de nitrogênio. Assim, a cristalização não isotérmica do processo foi registrada na faixa de 120 a $180^{\circ} \mathrm{C}$ e o valor de cristalinidade e ponto de fusão na faixa de 220 a $260 \stackrel{\circ}{\circ}$.

Para o caso dos experimentos por termogravimetria (Figura 17) também foi obtida a curva termogravimétrica do masterbatch de PA $6 \mathrm{com} 13 \%$ de $\mathrm{SiO}_{2}$ para

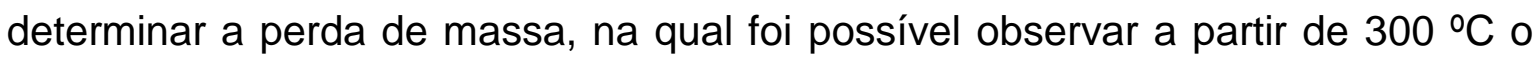
início da perda de massa neste caso a amostra foi aquecido até $600 \stackrel{\circ}{\circ}$. 
$\mathrm{Na}$ Figura 18 são mostradas as curvas termogravimétricas da PA 6 com $1 \%, 3 \%, 6 \%$ de $\mathrm{SiO}_{2}$ e PA 6 com $10 \%$ de talco.

Figura 18 - Curvas TG de compósitos de PA 6 com carga de $\mathrm{SiO}_{2}$ e carga de talco em atmosfera de ar com razão de aquecimento de $20 \stackrel{\circ}{\circ} / \mathrm{min}$

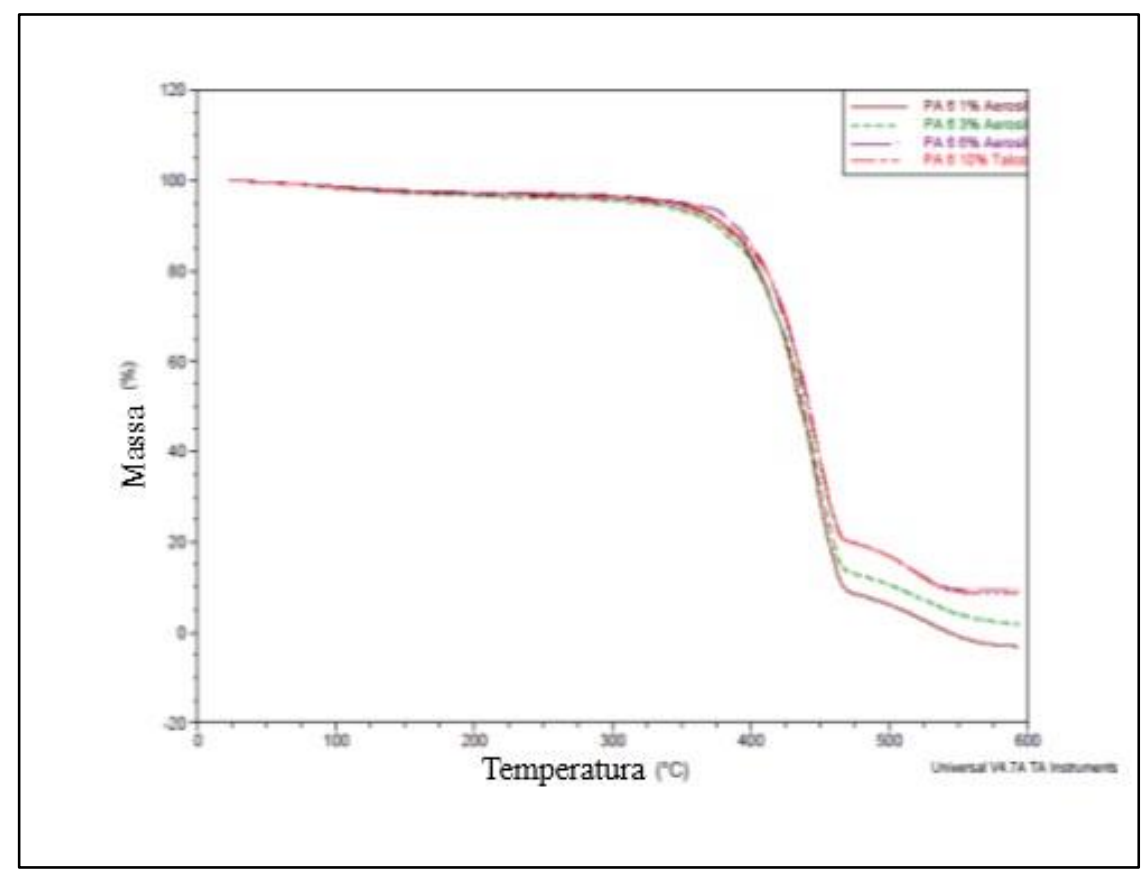

Fonte: autor da dissertação.

Observou-se que as poliamidas começaram a apresentar perda de massa, no início do aquecimento quando o processo de composição térmica iniciou a liberação dos componentes voláteis. A PA 6 apresentou perda de massa na faixa de $300^{\circ} \mathrm{C}$ até $480 \stackrel{\circ}{\mathrm{C}}$ e após essa temperatura observou-se a existência de um resíduo parecendo ser uma possível contaminação por fibra de vidro no compósito.

Os compósitos foram aquecidos até a temperatura de $600 \stackrel{\circ}{\circ}$. Deste modo, não foi possível observar se todo o resíduo de carga foi expelido, porém para o segundo lote as amostras foram aquecidas até a temperatura de $900 \stackrel{\circ}{C}$ para garantir que todo o resíduo fosse eliminado. 


\subsection{Termogravimetria}

Nas Figuras 19, 20 e 21 são mostradas as curvas de TG dos compósitos não irradiados de PA 6 com $1 \%$, $3 \%$ e $6 \%$ de $\mathrm{SiO}_{2}$ e irradiados com doses de 200 kGy, 300 kGy e 400 kGy.

Figura 19 - Curvas TG de compósitos irradiados e não irradiados de PA 6 com $1 \%$ de $\mathrm{SiO}_{2}$ em atmosfera de ar com razão de aquecimento de $20^{\circ} \mathrm{C} / \mathrm{min}$

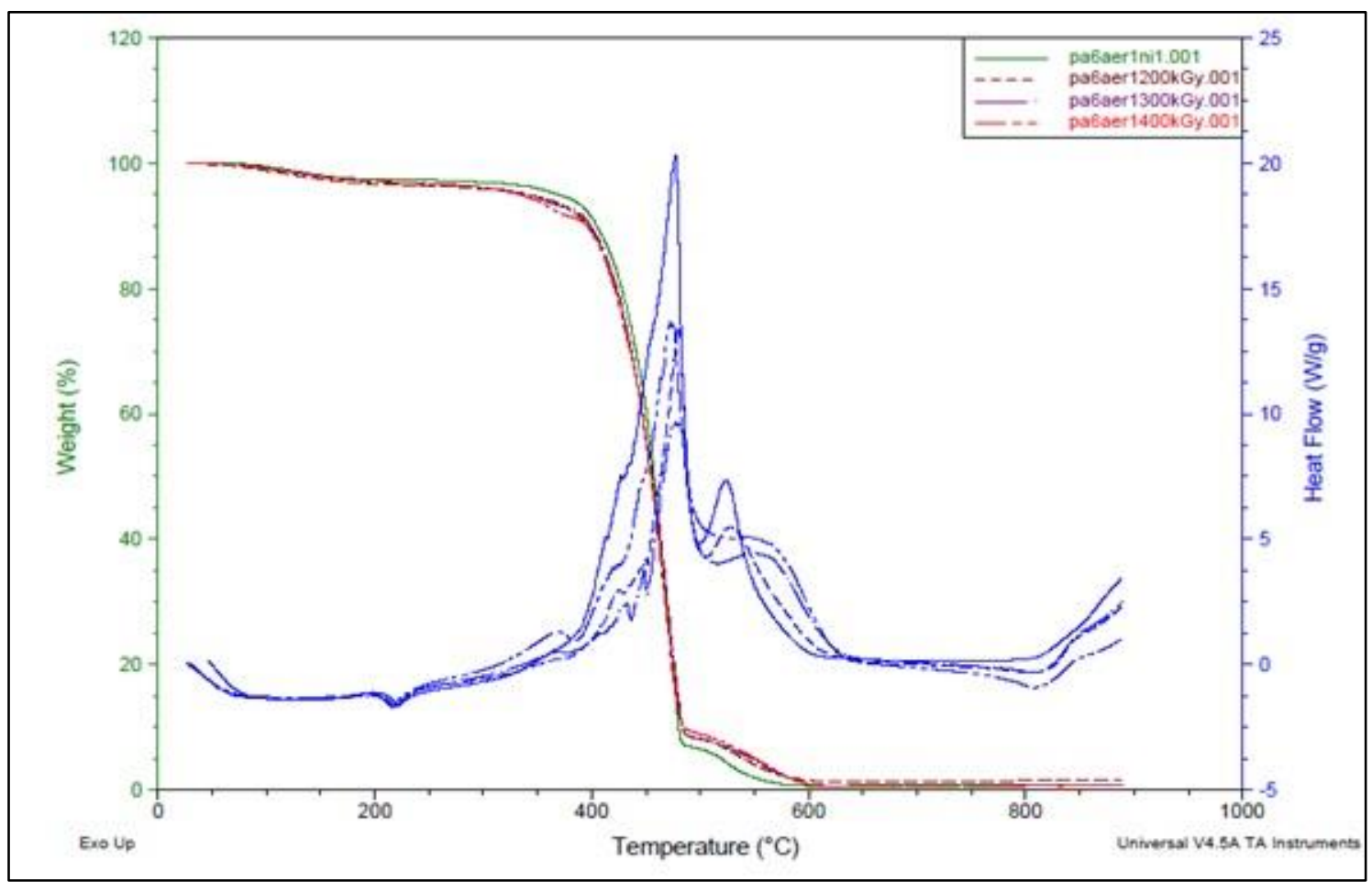

Fonte: autor da dissertação. 
Figura 20 - Curvas TG de compósitos irradiados e não irradiados de PA 6 com $3 \%$ de $\mathrm{SiO}_{2}$ em atmosfera de ar com razão de aquecimento de $20 \stackrel{\circ}{\circ} / \mathrm{min}$.

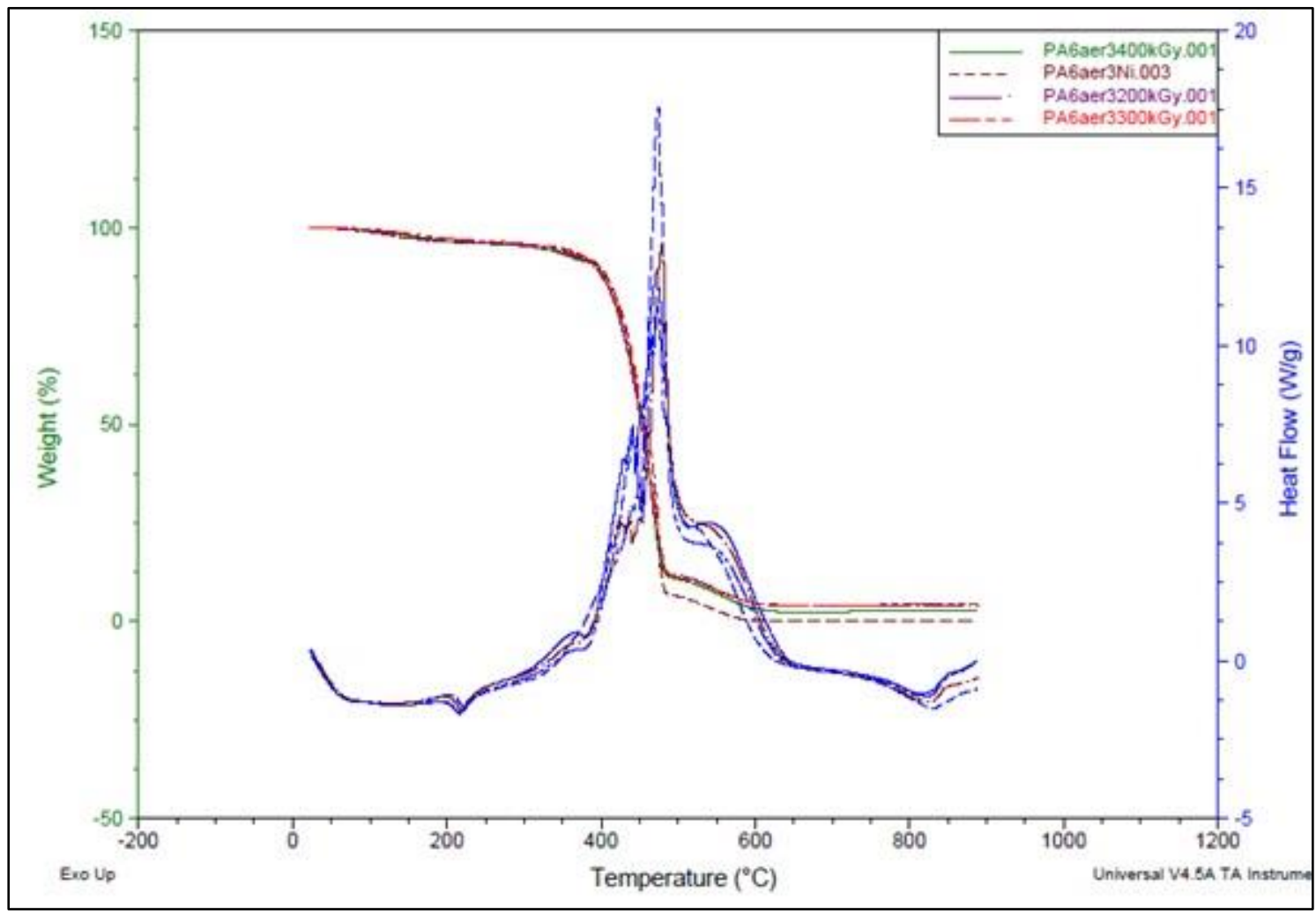

Fonte: autor da dissertação. 
Figura 21 - Curvas TG de compósitos irradiados e não irradiados de PA 6 com 6 $\%$ de $\mathrm{SiO}_{2}$ em atmosfera de ar com razão de aquecimento de $20 \stackrel{\circ}{\mathrm{C}} / \mathrm{min}$

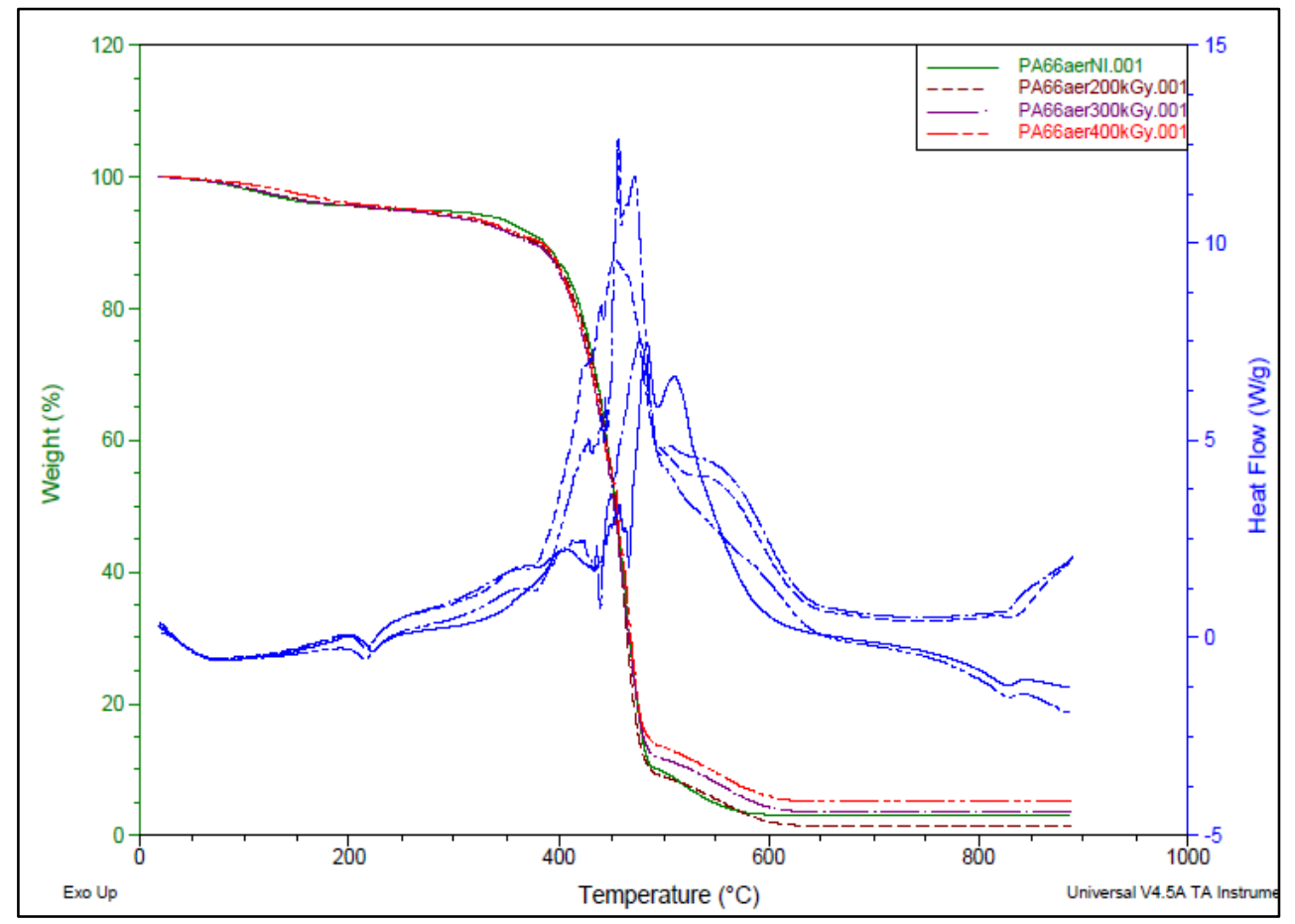

Fonte: autor da dissertação.

De acordo com as Figuras 19, 20 e 21 observou-se o início e o fim da perda de massa na faixa de $300 \stackrel{\circ}{\circ} \mathrm{C}$ a $\mathrm{T}_{\text {onset }}$ até $500 \stackrel{\circ}{\circ} \mathrm{C}$ a $\mathrm{T}_{\text {endset. }}$ Com os picos formados pelas curvas da DTG foi possível verificar a existência de uma série de eventos intermediários mas não é possível afirmar, se os mesmos foram causados pela carga ou por influência da radiação.

Por fim os compósitos foram aquecidos até $900 \stackrel{\circ}{\mathrm{C}}$ garantindo a liberação total do resíduo, porém observou-se que não foram todos os resíduos que chegaram a $0 \%$ de perda de massa. Uma possível explicação para este comportamento é que o ponto de fusão do $\mathrm{SiO}_{2}$ é de $1.710 \stackrel{\circ}{ } \mathrm{C}$, assim sendo seria necessário elevar a temperatura para garantir que não tenha sobrado resíduo de $\mathrm{SiO}_{2}$. 
Nas Figuras 22, 23, 24 e 25 são mostradas as curvas de TG dos compósitos não irradiados de PA 6 com $1 \%, 3 \%, 6 \%$ e $10 \%$ de talco e irradiados com doses de 200 kGy, 300 kGy e 400 kGy.

Figura 22 - Curvas TG de compósitos irradiados e não irradiados de PA 6 com $1 \%$ de talco em atmosfera de ar com razão de aquecimento de $20 \stackrel{\circ}{\mathrm{C}} / \mathrm{min}$

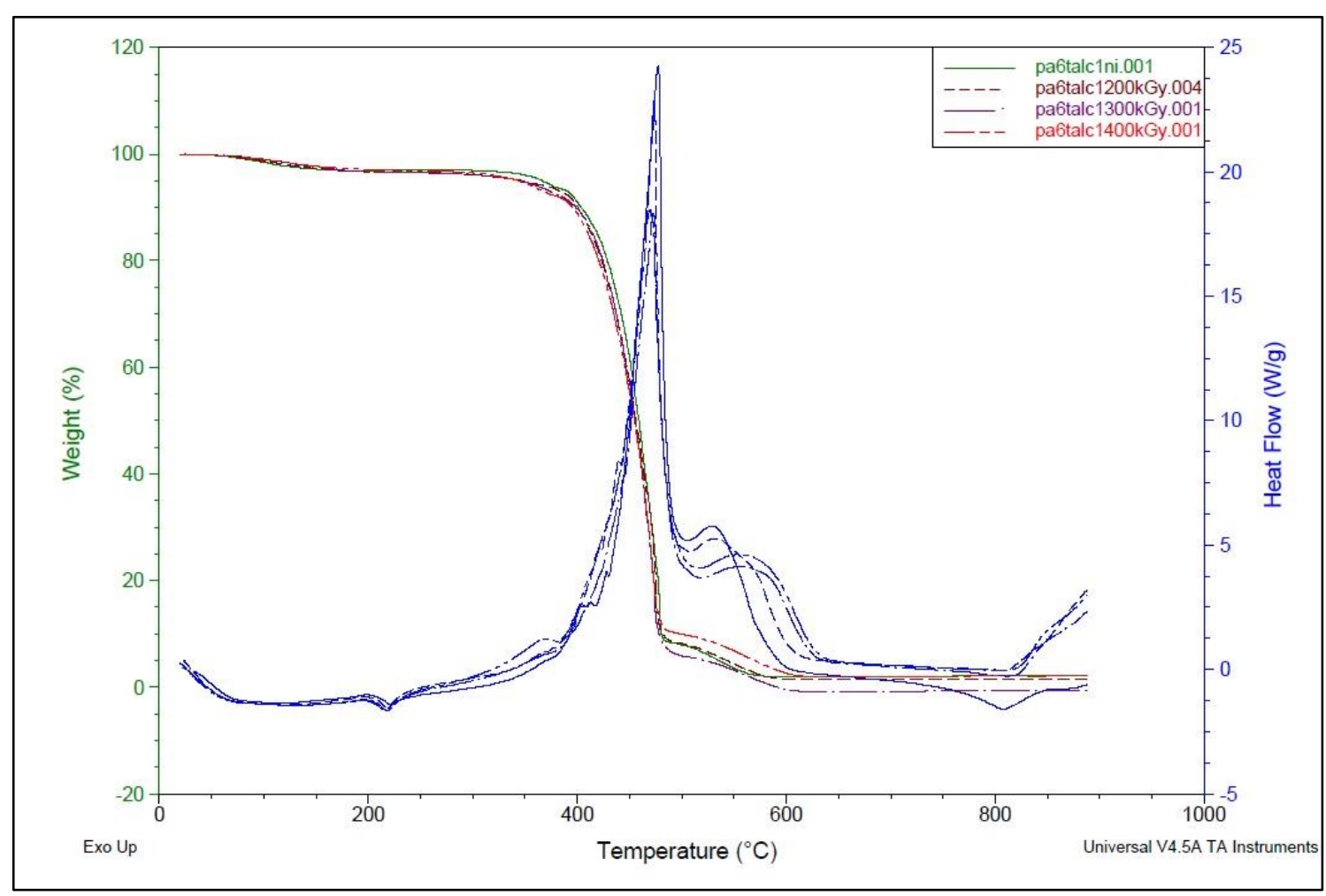

Fonte: autor da dissertação. 
Figura 23 - Curvas TG de compósitos irradiados e não irradiados de PA 6 com $3 \%$ de talco em atmosfera de ar com razão de aquecimento de $20 \stackrel{\circ}{\circ} / \mathrm{min}$

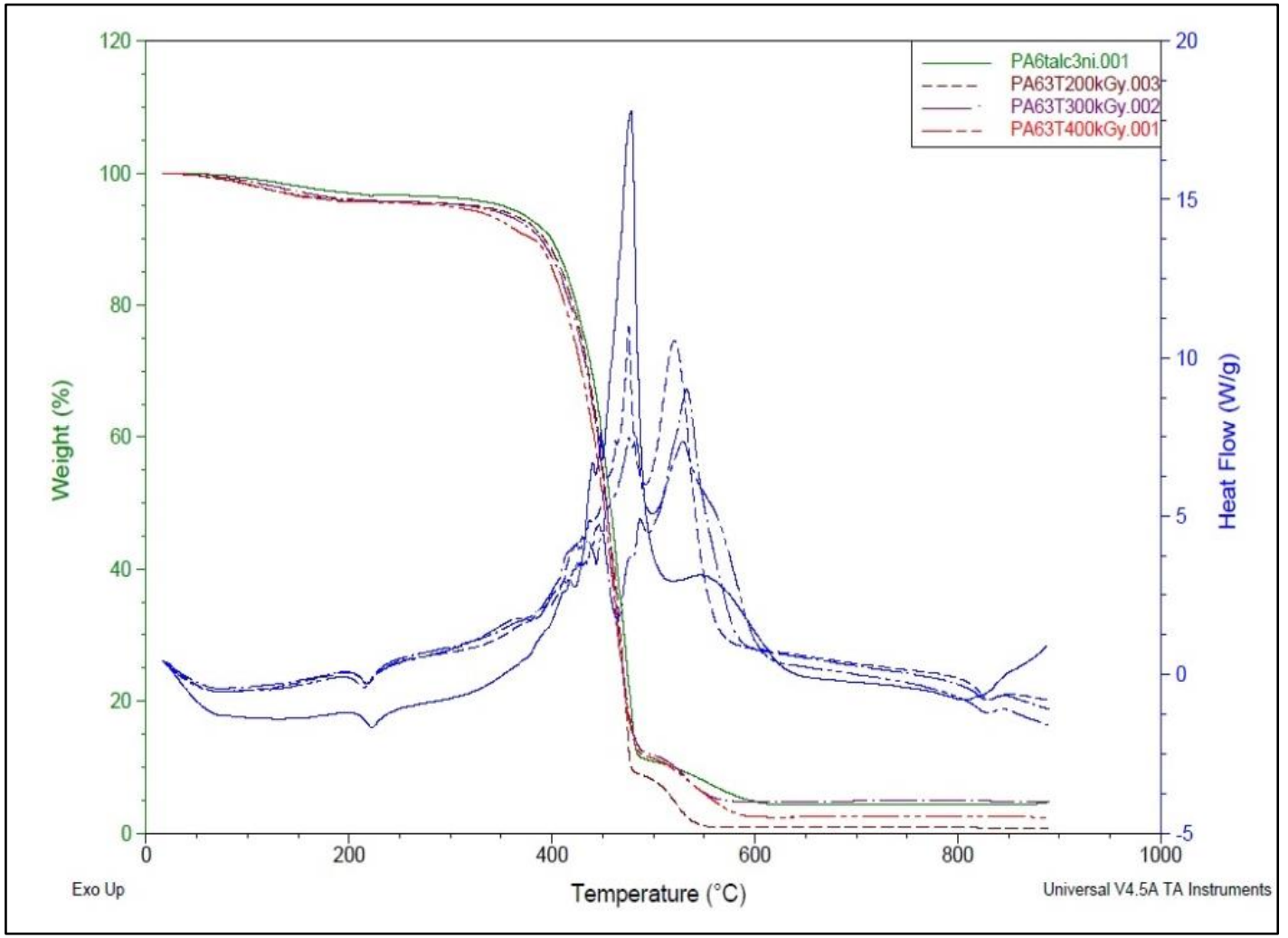

Fonte: autor da dissertação. 
Figura 24 - Curvas TG de compósitos irradiados e não irradiados de PA 6 com $6 \%$ de talco em atmosfera de ar com razão de aquecimento de $20 \stackrel{\circ}{\circ} / \mathrm{min}$

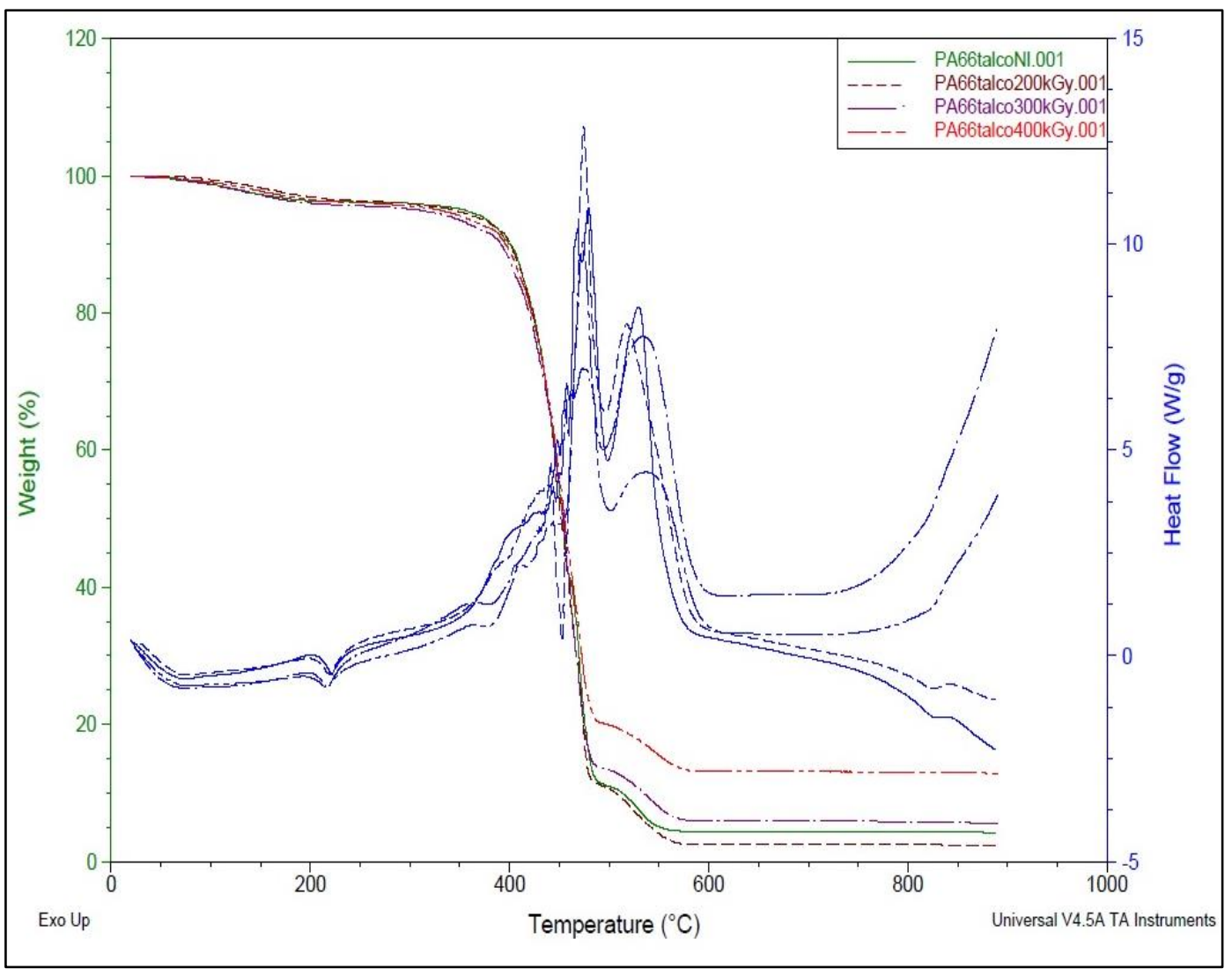

Fonte: autor da dissertação. 
Figura 25 - Curvas TG de compósitos irradiados e não irradiados de PA 6 com $10 \%$ de talco em atmosfera de ar com razão de aquecimento de $20{ }^{\circ} \mathrm{C} / \mathrm{min}$

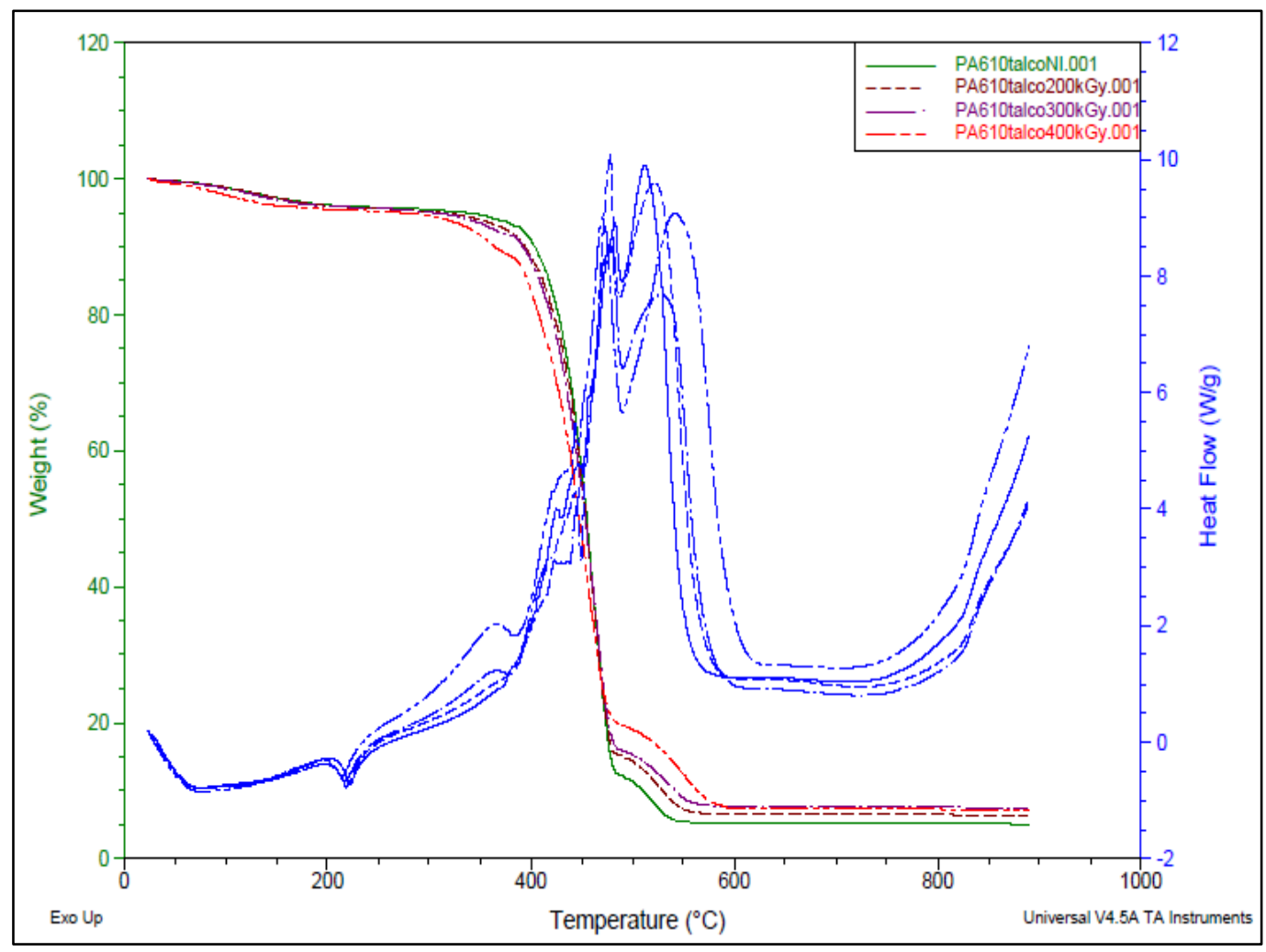

Fonte: autor da dissertação.

$\mathrm{Na}$ análise térmica simultânea TG-DTG, uma única amostra para cada formulação foi analisada e ambos os dados de TG foram obtidos simultaneamente à medida que a amostra foi aquecida, o que permitiu fazer uma associação mais adequada entre os resultados. Nas Figuras 22, 23, 24 e 25 estão mostradas as curvas TG dos compósitos não irradiados e irradiados de PA 6 com $1 \%, 3 \%, 6 \%$ e $10 \%$ talco em função da temperatura.

Por meio das curvas termogravimétricas foi possível perceber que as amostras se decompõem praticamente em um único estágio em torno de $300^{\circ} \mathrm{C}$ $T_{\text {onset }}$ e $500 \stackrel{\circ}{\circ} T_{\text {endset, }}$ permanecendo uma quantidade pequena de resíduo ao final da análise e assim como a PA 6 com $\mathrm{SiO}_{2}$ e a PA 6 com talco apresentaram os picos formados pelas curvas da DTG foi possível verificar a existência de uma série de eventos intermediários que não foi possível afirmar, se os mesmos foram causados pela carga ou por influência da radiação. Entretanto, segundo 
PETERSON (2000) o carbonato de magnésio presente no talco apresentou suas devidas decomposições secundárias nas faixas de temperatura entre $587^{\circ} \mathrm{C}$ até $720 \stackrel{\circ}{ } \mathrm{C}$. De acordo com a metodologia de PETERSON (2000) a presença de talco é revelada pela reação endotérmica em torno de $927^{\circ} \mathrm{C}$ e com perda de massa de $1,64 \%$ o que explica a presença do resíduo restante nas curvas termogravimétricas do compósitos de PA6 com talco.

\subsection{Calorimetria exploratória diferencial (DSC)}

Nas Figuras 26, 27 e 28 são mostradas as curvas de DSC dos compósitos irradiados e não irradiados de PA 6 com $1 \%$ de $\mathrm{SiO}_{2}$.

Figura 26 - Curvas de DSC de compósitos irradiados e não irradiado de PA 6 com $1 \%$ de $\mathrm{SiO}_{2}$

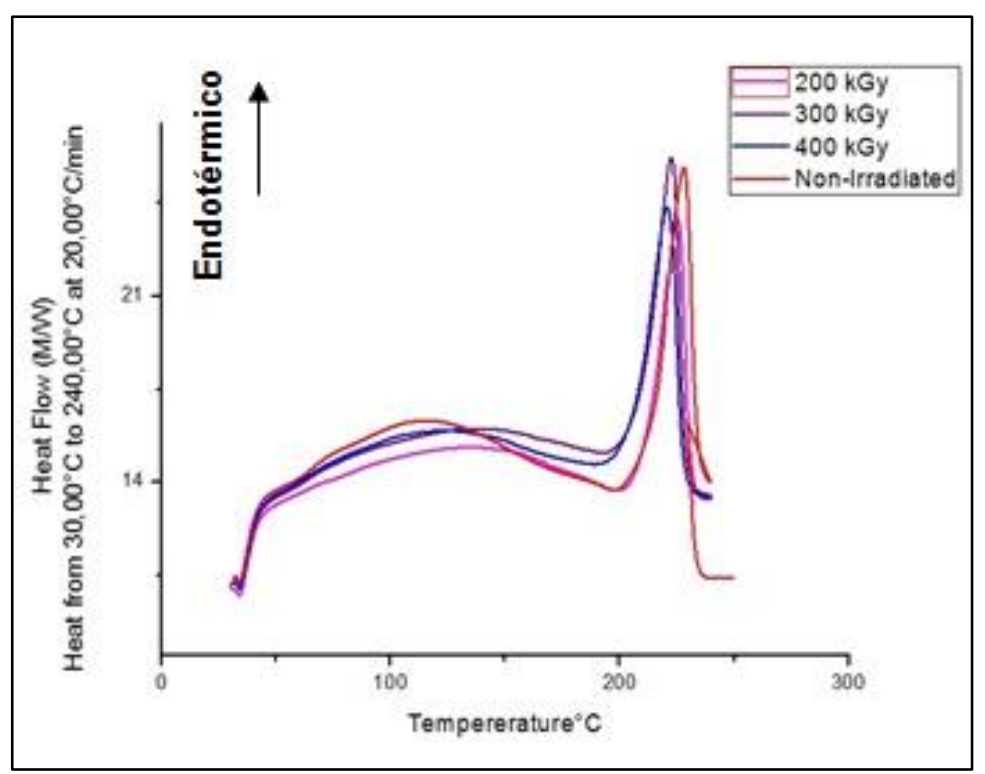

Fonte: autor da dissertação. 
Figura 27 - Curvas de DSC de compósitos irradiados e não irradiado de PA 6 com $1 \%$ de $\mathrm{SiO}_{2}$

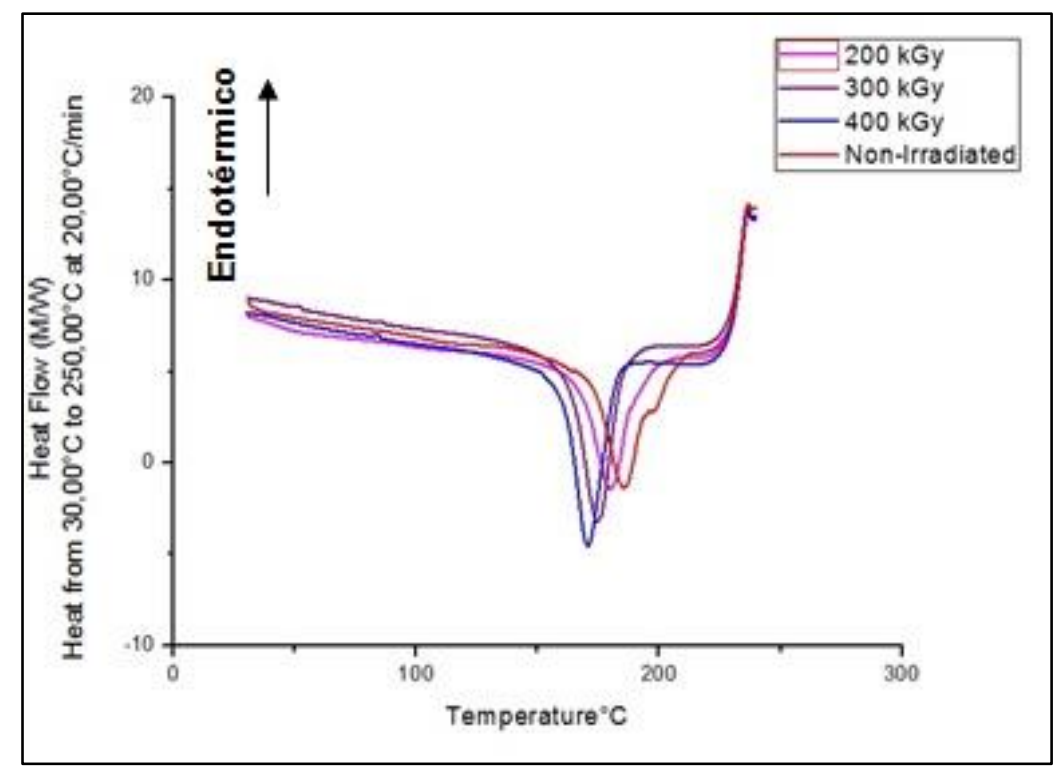

Fonte: autor da dissertação.

Figura 28 - Curvas de DSC de compósitos irradiados e não irradiado de PA 6 com $1 \%$ de $\mathrm{SiO}_{2}$

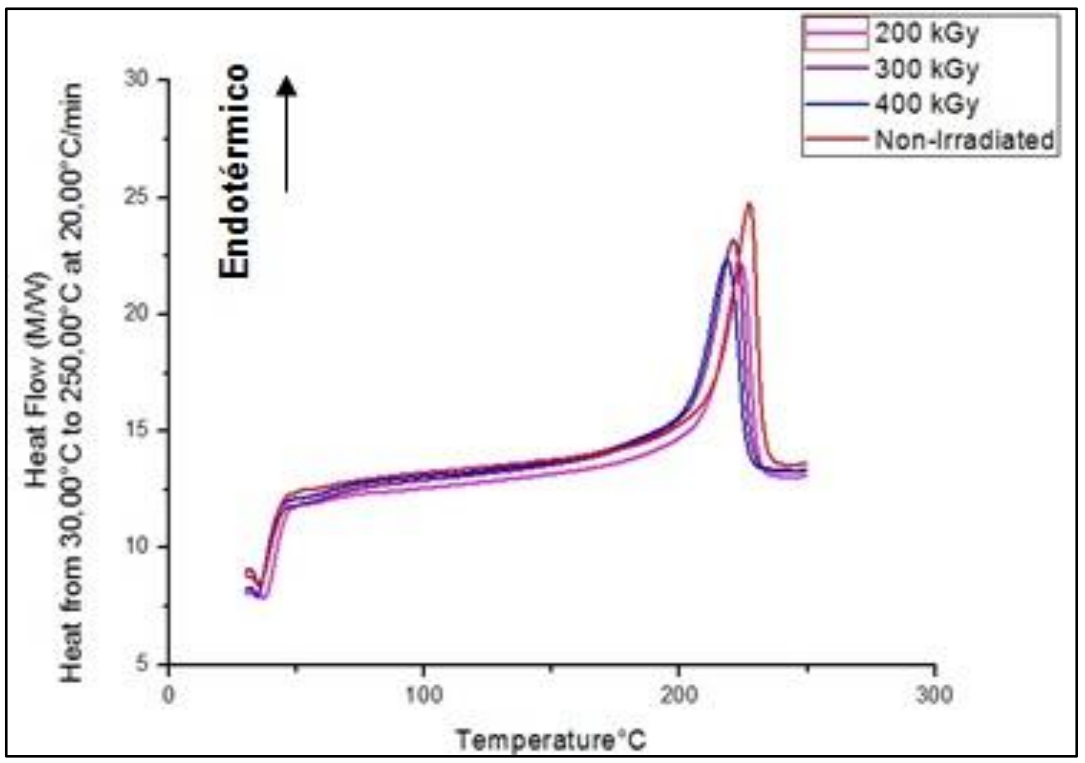

Fonte: autor da dissertação.

Nas Figuras 29, 30 e 31 são mostradas as curvas de DSC dos compósitos irradiados e não irradiados da PA 6 com $3 \%$ de $\mathrm{SiO}_{2}$. 
Figura 29 - Curvas de DSC de compósitos irradiados e não irradiado de PA 6 com $3 \%$ de $\mathrm{SiO}_{2}$

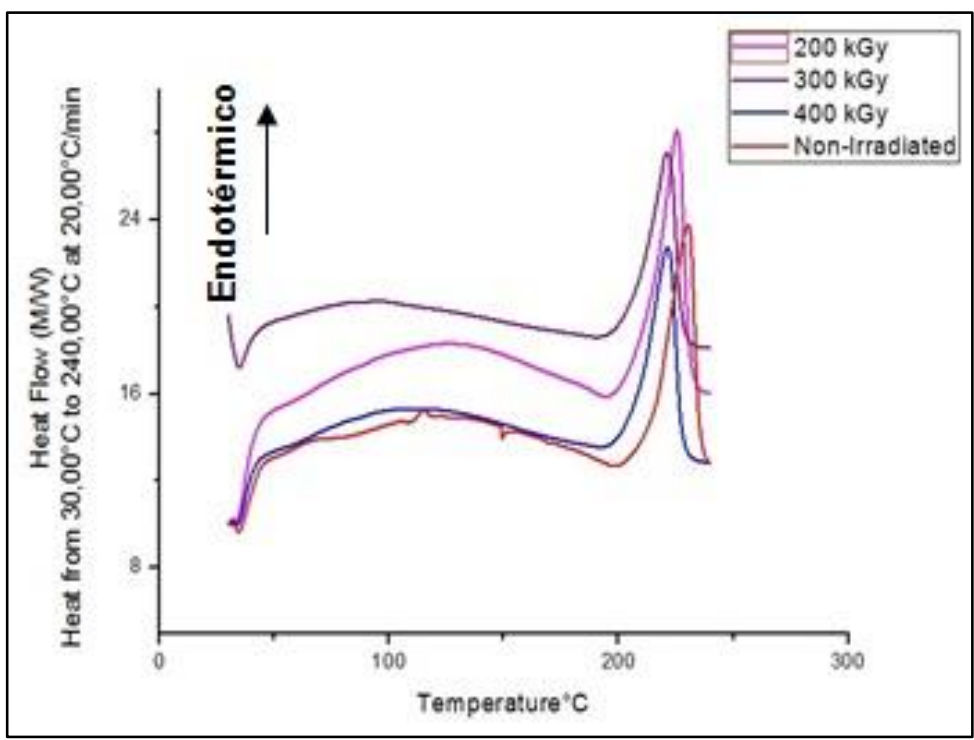

Fonte: autor da dissertação.

Figura 30 - Curvas de DSC de compósitos irradiados e não irradiado de PA 6 com $3 \%$ de $\mathrm{SiO}_{2}$

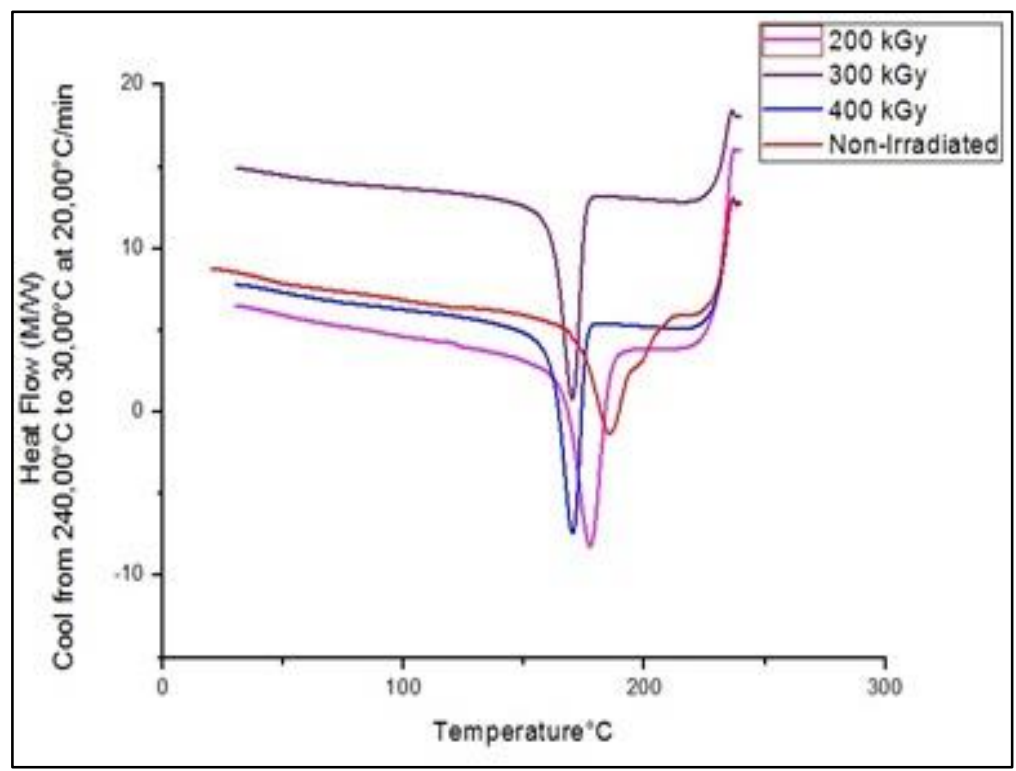

Fonte: autor da dissertação. 
Figura 31 - Curvas de DSC de compósitos irradiados e não irradiado de PA 6 com $3 \%$ de $\mathrm{SiO}_{2}$

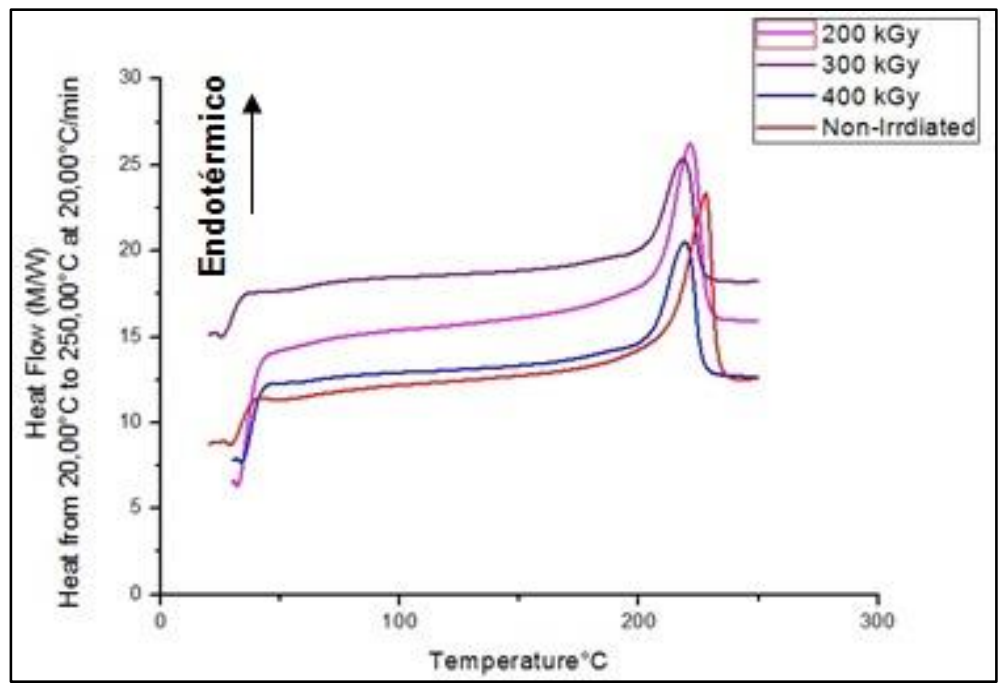

Fonte: autor da dissertação.

Nas Figuras 32, 33 e 34 são mostradas as curvas de DSC dos compósitos irradiados e não irradiados de $\mathrm{PA} 6 \operatorname{com} 6 \% \mathrm{SiO}_{2}$.

Figura 32 - Curvas de DSC de compósitos irradiados e não irradiado de PA 6 com $6 \%$ de $\mathrm{SiO}_{2}$

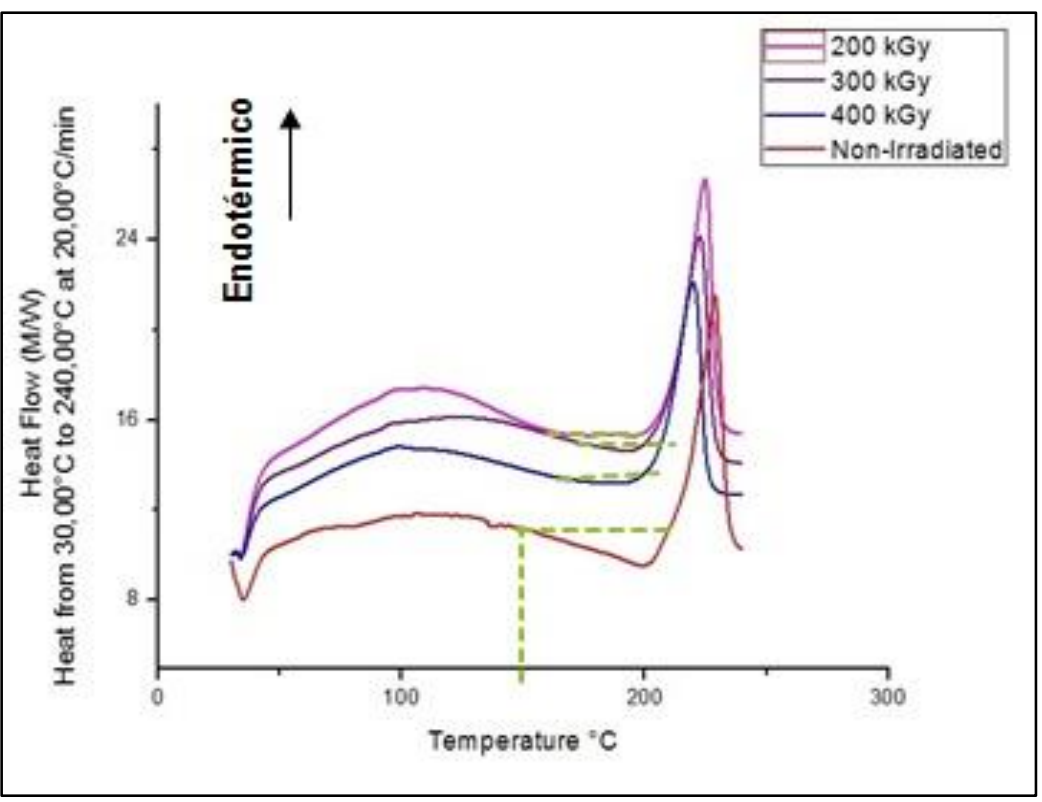

Fonte: autor da dissertação. 
Figura 33 - Curvas de DSC de compósitos irradiados e não irradiado de PA $6 \mathrm{com} 6 \%$ de $\mathrm{SiO}_{2}$

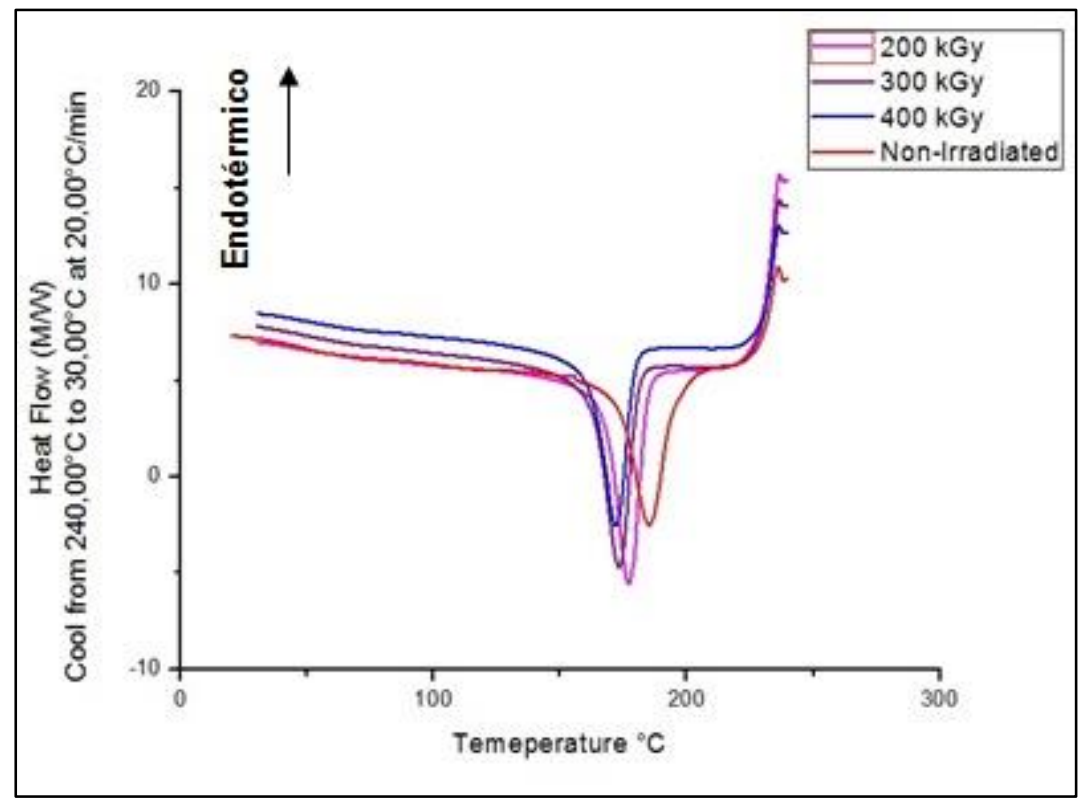

Fonte: autor da dissertação.

Figura 34 - Curvas de DSC de compósitos irradiados e não irradiado de PA 6 com $6 \%$ de $\mathrm{SiO}_{2}$

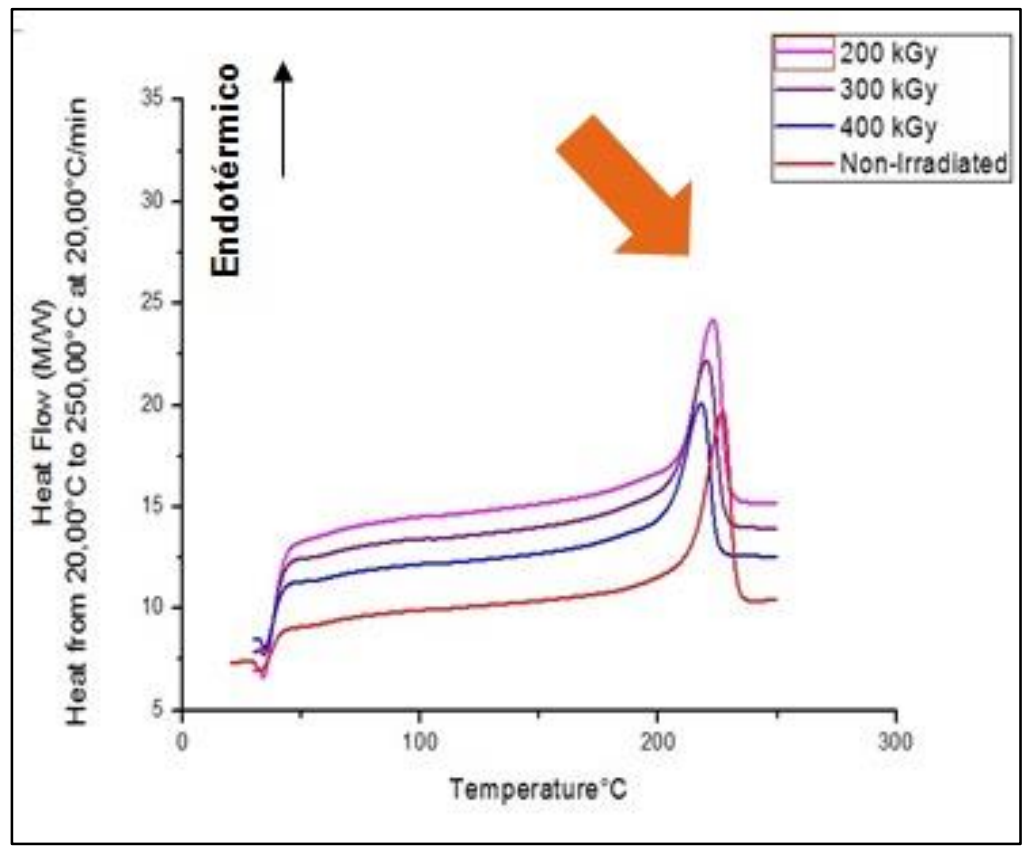

Fonte: autor da dissertação. 
Nas Figuras 26, 29 e 32 são mostradas as curvas das temperaturas de fusão no primeiro aquecimento para os compósitos de PA 6 irradiados e não irradiados com $1 \%$, $3 \%$ e $6 \%$ de $\mathrm{SiO}_{2}$, respectivamente. Também foi possível observar que na faixa (área) de temperatura entre 150 e $215{ }^{\circ} \mathrm{C}$ encontra-se a temperatura de cristalização pré-fusão.

Conforme aumentou-se a dose de radiação esta área diminuiu, sendo mais acentuada na composição de PA 6 com $6 \%$ de $\mathrm{SiO}_{2}$. Nas Figuras 27, 28 e 33 são mostradas as curvas do segundo aquecimento com as temperaturas de cristalização dos compósitos irradiados e não irradiados de PA 6 com $1 \%$, 3 \% e $6 \%$ de $\mathrm{SiO}_{2}$, respectivamente.

Finalmente, nas Figuras 28, 31 e 34 são mostradas as curvas do terceiro aquecimento para os compósitos PA 6 irradiados e não irradiados com $1 \%, 3 \% \mathrm{e}$ $6 \%$ de $\mathrm{SiO}_{2}$, respectivamente. Foi possível observar nesta etapa que as curvas irradiadas não apresentaram perda da área na faixa da temperatura de cristalização pré-fusão e os picos de fusão foram sobrepostos, sendo possível identificar este comportamento com mais clareza na Figura 34.

\subsection{Espectroscopia de absorção no infravermelho por transformada de Fourier (FTIR)}

Nas Figuras 35, 36 e 37 são mostradas as bandas de absorção dos compósitos não irradiados e irradiados de PA 6 com $1 \%$, 3 \% e $6 \%$ de $\mathrm{SiO}_{2}$. 
Figura 35 - Espectros de FTIR de compósitos irradiados e não irradiado de PA 6 com $1 \%$ de $\mathrm{SiO}_{2}$

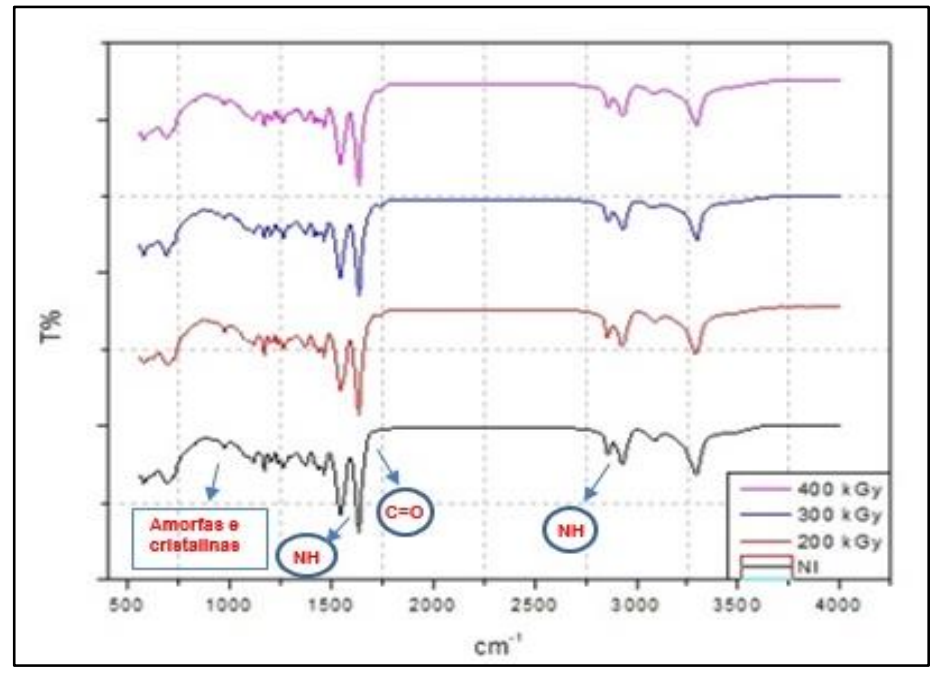

Fonte: autor da dissertação.

Figura 36 - Espectros de FTIR de compósitos irradiados e não irradiado de PA 6 com $3 \%$ de $\mathrm{SiO}_{2}$

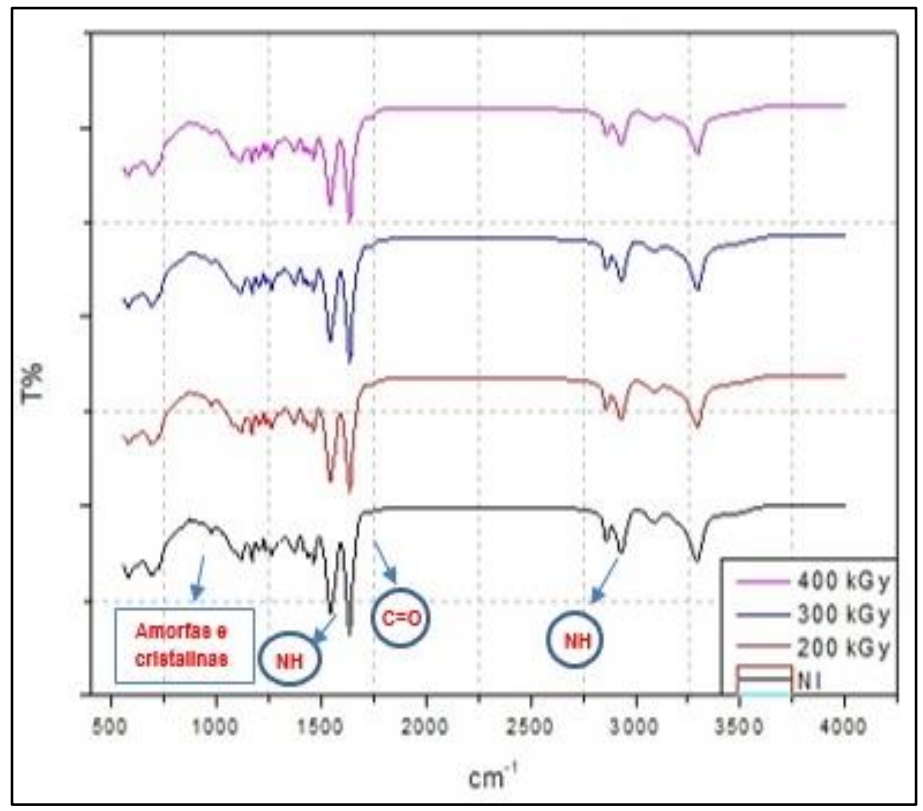

Fonte: autor da dissertação. 
Figura 37 - Espectros de FTIR de compósitos irradiados e não irradiado de PA 6 com $6 \%$ de $\mathrm{SiO}_{2}$

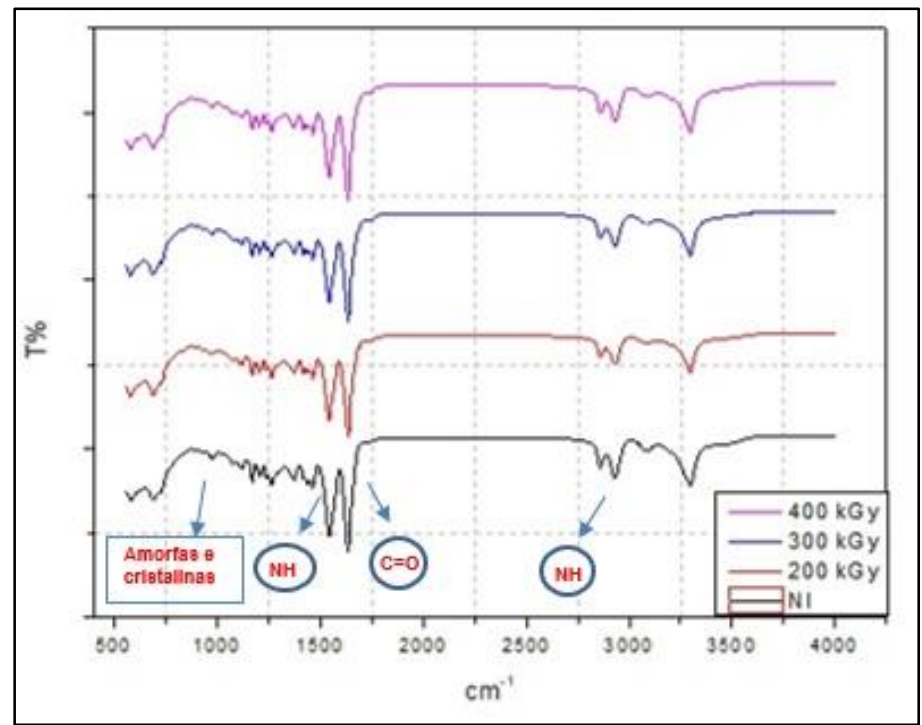

Fonte: autor da dissertação.

Nas Figuras 38, 39, 40 e 41 são mostradas as bandas dos compósitos não irradiados e irradiados de PA 6 com $1 \%, 3 \%, 6 \%$ e $10 \%$ de talco.

Figura 38 - Espectros de FTIR de compósitos irradiados e não irradiado de PA 6 com $1 \%$ de talco

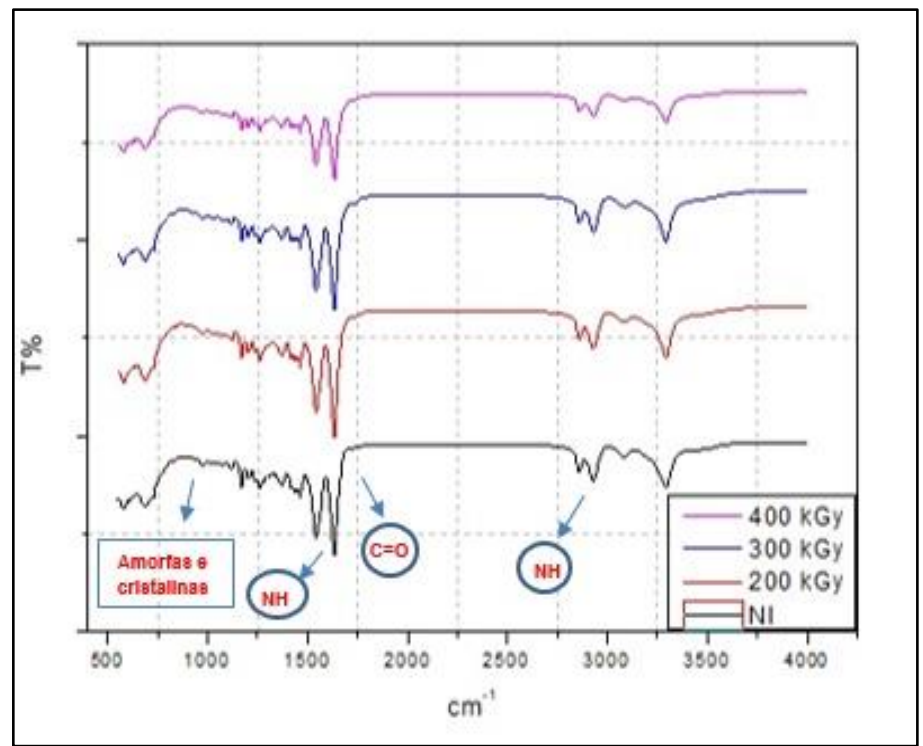

Fonte: autor da dissertação. 
Figura 39 - Espectros de FTIR de compósitos irradiados e não irradiado de PA 6 com $3 \%$ de talco

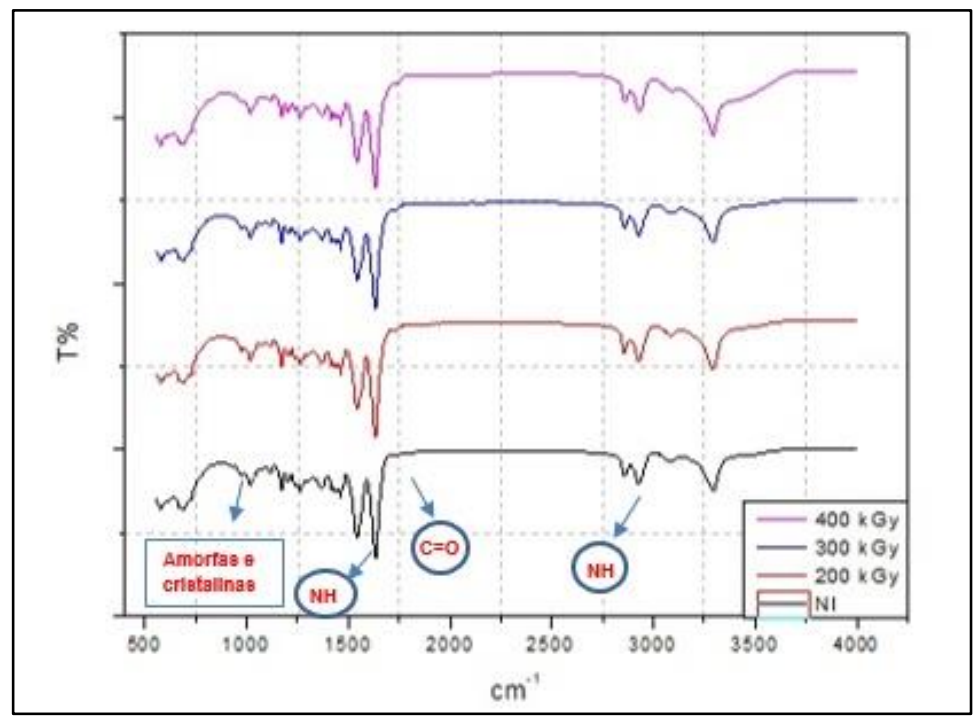

Fonte: autor da dissertação.

Figura 40 - Espectros de FTIR de compósitos irradiados e não irradiado de PA 6 com $6 \%$ de talco

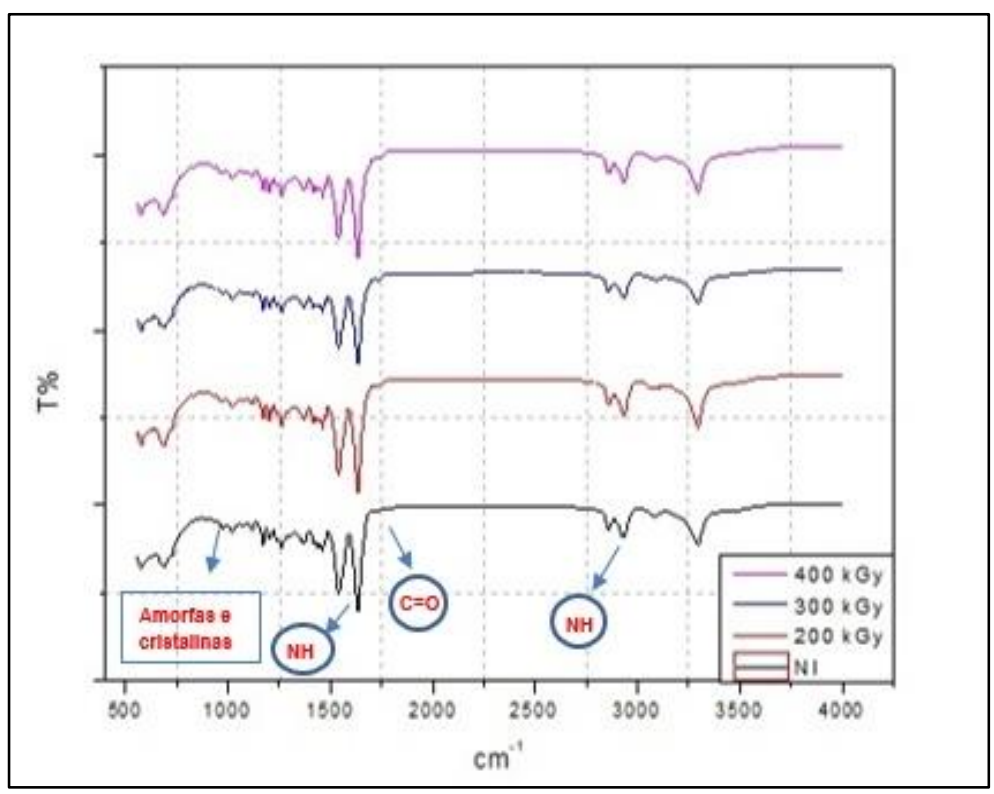

Fonte: autor da dissertação. 
Figura 41 - Espectros de FTIR de compósitos irradiados e não irradiado de PA 6 com $10 \%$ de talco

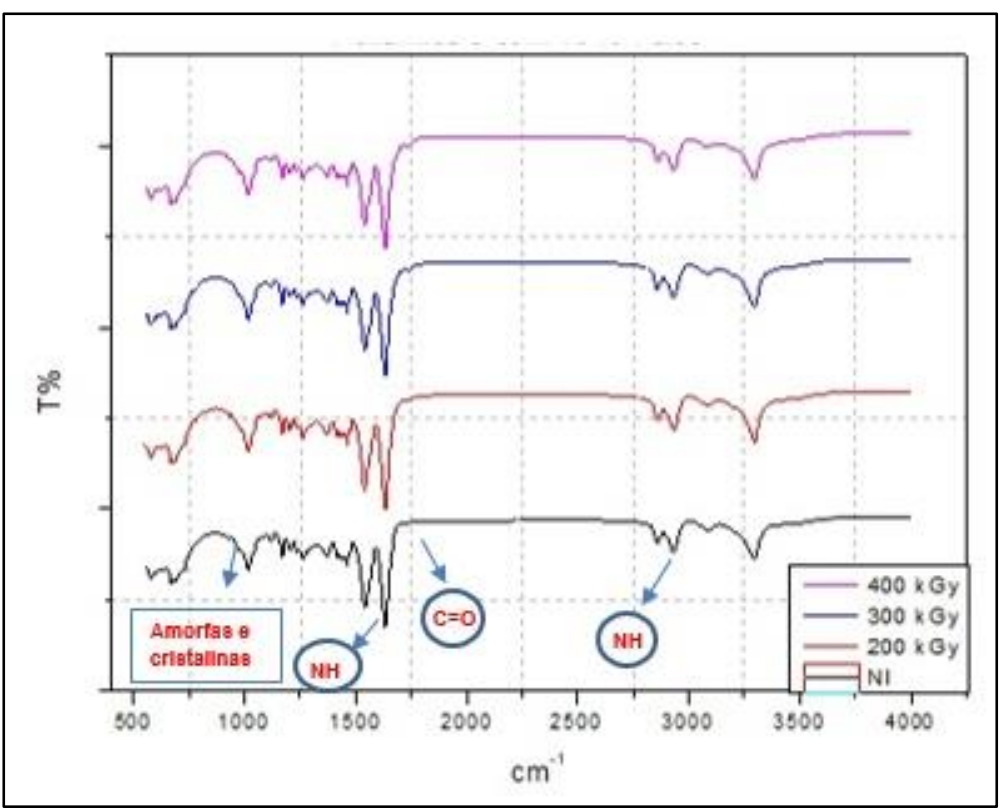

Fonte: autor da dissertação.

Este ensaio forneceu informações detalhadas sobre as estruturas associadas ao grupo amida. Foi possível observar que não houve mudanças significativas apresentadas nos compósitos com e sem irradiação que está de acordo com a literatura no trabalho realizado por EVORA, 2002.

De acordo com ERIKSON et al. (1997) as poliamidas possuem características diferentes e foi observado que PA 6 na região de $700-200 \mathrm{~cm}^{-1}$ é uma região de diferentes tipos de poliamidas, o mesmo comportamento foi observado neste estudo nas Figuras 35 e 41 que as bandas de absorção são correspondentes aos grupos $\mathrm{NH}$ para as amostras de poliamida com $\mathrm{SiO}_{2}$ e talco.

Todas as curvas dos compósitos irradiados e não irradiados de PA 6 com $3 \%$ e $6 \%$ de $\mathrm{SiO}_{2}$ (Figuras 36 e 37 ) e $3 \%, 6 \%$ e $10 \%$ (Figuras 38, 39, 40 e 41 ) de talco, respectivamente, mostraram absorções nas regiões de 3200 a $3300 \mathrm{~cm}$. ${ }^{1}$ correspondente a um grupo funcional $\mathrm{NH}, 1630$ a $1650 \mathrm{~cm}^{-1}$ (grupo $\mathrm{C}=\mathrm{O}$ ) e $1550 \mathrm{~cm}^{-1}$ (grupo NH).

Os compósitos de PA $6 \mathrm{com} \mathrm{SiO}_{2} \mathrm{com}$ as bandas entre $1250 \mathrm{~cm}^{-1}$ e 980 $\mathrm{cm}^{-1}$, são classificadas como picos de absorções de regiões cristalinas e amorfa. No entanto, pode-se dizer que devido ao processo de irradiação existe a 
possibilidade de terem cadeias moleculares reticuladas e/ou degradadas de acordo com os resultados de outras técnicas avaliadas neste trabalho, porém não foi possível detectar esse resultado somente com a técnica de FTIR. Assim sendo, foi possível afirmar que os grupos funcionais das poliamidas não foram alterados independentes da dose de radiação aplicada.

\subsection{Difração de raios $X$}

Nas Figuras 42, 43 e 44 são mostrados os espectros de difração de raios $X$ de compósitos irradiados e não irradiados de PA 6 com $1 \%$, $3 \%$ e $6 \%$ de $\mathrm{SiO}_{2}$, possibilitando realizar a comparação entre eles.

Figura 42 - Espectros DRX (intensidade) de compósitos não irradiado e irradiados de PA 6 com $1 \%$ de $\mathrm{SiO}_{2}$

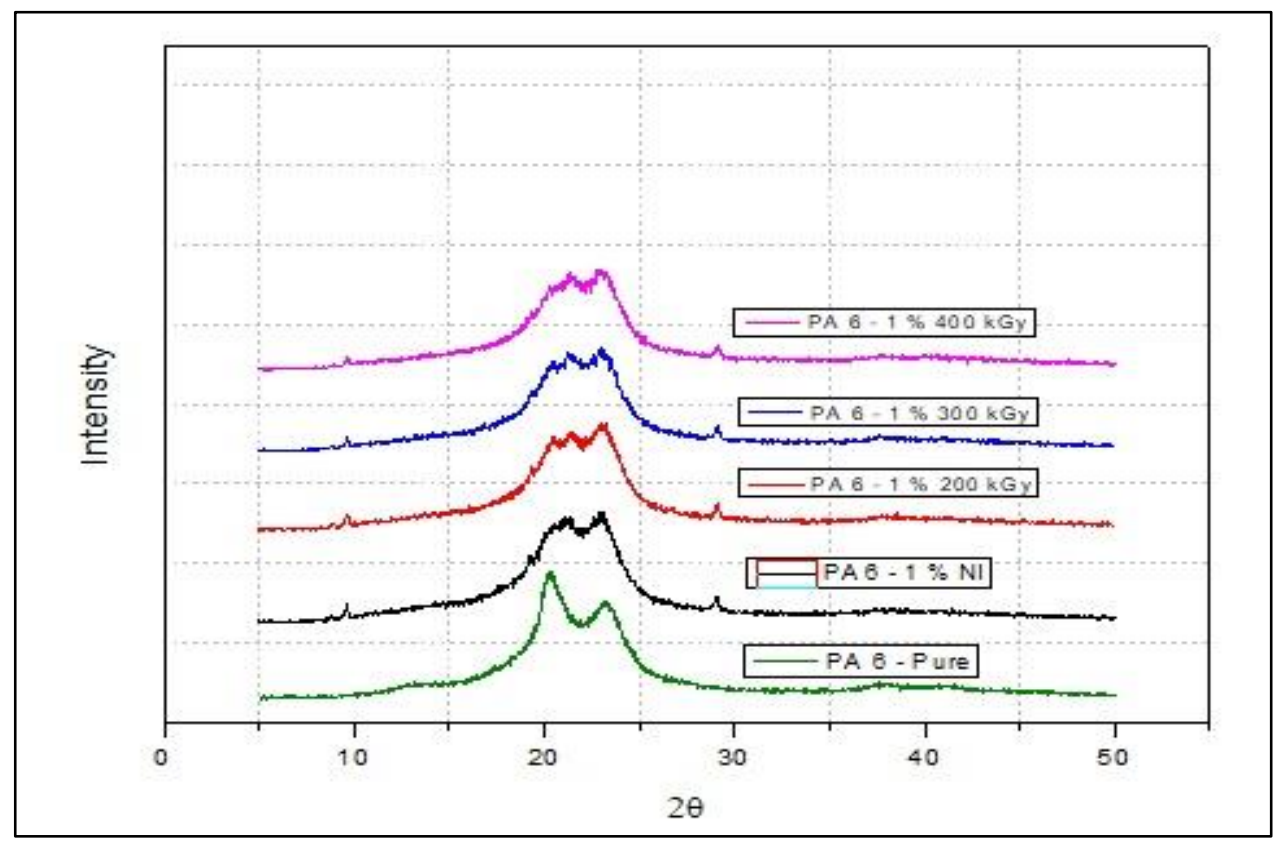

Fonte: autor da dissertação. 
Figura 43 - Espectros DRX (intensidade) de compósitos não irradiado e irradiados de $\mathrm{PA} 6$ com $3 \%$ de $\mathrm{SiO}_{2}$

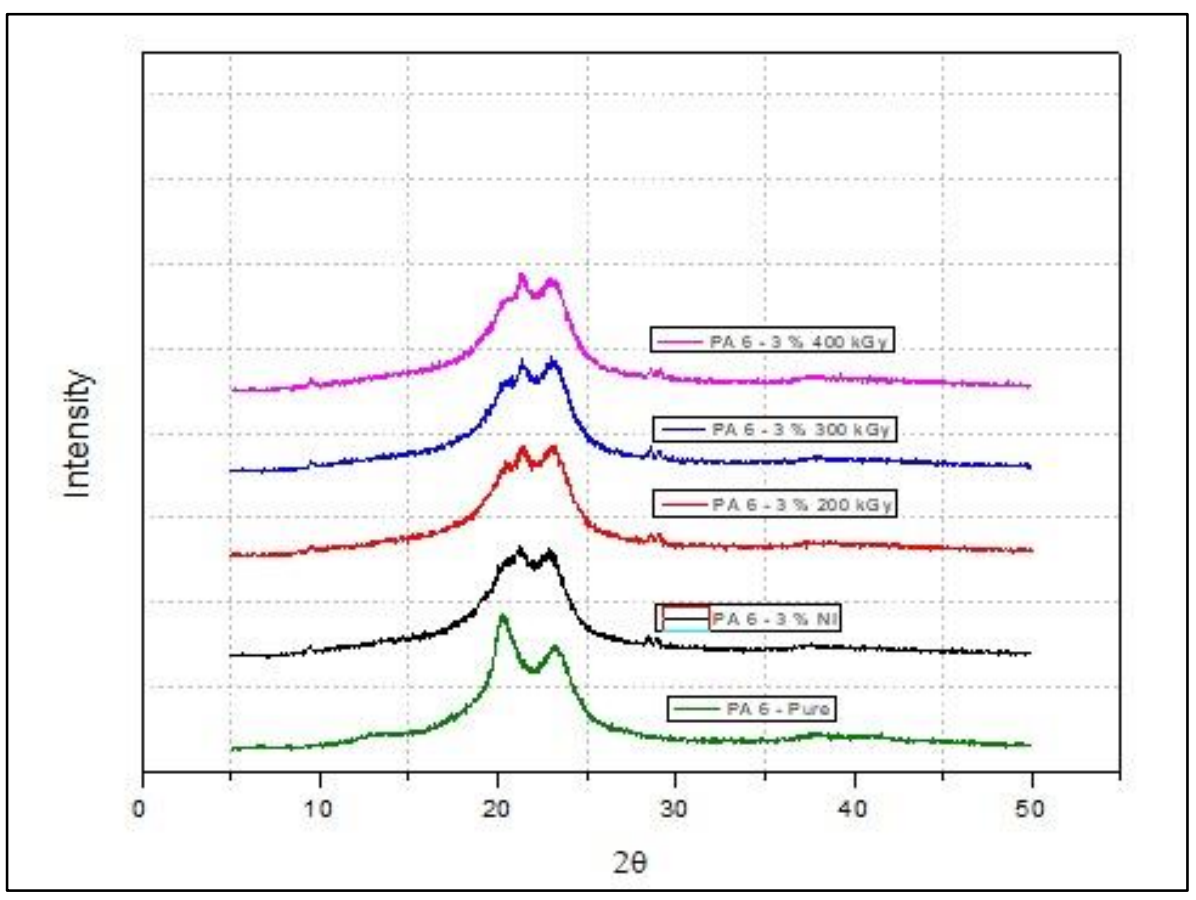

Fonte: autor da dissertação. 
Figura 44 - Espectros DRX (intensidade) de compósitos não irradiado e irradiados de PA 6 com $6 \%$ de $\mathrm{SiO}_{2}$

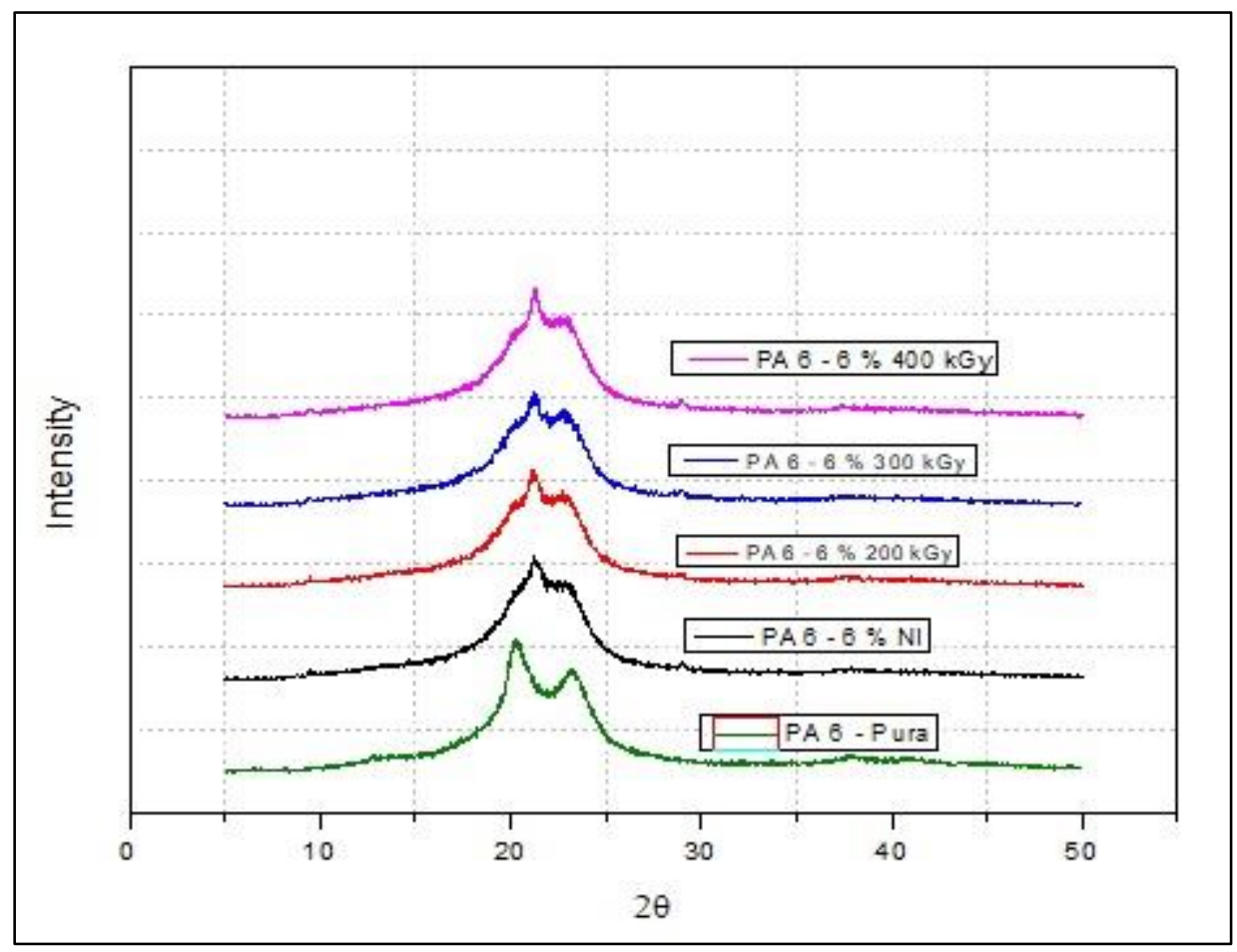

Fonte: autor da dissertação.

As curvas de difração de raios X da PA 6 pura apresentaram o pico $2 \theta$ entre $21^{\circ}$ e $24^{\circ}$ que repesenta o pico da PA 6 , o mesmo comportamento ocorreu também para todas as formulações quando se adicionou $\mathrm{SiO}_{2}$. Além disso, foi possível observar novos picos a $10^{\circ}$ e $22^{\circ}$, os quais aumentaram de acordo com a quantidade de $\mathrm{SiO}_{2}$ adicionada.

Desta forma, o processo de irradiação para todas as amostras demonstrou intensidade para todas as curvas e foi interessante enfatizar que, a uma dose de $400 \mathrm{kGy}$ especialmente para PA $6 \mathrm{~cm} 6 \%$ de $\mathrm{SiO}_{2}$ mostrou ter o pico mais alto e mais cristalino (Figura 44).

Nas Figuras 45, 46, 47 e 48 são mostrados os espectros de difração de raios $\mathrm{X}$ dos compósitos irradiadas e não irradiadas de PA 6 com $1 \%$, $3 \%, 6$ e $10 \%$ de talco, possibilitando realizar a comparação entre eles. 
Figura 45 - Espectros DRX (intensidade) de compósitos não irradiado e irradiados de PA 6 com $1 \%$ de talco

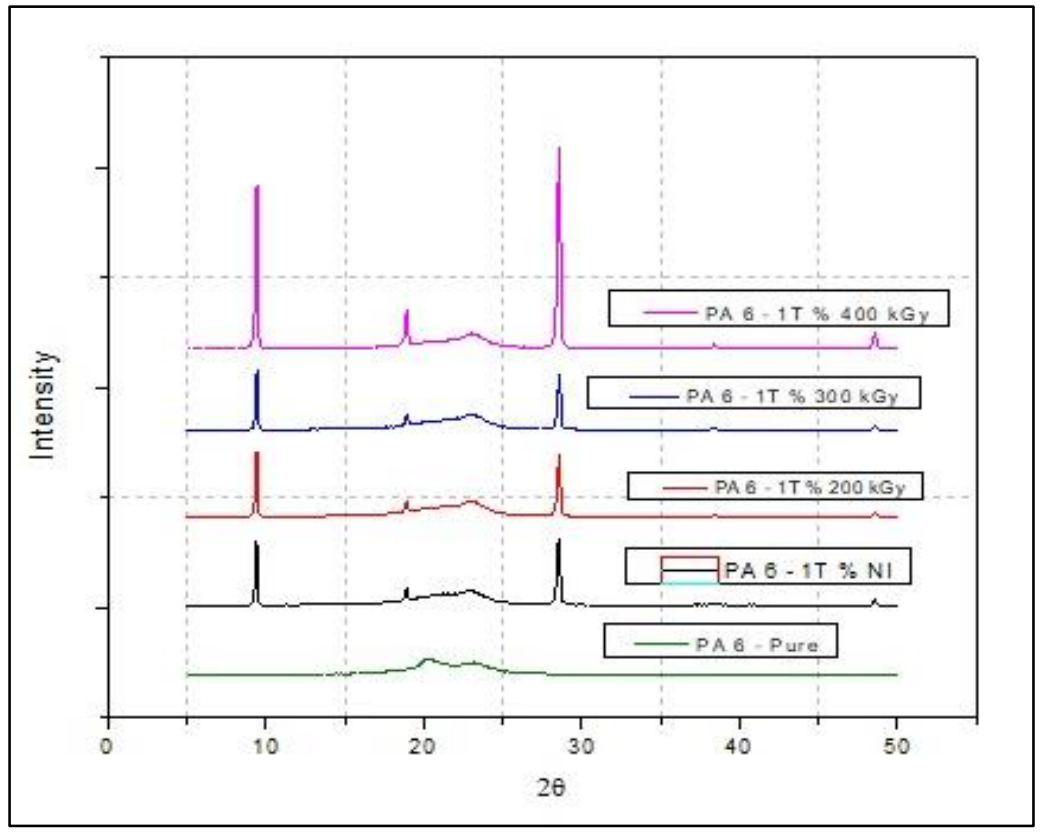

Fonte: autor da dissertação.

Figura 46 - Espectros DRX (intensidade) de compósitos não irradiado e irradiados de PA 6 com $3 \%$ de talco

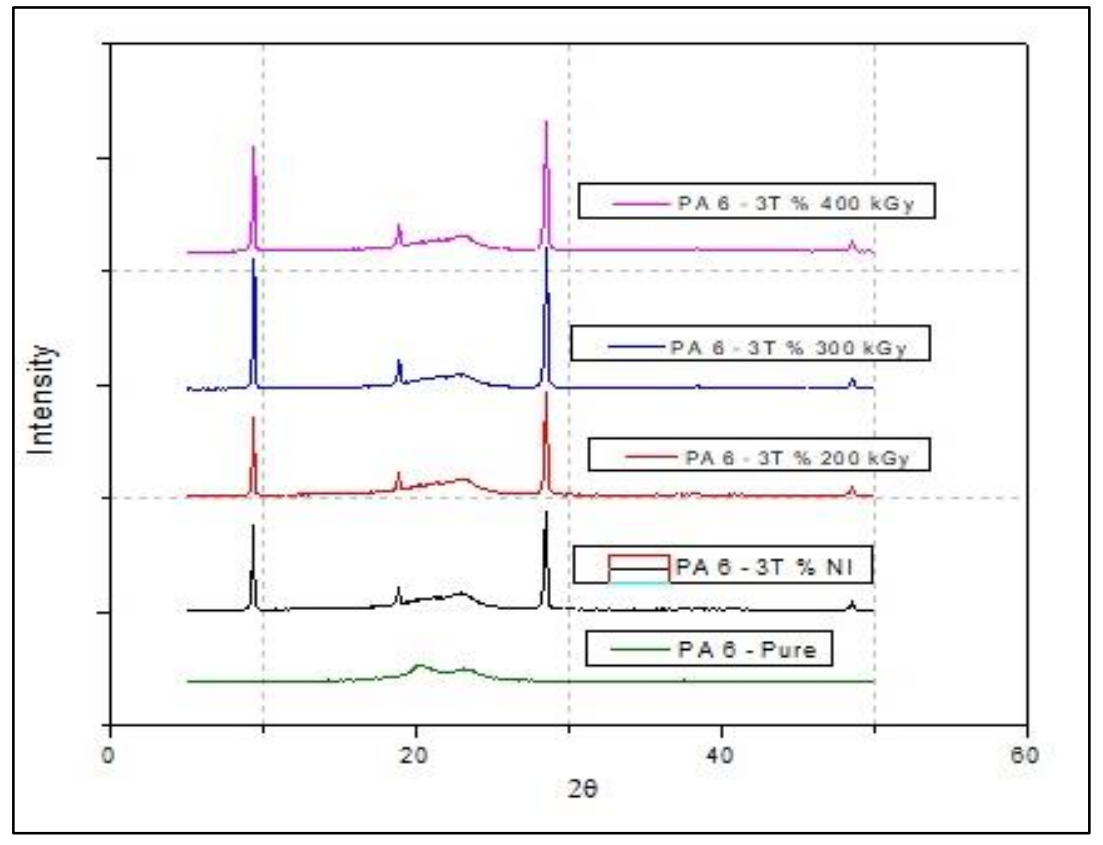

Fonte: autor da dissertação 
Figura 47 - Espectros DRX (intensidade) de compósitos não irradiado e irradiados de PA 6 com $6 \%$ de talco

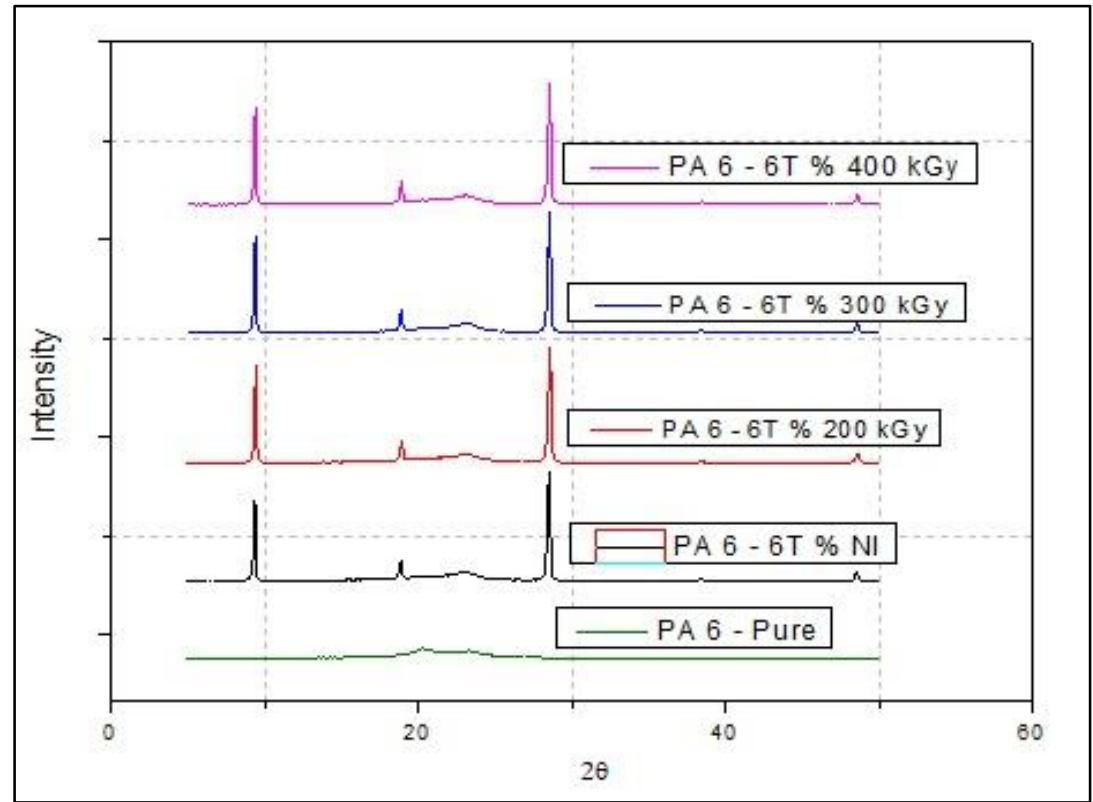

Fonte: autor da dissertação.

Figura 48 - Espectros DRX (intensidade) de compósitos não irradiado e irradiados de PA 6 com $10 \%$ de talco

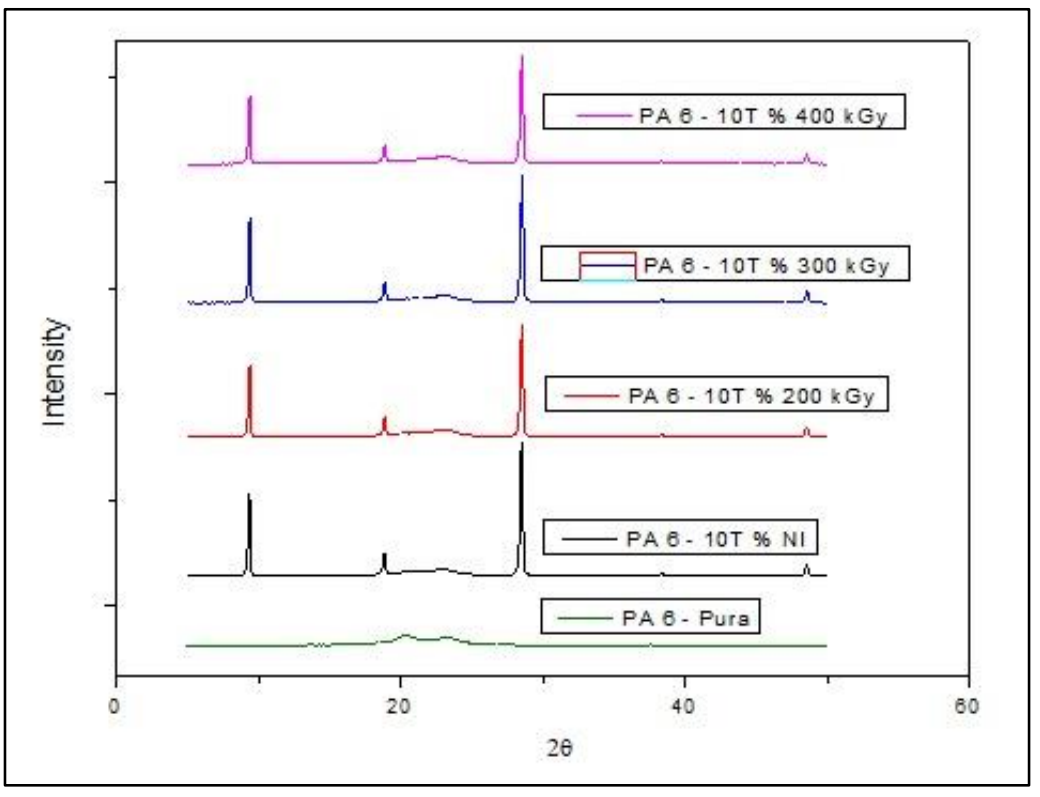

Fonte: autor da dissertação. 
As curvas de difração de raios X da PA 6 pura apresentaram o pico $2 \Theta$ entre $21^{\circ}$ e $24^{\circ}$ que representa o pico da PA 6, o mesmo comportamento ocorreu também para todas as formulações quando se adicionou talco.

Segundo VIEIRA, 2008 o talco apresenta de difração predominantes de feldspatos, tanto do tipo sódico quanto albítico, e potássico, como a microclina. São observados ainda picos de difração de pequena intensidade da anortita, feldspato cálcico, biotita e pirita e também é possível notar picos característicos

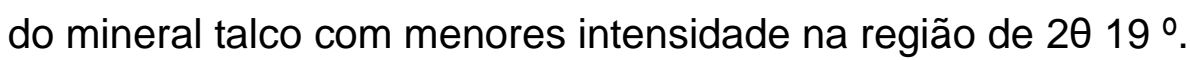

De acordo com a literatura foi possível observar novos picos $2 \theta$ a $10^{\circ}, 19^{\circ}$ e $29^{\circ}$, os quais aumentaram de acordo com a quantidade de talco adicionada e de dose de radiação aplicada. Assim, o processo de irradiação para todas as amostras mostrou picos de intensidade maiores para todas as curvas sendo interessante enfatizar que, a uma dose de 400 kGy especialmente para PA 6 com $6 \%$ e $10 \%$ de talco foi possível observar picos mais alto e mais cristalino (Figuras 47 e 48).

\subsection{Microscopia eletrônica de varredura (MEV)}

5.6.1 Microscopia eletrônica de varredura das cargas e da PA 6

$\mathrm{Na}$ Figura 49 ( $\mathrm{A}$ e B) são mostradas as micrografias do $\mathrm{SiO}_{2}$ puro e, talco puro.

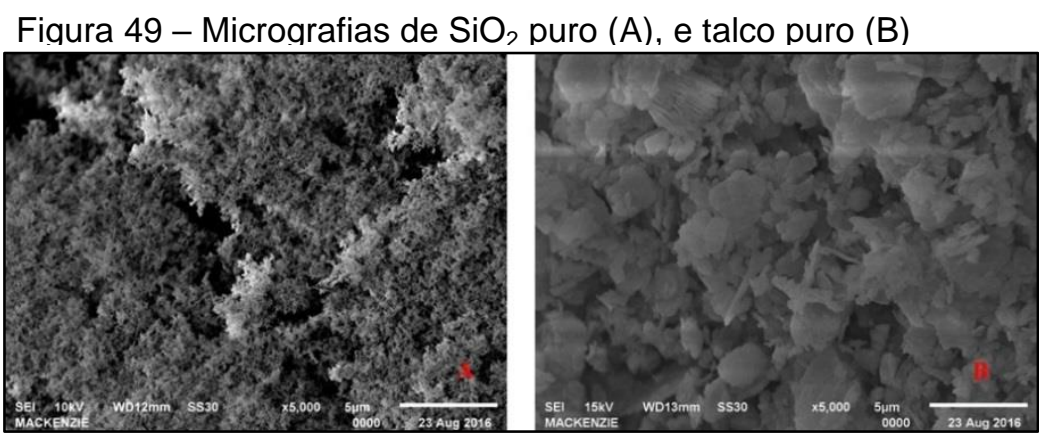

Fonte: autor da dissertação. 
$\mathrm{Na}$ análise de microscopia eletrônica de varredura (MEV) foi possível comprovar de acordo com a Figura 49 (A) que o $\mathrm{SiO}_{2}$ possui uma estrutura amorfa e transparente estando de acordo com a literatura. Por outro lado, conforme a Figura 49 (B) foi possível observar que diferente do $\mathrm{SiO}_{2}$ que possui uma estrutura amorfa, o talco apresentou uma estrutura lamelar em sua composição.

\subsubsection{Microscopia eletrônica de varredura das amostras}

Na Figura 50 são mostradas as micrografias de MEV dos compósitos não irradiados e irradiados com doses de $400 \mathrm{kGy}$ da PA 6 com $6 \%$ de $\mathrm{SiO}_{2}$ e PA 6 com $6 \%$ de talco.

Figura 50 - Micrografias dos compósitos irradiados e não irradiados de PA 6 com $6 \%$ de $\mathrm{SiO}_{2}$ e com $10 \%$ de talco

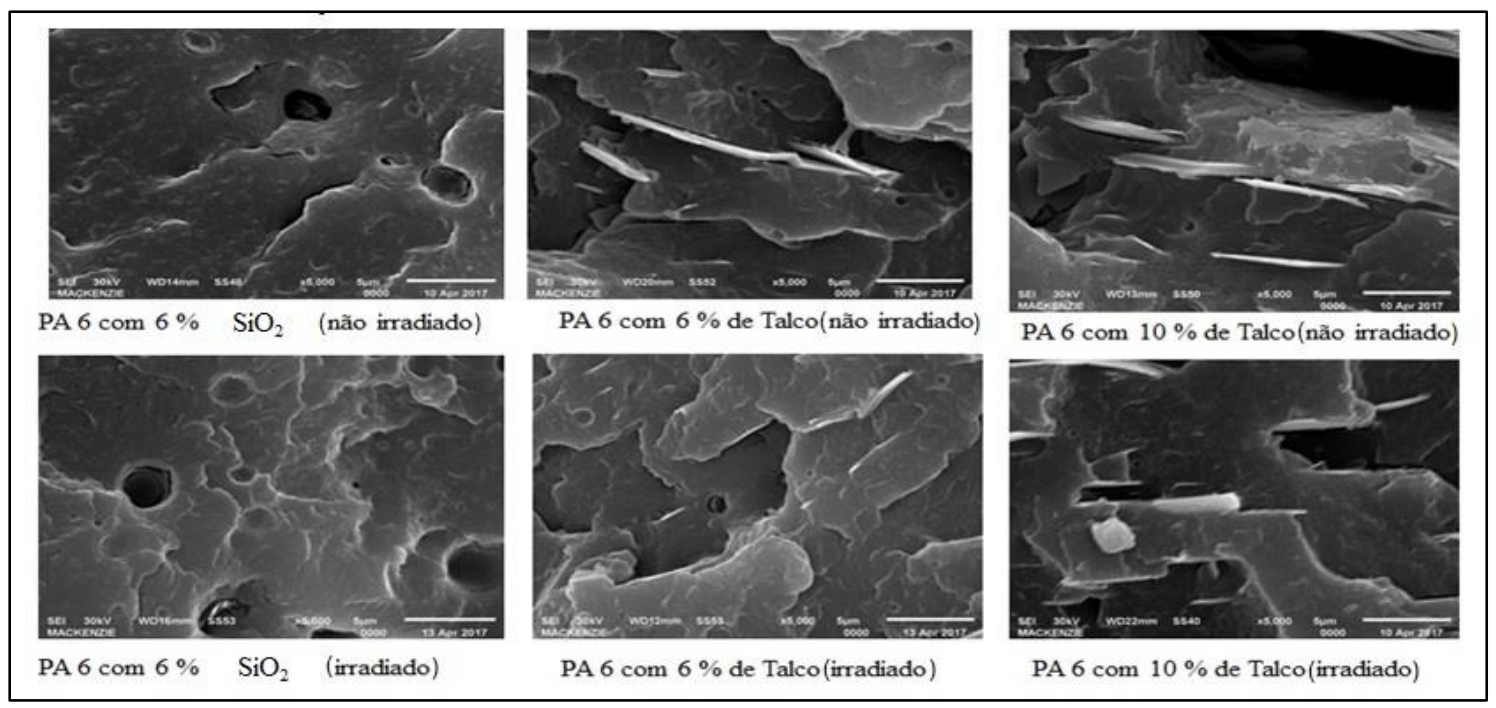

Fonte: autor da dissertação. 
$\mathrm{Na}$ Figura 51 são mostrados os gráficos de espectroscopia por energia dispersiva dos compósitos não irradiados e irradiados de PA 6 com $6 \%$ de $\mathrm{SiO}_{2} \mathrm{e}$ PA 6 com $6 \%$ de talco.

Figura 51 - Gráficos de EDS do compósito não irradiado de PA 6 com $6 \%$ de SiO2 e PA 6 com 6 $\%$ talco e irradiado

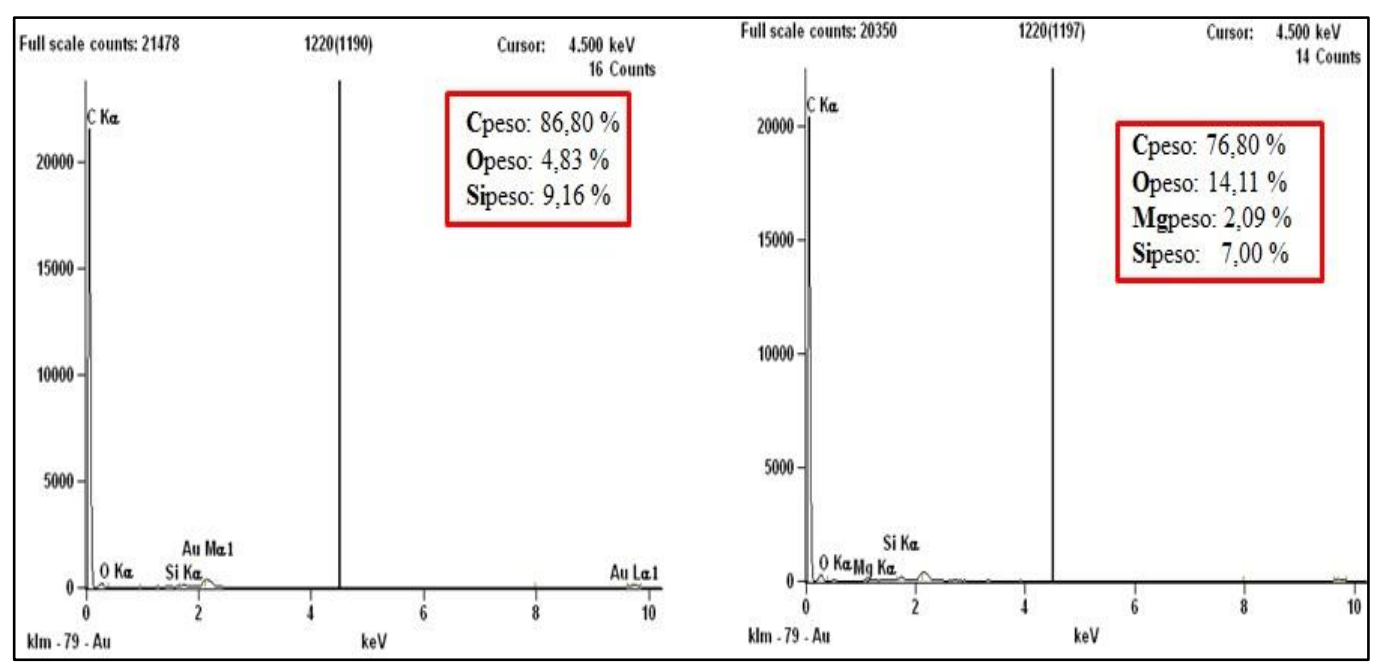

Fonte: autor da dissertação.

Para as amostras de PA 6 processadas com $6 \%$ de $\mathrm{SiO}_{2}$ e as amostras processadas com $6 \%$ e $10 \%$ de talco (Figura 50 ) observou-se que os materiais apresentaram comportamento homogêneo, de forma que, ambas as cargas estavam totalmente aglomeradas dentro da matriz polimérica, sendo que neste caso, não foram encontradas a presença de trincas nas micrografias.

Deste modo, a radiação ionizante não interferiu na estrutura molecular para o segundo lote. Também foi possível comprovar por meio do gráfico EDS (Figura 51) que os compósitos de PA 6 com $6 \%$ de $\mathrm{SiO}_{2}$ e os compósitos de PA 6 com $6 \%$ de talco não apresentaram quaisquer contaminações em sua estrutura molecular. 


\subsection{Análise de densidade}

Na Figura 52 são mostrados os resultados das análises de densidade de PA 6 com $1 \%, 3 \%, 6 \%$ de $\mathrm{SiO}_{2}$ e PA 6 com $10 \%$ de talco.

Figura 52 - Quadro com as análises de densidade

\begin{tabular}{|c|c|c|c|c|c|c|c|}
\hline \multicolumn{4}{|l|}{ DATA: $31 / 03 / 2016$} & \multicolumn{4}{|l|}{ DATA: $31 / 03 / 2016$} \\
\hline \multirow{2}{*}{\multicolumn{4}{|c|}{$\begin{array}{l}\text { DENSIDADE } \\
\text { Material: PA } 6 \text { com } 1 \% \text { Aerosil }\end{array}$}} & \multicolumn{4}{|c|}{ DENSIDADE } \\
\hline & & & & \multicolumn{4}{|c|}{ Material: PA 6 com $3 \%$ Aerosil } \\
\hline Amostra & Peso 1 & Peso 2 & Densidade & Amostra & Peso 1 & \begin{tabular}{l|l} 
Peso 2 \\
\end{tabular} & Densidade \\
\hline $\mathrm{CP} 1$ & 1,3774 & 0,3177 & 1,15032462 & $\mathrm{CP} 1$ & 1,3639 & 0,2912 & 1,12524611 \\
\hline CP 2 & 1,3366 & 0,2950 & 1,13564804 & $\mathrm{CP} 2$ & 1,3848 & 0,2948 & 1,12435596 \\
\hline $\mathrm{CP} 3$ & 1,3555 & 0,2909 & 1,12682463 & $\mathrm{CP} 3$ & 1,3643 & 0,2870 & 1,12076998 \\
\hline CP 4 & 1,3494 & 0,2806 & 1,11734562 & CP 4 & 1,3652 & 0,2826 & 1,11601884 \\
\hline CP 5 & 1,3657 & 0,2902 & 1,12379777 & CP 5 & 1,3712 & 0,2929 & 1,12539368 \\
\hline $\mathrm{CP} 6$ & 1,3584 & 0,2853 & 1,12029075 & $\mathrm{CP} 6$ & 1,3830 & 0,2937 & 1,12361608 \\
\hline \multirow{2}{*}{\multicolumn{4}{|c|}{\begin{tabular}{|l|} 
Média \\
Arredondamento:
\end{tabular}}} & \multicolumn{3}{|l|}{ Média } & 1,12256678 \\
\hline & & & 1,13 & \multirow{2}{*}{\multicolumn{3}{|c|}{\begin{tabular}{|l|} 
Arredondamento: \\
Desvio Padrão:
\end{tabular}}} & 1,12 \\
\hline \multicolumn{4}{|l|}{ Desvio Padrão: } & & & & 0,003305962 \\
\hline \multicolumn{4}{|l|}{ DATA: $31 / 03 / 2016$} & \multicolumn{4}{|l|}{ DATA: $31 / 03 / 2016$} \\
\hline \multicolumn{4}{|c|}{ DENSIDADE } & \multicolumn{4}{|c|}{ DENSIDADE } \\
\hline \multicolumn{4}{|c|}{ Material: PA 6 com $6 \%$ Aerosil } & \multicolumn{4}{|c|}{ Material: PA 6 com $10 \%$ Talco } \\
\hline Amostra & Peso 1 & Peso 2 & Densidade & Amostra & Peso 1 & Peso 2 & Densidade \\
\hline $\mathrm{CP} 1$ & 1,3619 & 0,2850 & 1,11921395 & $\mathrm{CP} 1$ & 1,4486 & 0,3622 & 1,18005431 \\
\hline $\mathrm{CP} 2$ & 1,3890 & 0,2918 & 1,12036548 & $\mathrm{CP} 2$ & 1,4485 & 0,3614 & 1,17921304 \\
\hline $\mathrm{CP} 3$ & 1,3615 & 0,2822 & 1,11639720 & CP 3 & 1,4563 & 0,3654 & 1,18143322 \\
\hline $\mathrm{CP} 4$ & 1,3625 & 0,2830 & 1,11701019 & CP 4 & 1,4433 & 0,3558 & 1,17454759 \\
\hline $\mathrm{CP} 5$ & 1,3753 & 0,2858 & 1,11715512 & CP 5 & 1,4648 & 0,3642 & 1,17785572 \\
\hline $\mathrm{CP} 6$ & 1,3617 & 0,2815 & 1,11563090 & $\mathrm{CP} 6$ & 1,4545 & 0,3636 & 1,17997296 \\
\hline Média & & & 1,11762881 & Média & & & 1,17884614 \\
\hline Arredondamento & & & 1,12 & Arredondamento: & & & 1,18 \\
\hline Desvio Padrão: & & & 0,001638982 & Desvio Padrão: & & & 0,002199072 \\
\hline
\end{tabular}

Fonte: autor da dissertação.

Nos resultados da análise de densidade (Figura 52) foi possível verificar que o $\mathrm{SiO}_{2}$ tem uma densidade menor em relação a carga de talco que está de acordo com a literatura (PINHEIRO, 1973; ANTON, 2009). Assim, foi possível obter o processamento da poliamida 6 mais leve com $\mathrm{SiO}_{2}$ do que as poliamidas 6 processadas com talco. Assim, pode-se dizer que quanto menor a quantidade de carga no material menor também será o custo da poliamida 6 .

\subsection{Análise de tração}

Nas Figuras 53 e 54 e são mostrados os resultados das análises de tração dos compósitos não irradiados e irradiados com 200 kGy de PA 6 com $1 \%$ de $\mathrm{SiO}_{2} \mathrm{CP} 1$. 
Figura 53 - Curvas de deformação de Green e coeficiente de Poisson de compósitos não irradiados de PA 6 com $1 \%$ de $\mathrm{SiO}_{2} \mathrm{CP} 1$
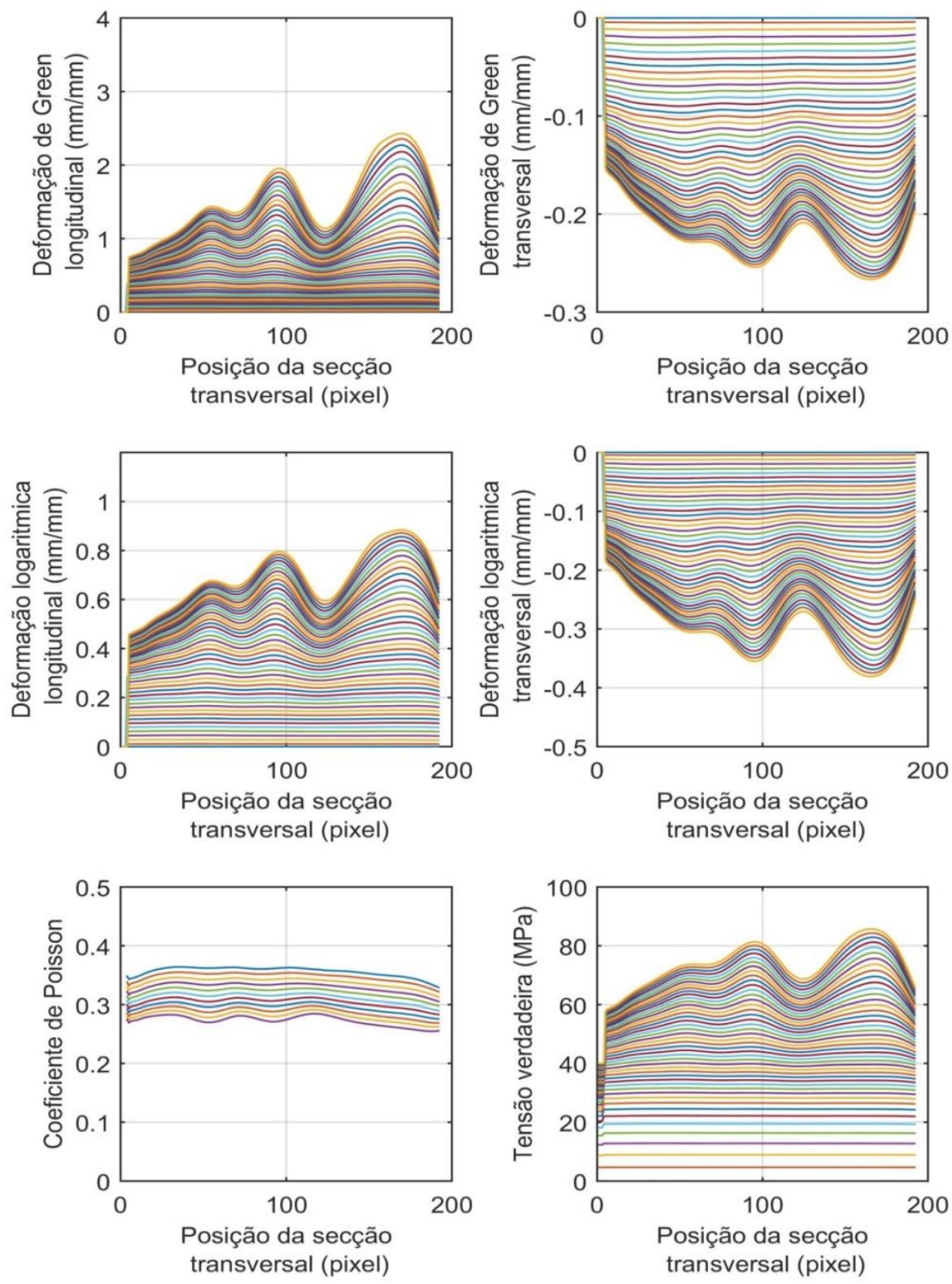

Fonte: autor da dissertação. 
Figura 54 - Curvas de deformação de Green e coeficiente de Poisson de compósitos irradiados com 200 kGy de PA 6 com $1 \%$ de $\mathrm{SiO}_{2} \mathrm{CP} 1$

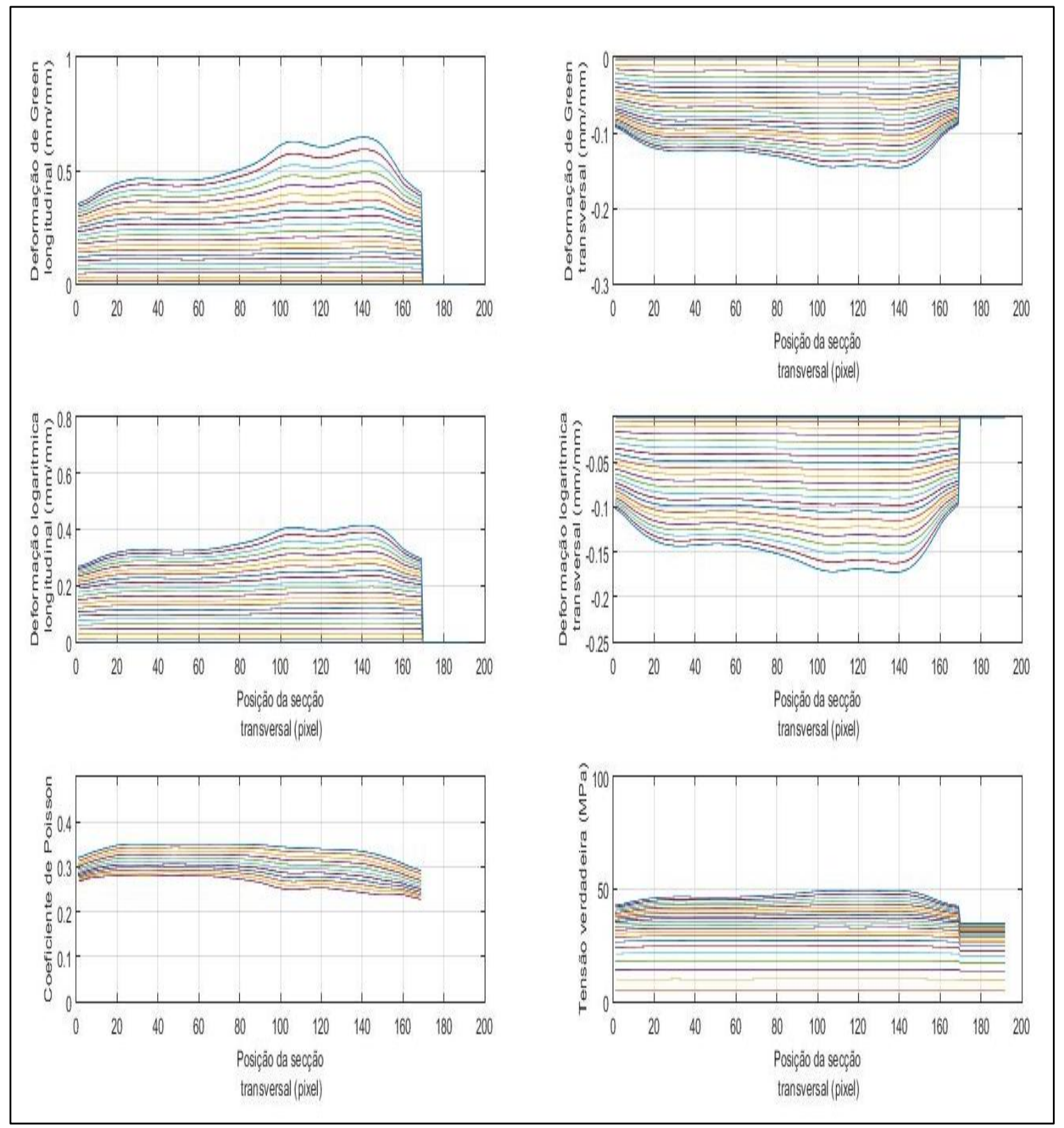

Fonte: autor da dissertação.

Nas Figuras 55 e 56 são mostrados os resultados das análises de tração dos compósitos não irradiados e irradiados com 200 kGy de PA 6 com $10 \%$ de talco CP1. 
Figura 55 - Curvas de deformação de Green e coeficiente de Poisson dos compósitos não irradiados de PA 6 com $10 \%$ de talco CP1

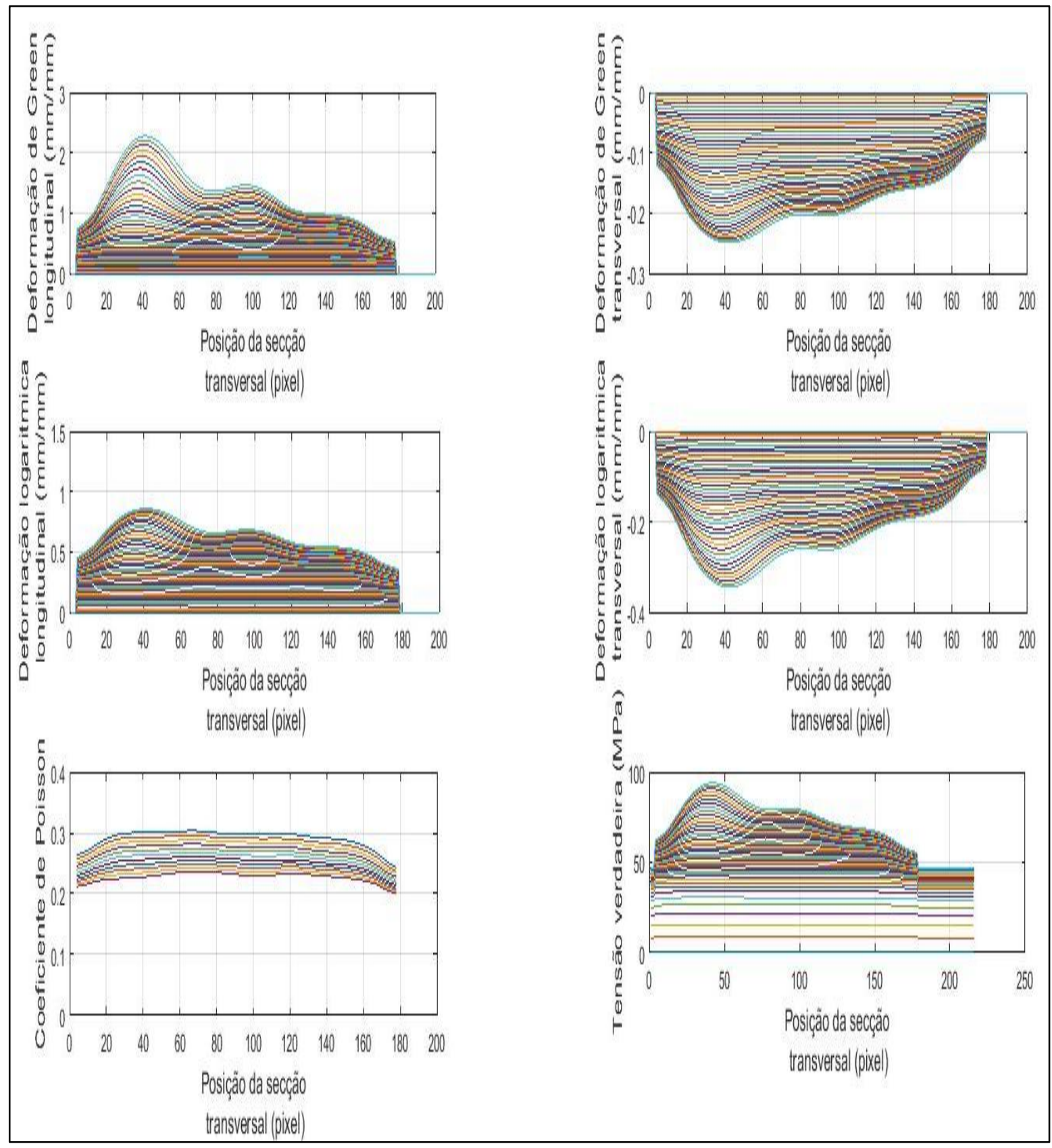

Fonte: autor da dissertação. 
Figura 56 - Curvas de deformação de Green e coeficiente de Poisson dos compósitos irradiados com 200 kGy de PA 6 com $10 \%$ de talco CP1

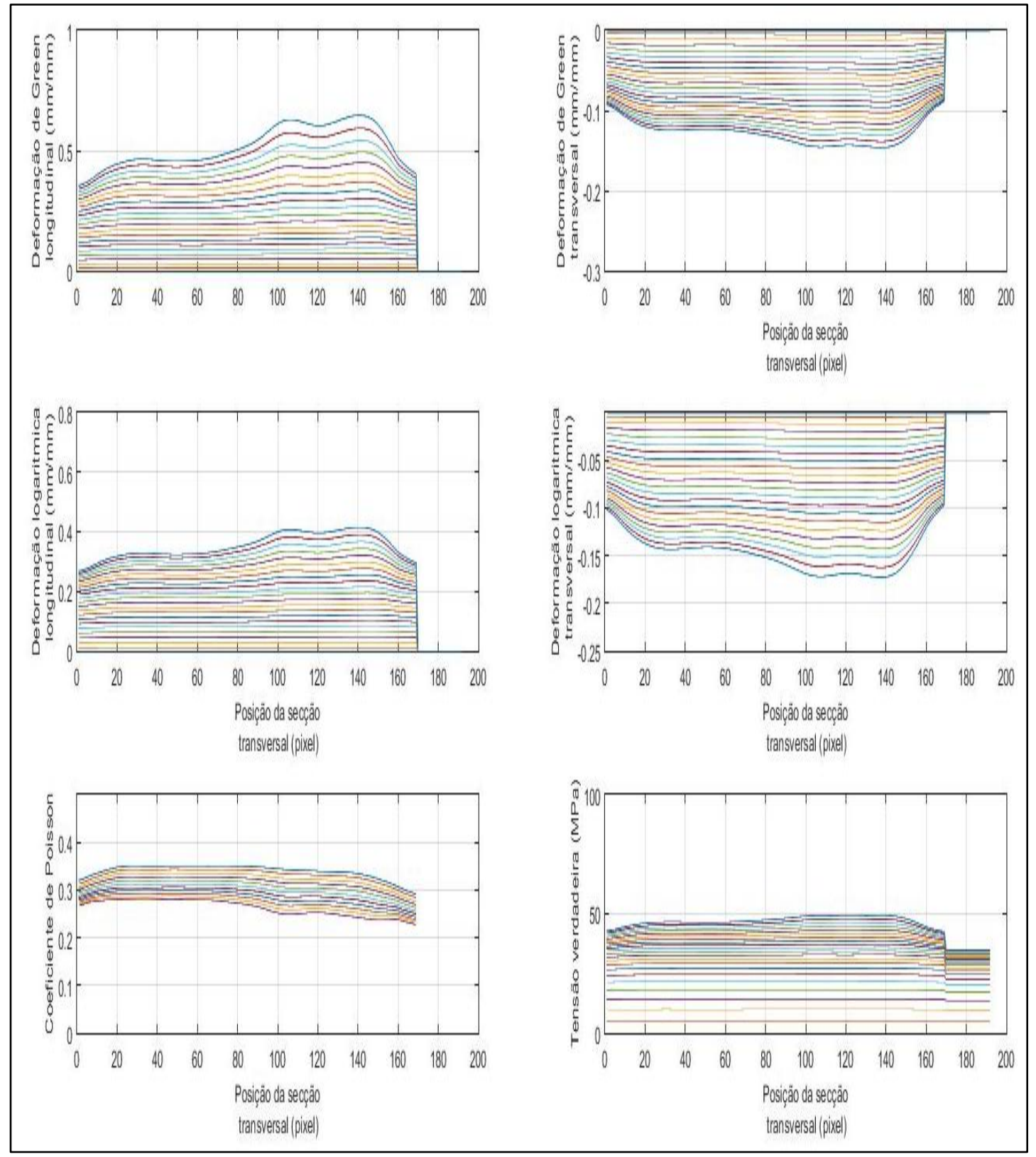

Fonte: autor da dissertação.

A curva de força por deslocamento foi calculado pelos dados da Instron e ambos foram adquiridos com a frequência de amostragem de $10 \mathrm{~Hz}$ por meio da celular de carga e de encoder no motor.

Desta forma, apartir do uso do software ncorr dentro do ambiente MatLab ${ }^{\circledR}$ (vide apêndices A, B, C e D para o endendimento dos calculos) foram obtidas as deformações de Green longitudinais e transversais para cada secção transversal 
definida como a região de interesse nas fotos capturadas por uma câmera NiKon DX AF- S NIKKOR 18-105 mm 1:3.5-56G ED a cada 3 ou 5 segundos.

Por meio da deformação transversal, da geometria inicial do corpo de prova e das forças mensuradas no tempo, foi possível obter a tensão real para cada secção transversal.

Portanto, apartir de um único corpo de prova foi possível obter de uma curva de tensão verdadeira $X$ e a deformação logaritimica para cada secção transversal definida na região de interesse.

Nas Figuras 57, 58, 59 e 60 são mostrados os resultados da deformação verdadeira dos compósitos não irradiados e irradiados com 200 kGy de PA 6 com $1 \%$ de $\mathrm{SiO}_{2} \mathrm{CP} 1$ e CP2

Figura 57 - Deformação logarítmica (a) e alongamento (b) dos compósitos não irradiados de PA 6 com $1 \%$ de $\mathrm{SiO}_{2} \mathrm{CP} 1$

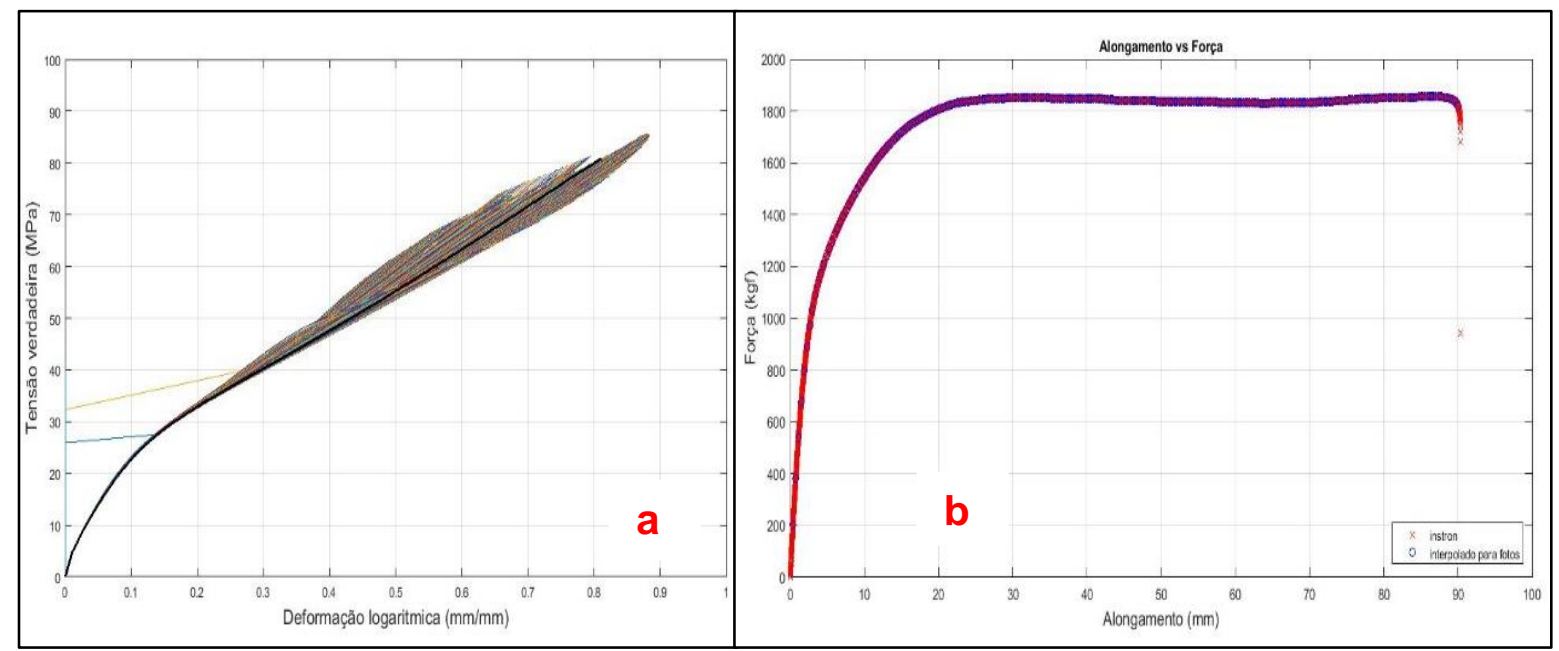

Fonte: autor da dissertação. 
Figura 58 - Deformação logarítmica (a) e alongamento (b) dos compósitos não irradiados de PA 6 com $1 \%$ de $\mathrm{SiO}_{2} \mathrm{CP} 2$

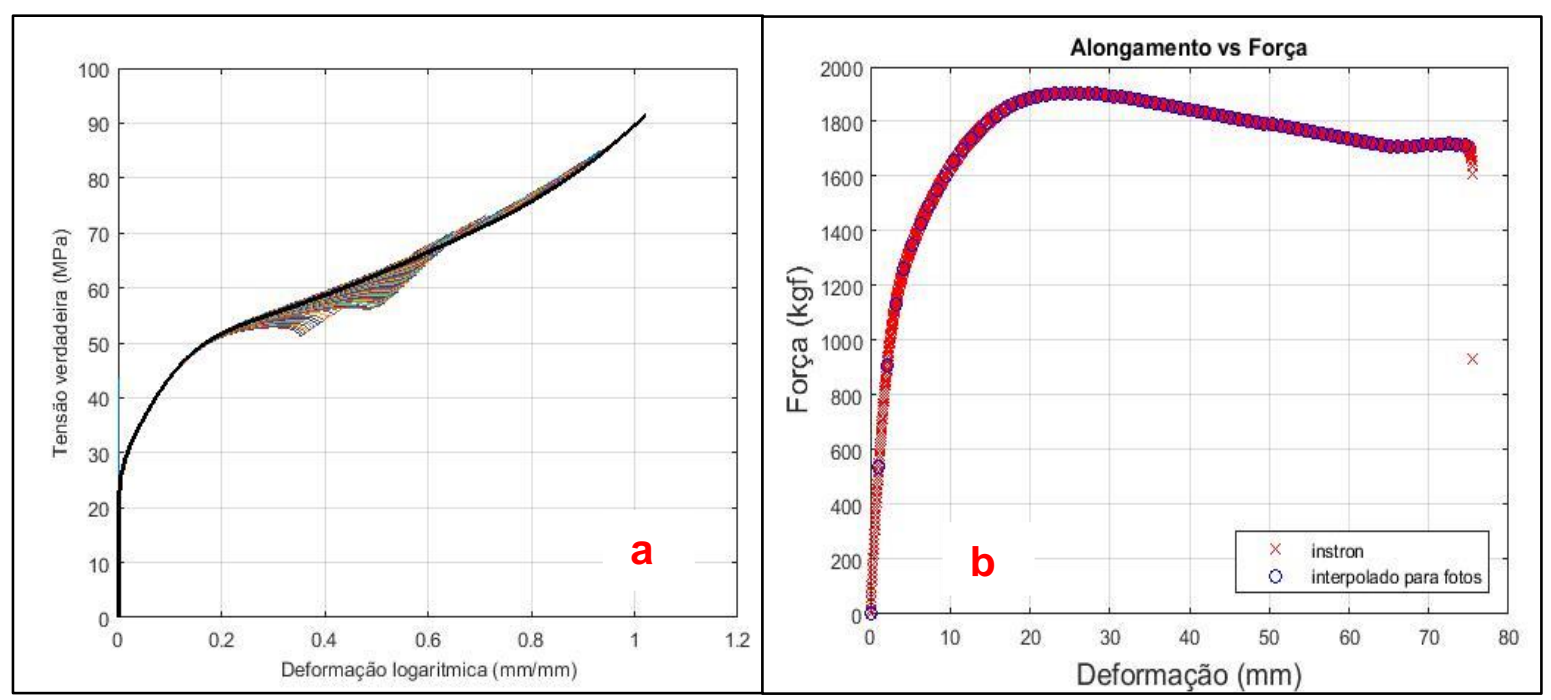

Fonte: autor da dissertação. 
Figura 59 - Deformação logarítmica (a) e alongamento (b) dos compósitos irradiados com 200 kGy de PA 6 com $1 \%$ de $\mathrm{SiO}_{2} \mathrm{CP} 1$

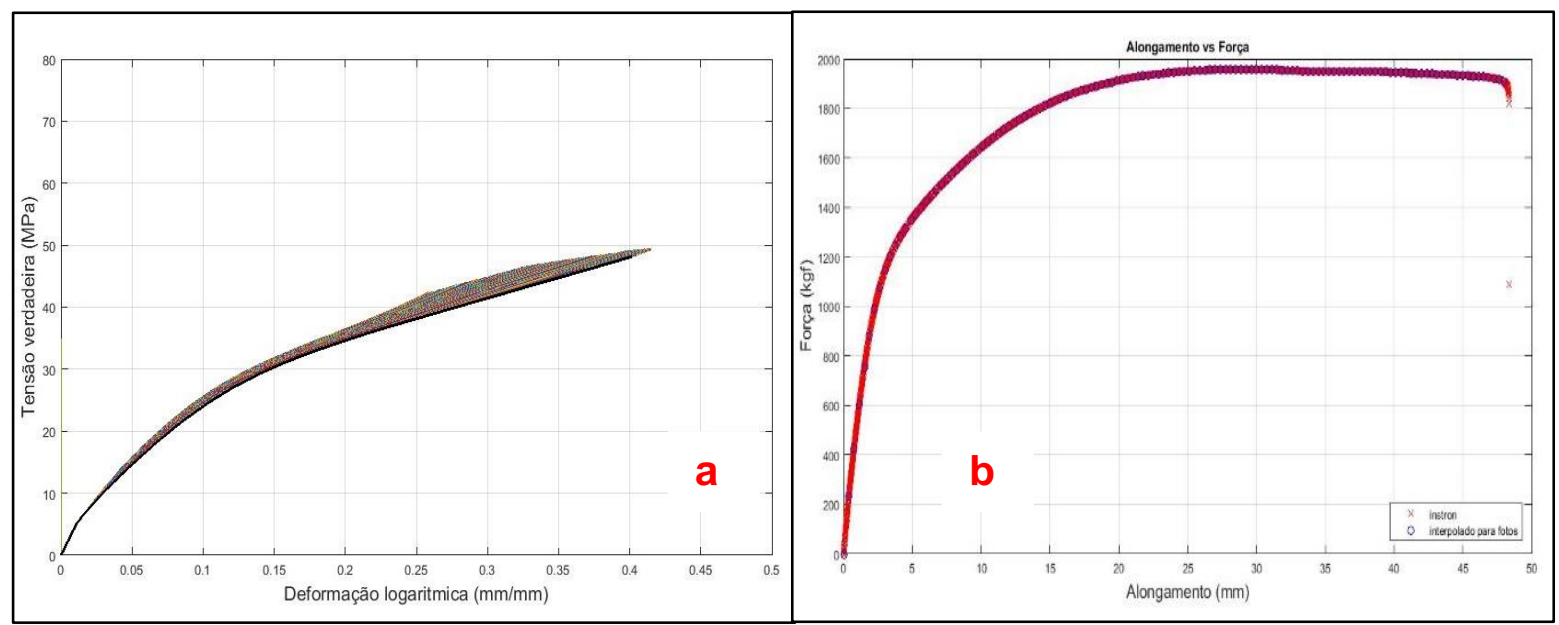

Fonte: autor da dissertação.

Figura 60 - Deformação logarítmica (a) e alongamento (b) dos compósitos irradiados com 200 kGy de PA 6 com $1 \%$ de $\mathrm{SiO}_{2} \mathrm{CP} 2$
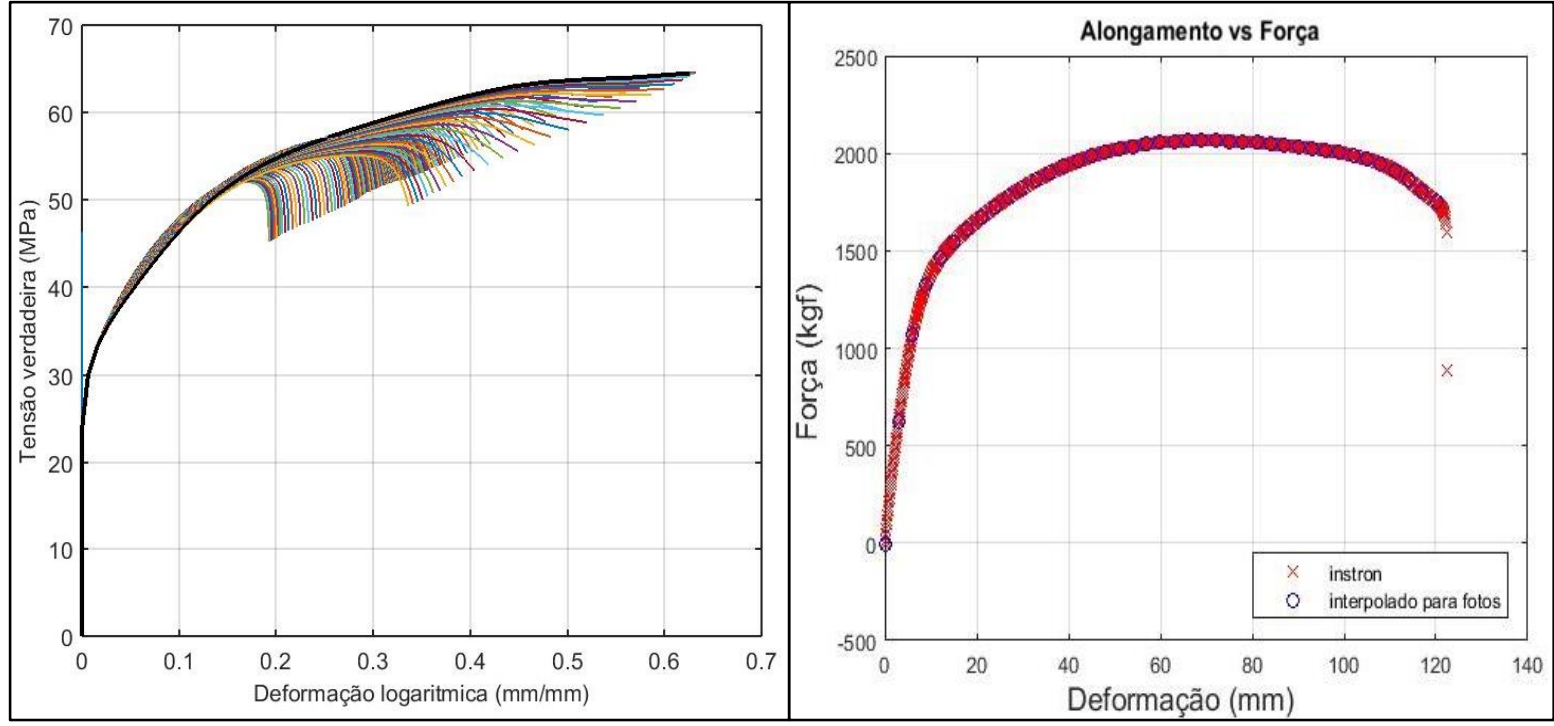

Fonte: autor da dissertação. 
Nas Figuras 61, 62, 63 e 64 são mostrados os resultados da deformação verdadeira dos compósitos não irradiados e irradiados com 200 kGy de PA 6 com $10 \%$ de talco CP1 e CP2.

Figura 61 - Deformação logarítmica (a) e alongamento (b) dos compósitos não irradiados de PA 6 com $10 \%$ de talco CP1

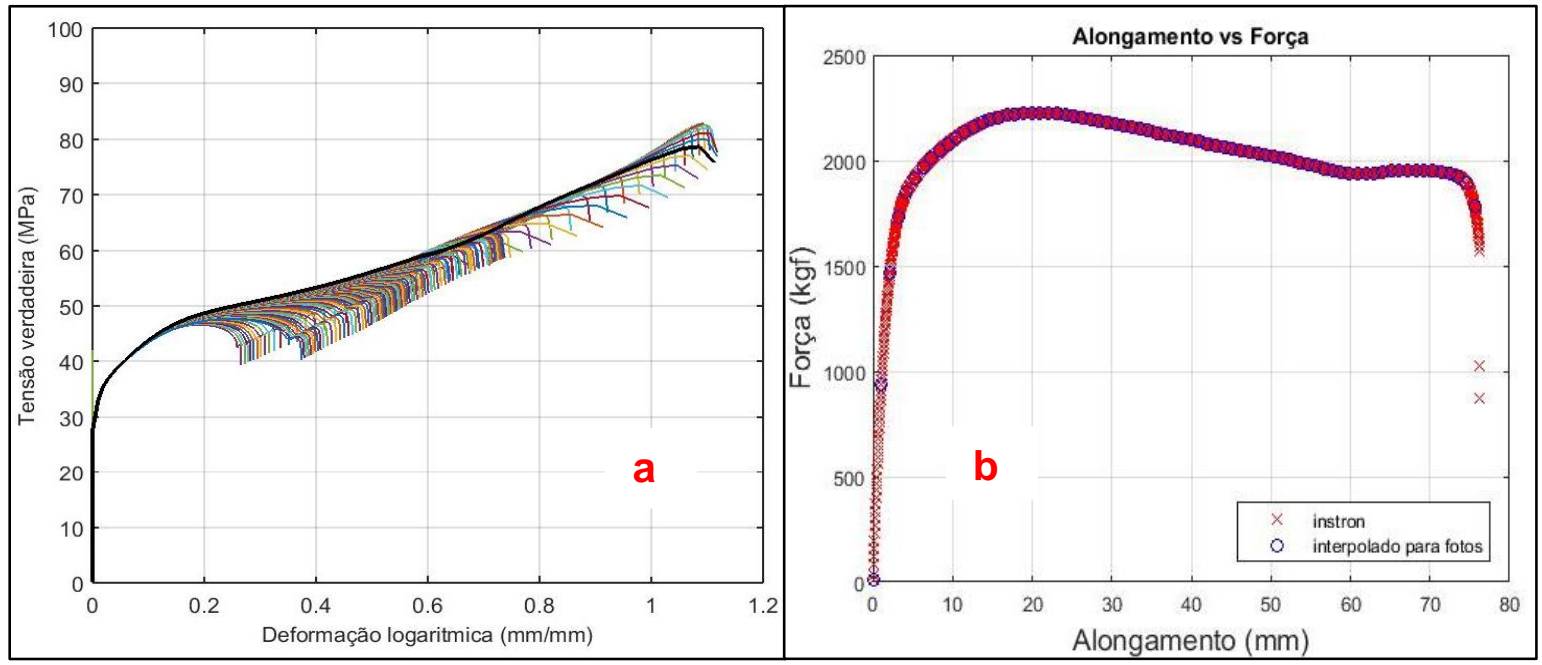

Fonte: autor da dissertação.

Figura 62 - Deformação logarítmica (a) e alongamento (b) dos compósitos não irradiados de PA 6 com $10 \%$ de talco CP2
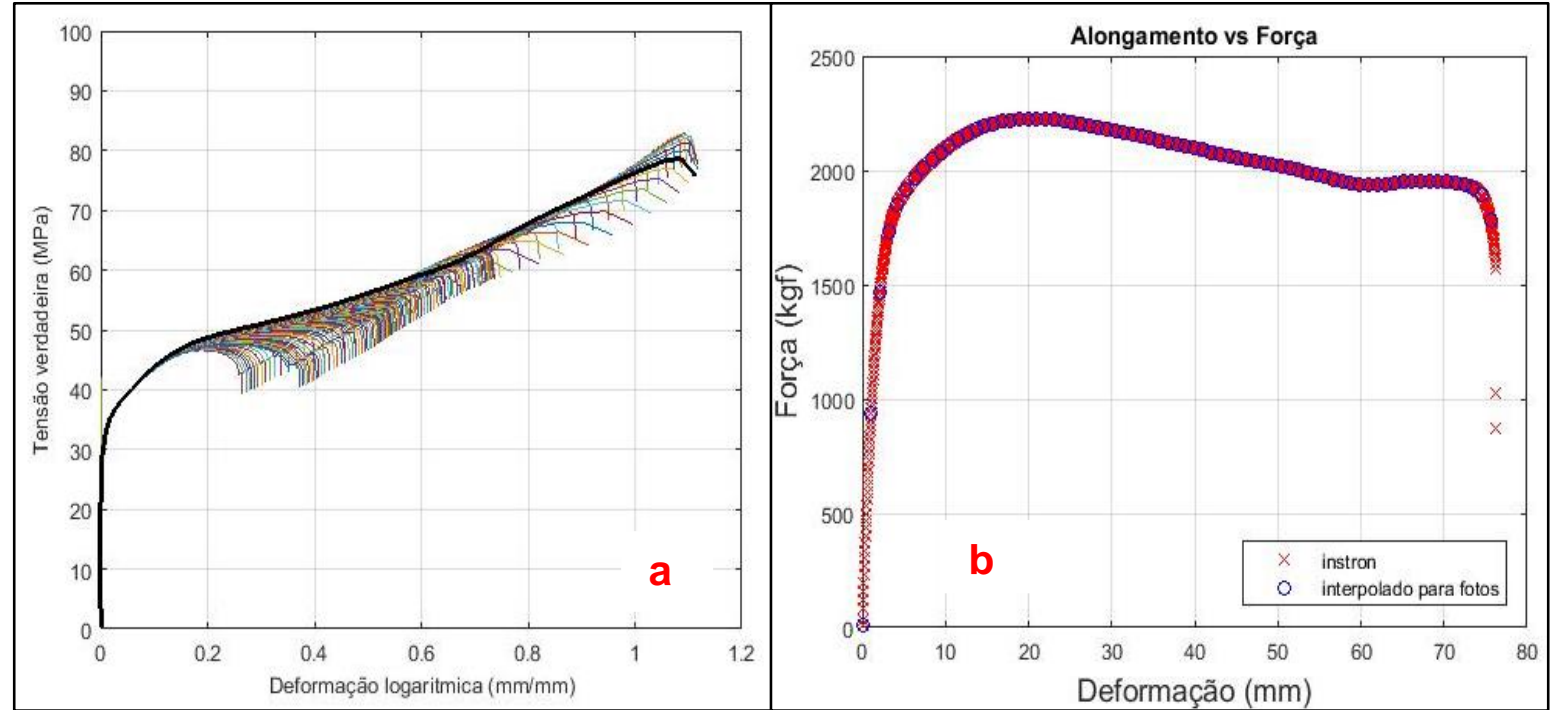

Fonte: autor da dissertação. 
Figura 63 - Deformação logarítmica (a) e alongamento (b) dos compósitos irradiados com 200 kGy de PA 6 com $10 \%$ de talco CP1
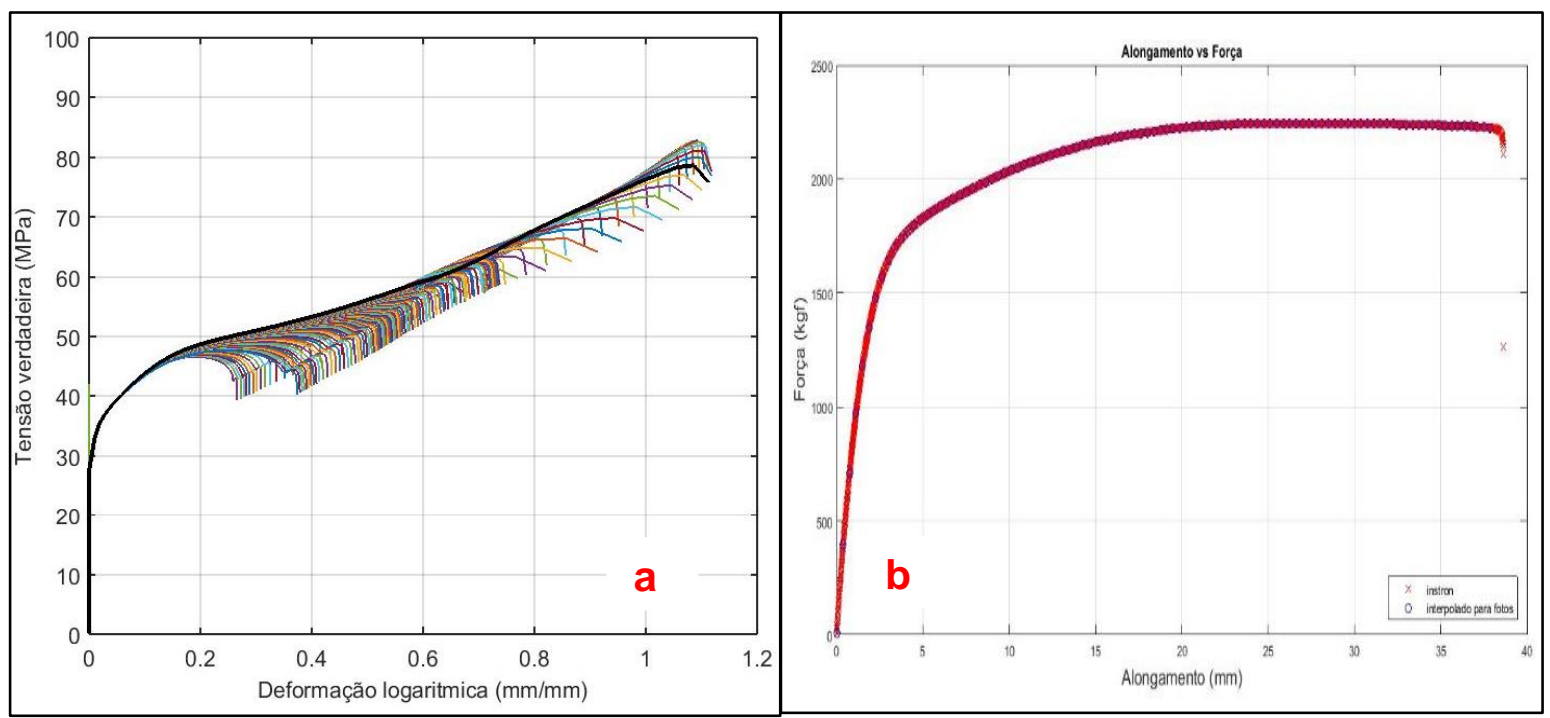

Fonte: autor da dissertação.

Figura 64 - Deformação logarítmica (a) e alongamento (b) dos compósitos irradiados com 200 kGy de PA 6 com $10 \%$ de talco CP2
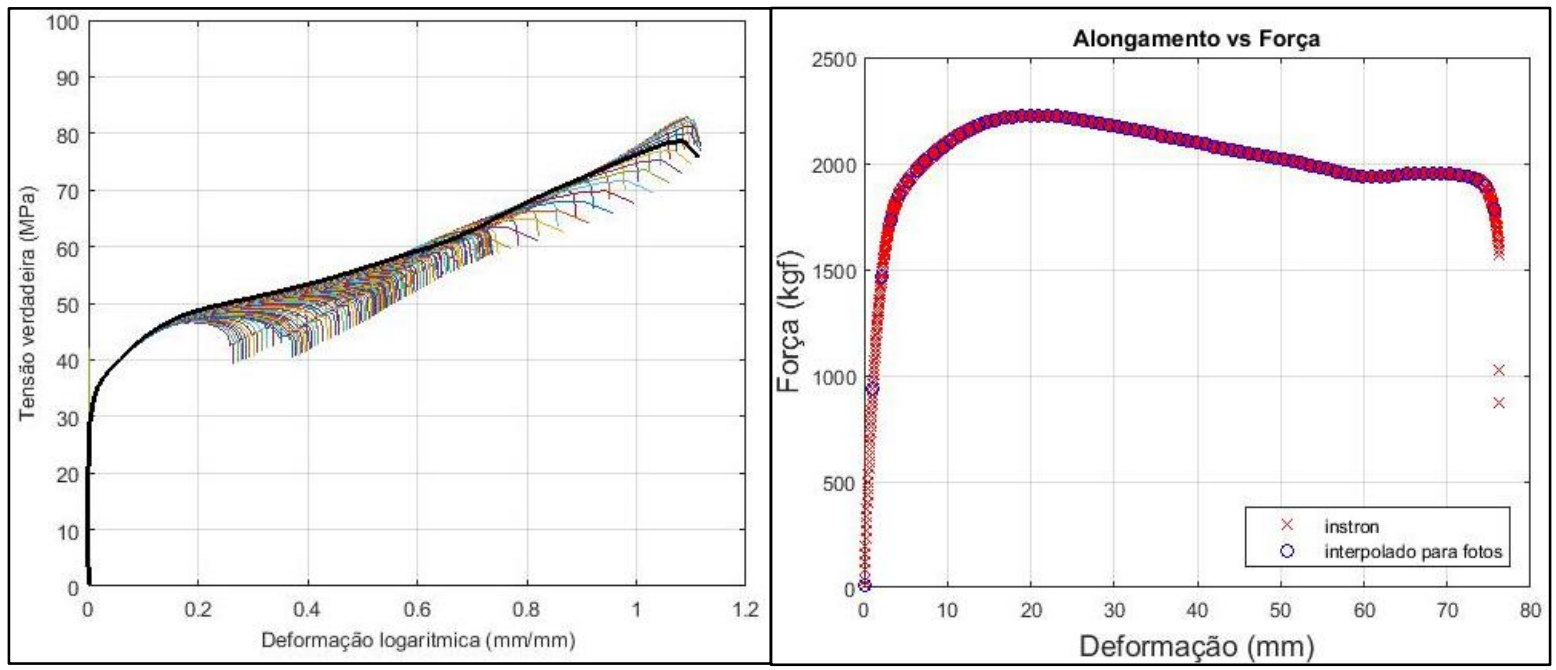

Fonte: autor da dissertação. 
Nas Figuras 65, 66, 67 são mostrados os gráficos comparativos das curvas CP1 e CP2 dos compósitos de PA 6 com $1 \%, 6 \%$ de $\mathrm{SiO}_{2}$ e $10 \%$ de talco não irradiados e irradiados.

Figura 65 - Comparação das curvas CP1 e CP2 dos compósitos de PA 6 com $1 \%$ de $\mathrm{SiO}_{2}$ não irradiados e irradiados.

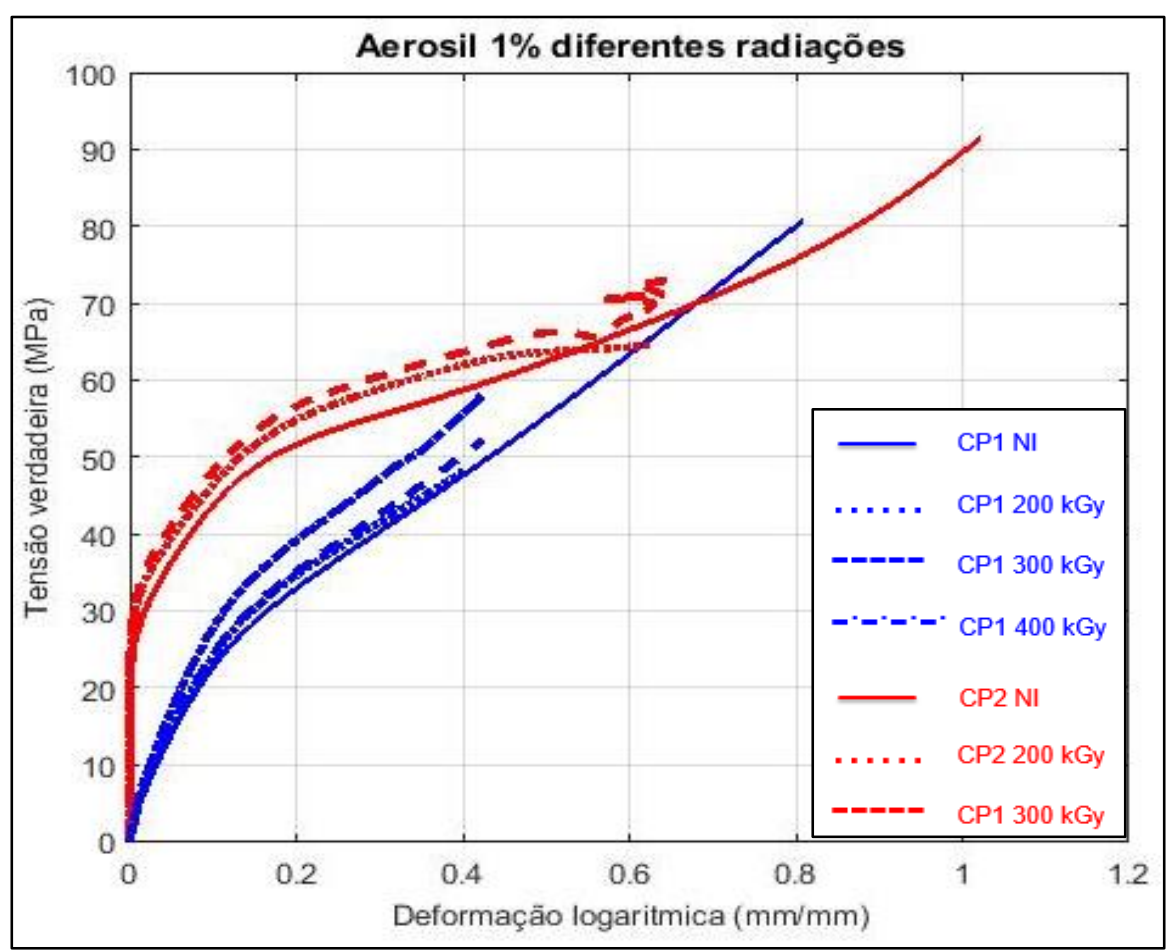

Fonte: autor da dissertação. 
Figura 66 - Comparação das curvas CP1 e CP2 dos compósitos de PA $6 \mathrm{com} 6 \%$ de $\mathrm{SiO}_{2}$ não irradiados e irradiados.

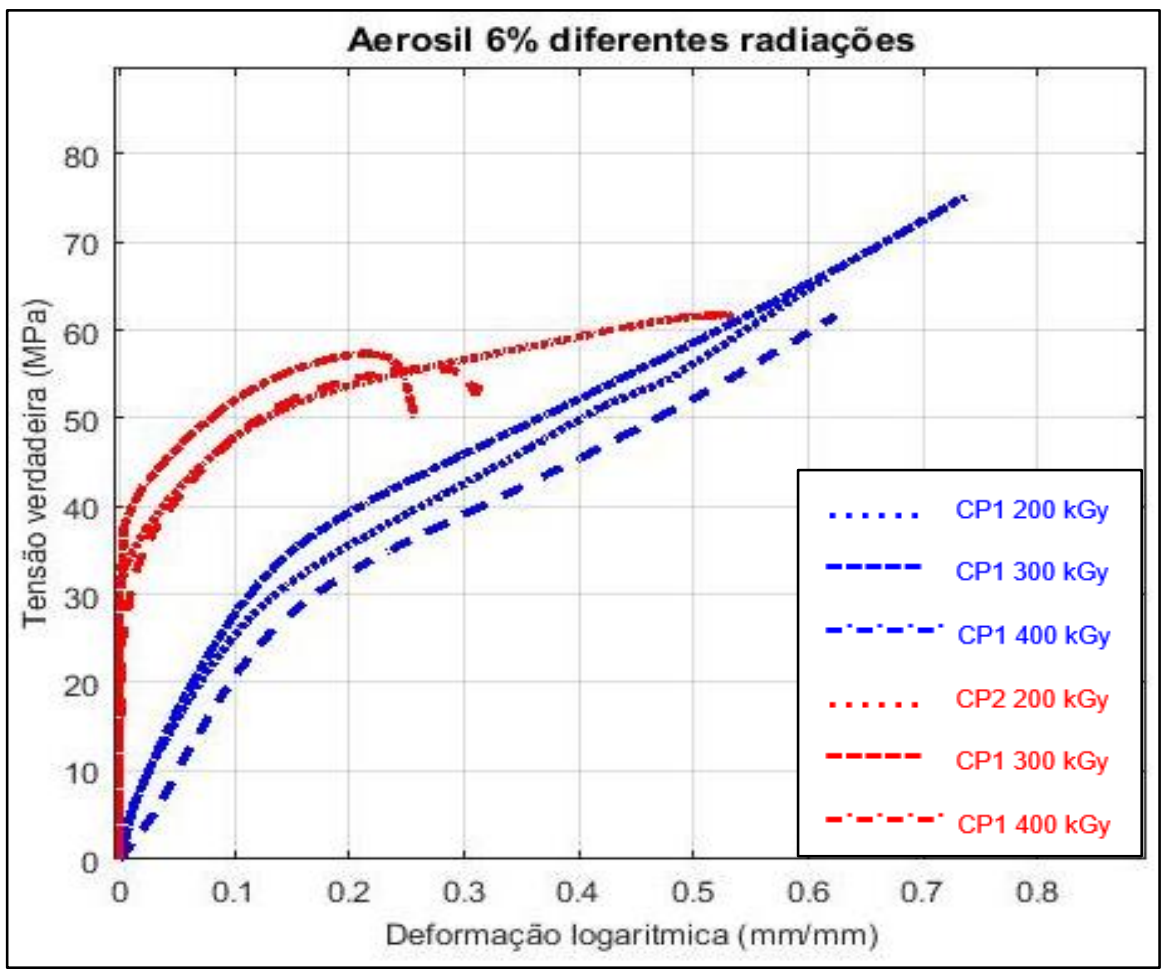

Fonte: autor da dissertação. 
Figura 67 - Comparação das curvas CP1 e CP2 dos compósitos de PA 6 com $10 \%$ de talco 2 não irradiados e irradiados.

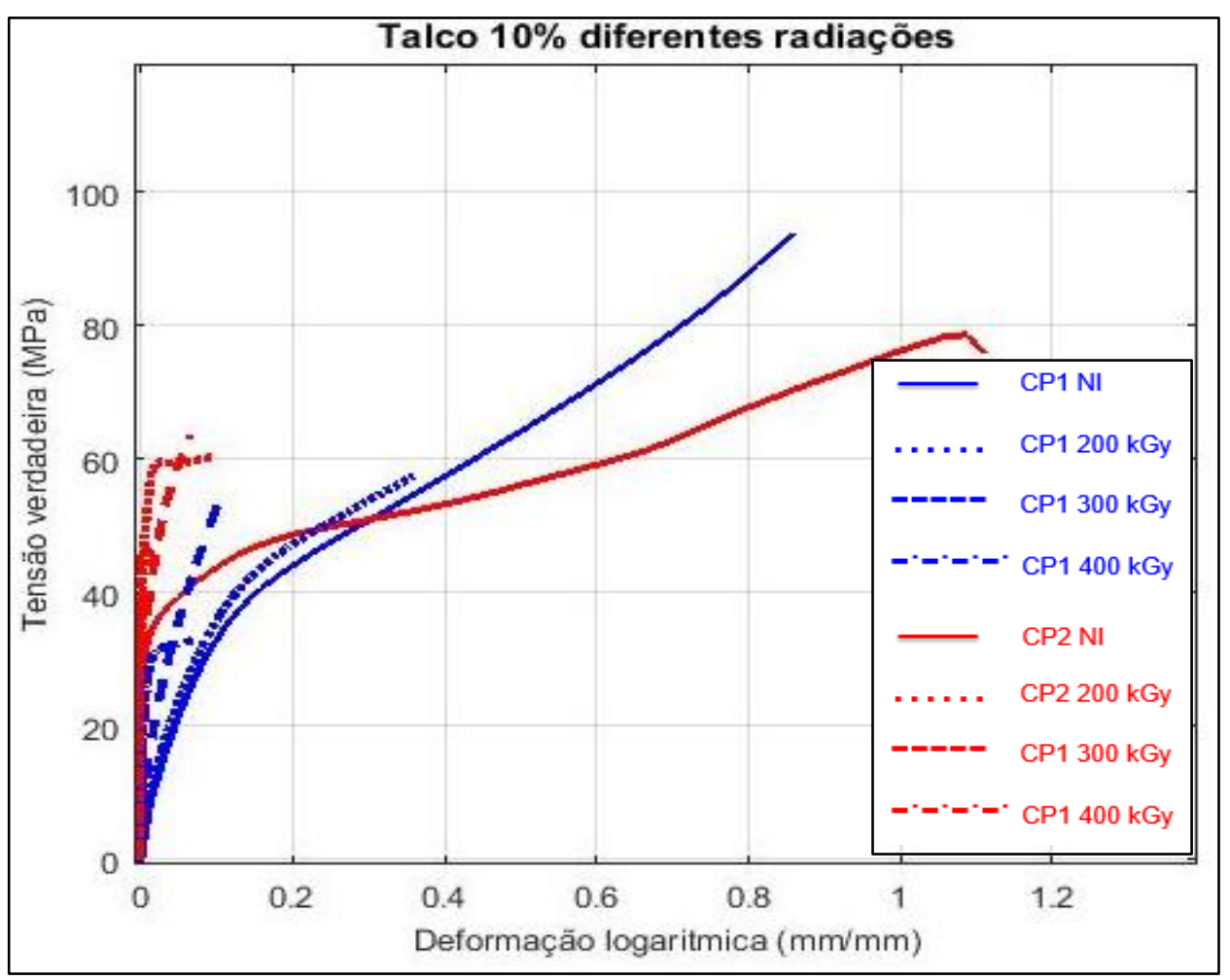

Fonte: autor da dissertação.

De acordo com as Figuras 65, 66 e 67 a velocidade mais lenta (amostras de CP1 cor azul 0,075 mm/s) o material obteve um limite de escoamento menor e uma deformação maior. Portanto, quanto maior a dose de radiação aplicada, maior foi a rapidez com que o material chegou a romper.

Nos corpos de prova com velocidade mais rápida (amostras CP2 cor vermelha $0,35 \mathrm{~mm} / \mathrm{s}$ ) as amostras dos compósitos de $\mathrm{PA} 6 \mathrm{com} \mathrm{SiO}_{2}$ e com talco apresentaram um limite de escoamento maior chegando a sofrer uma deformação menor. No entanto, também foi possível concluir que o aumento da dose de radiação interferiu para que as amostras rompessem rapidamente. 


\section{CONCLUSÕES}

Por meio das curvas termogravimétricas TG/DTG observou-se que a poliamida tem uma perda de massa inicial devido à umidade. Posteriormente, foi possível verificar a ocorrência de uma série de eventos intermediários na faixa de temperatura de 300 a $500 \stackrel{\circ}{\circ}$ sendo também, esta faixa onde ocorreu a perda de massa/degradação da PA 6. Porém, não foi possível afirmar se esses eventos ocorreram pela presença das cargas ou por influência da radiação.

Por meio das curvas de DSC foi identificado que a radiação alterou o pico máximo da temperatura de fusão e a região de cristalização pré-fusão desapareceu.

Por FTIR foi possível identificar os grupos funcionais correspondentes a PA 6. Após o processo de irradiação nenhuma alteração expressiva foi observada.

Por meio dos espectros de DRX foi possível afirmar que quanto maior a dose de radiação maior a cristalinidade dos compósitos de PA 6 com $\mathrm{SiO}_{2}$ e com talco.

Ensaios com MEV/EDS apresentaram resultados satisfatórios, pois neste caso as micrografias apresentaram a ausência de trincas e uma excelente homogeneidade da PA 6 com as cargas estudadas. Pode-se dizer que a radiação ionizante não interferiu na estrutura molecular dos compósitos de PA $6 \mathrm{com} \mathrm{SiO}_{2}$ e com talco.

De acordo com os resultados das análises mecânicas foi possível afirmar que os compósitos de PA 6 apresentaram um duplo empescoçamento durante o ensaio de tração sendo mais acentuados para as poliamidas $\mathrm{com} \mathrm{SiO}_{2}$ indicando assim uma possível falha no molde usado no processamento das amostras.

Foi possível concluir que para a velocidade mais lenta (amostras CP1 $0,075 \mathrm{~mm} / \mathrm{s}$ ) o material obteve um limite de escoamento menor e uma deformação maior. Assim, quanto maior a dose de radiação aplicada, maior foi a rapidez com que o material chegou a romper.

Para os corpos de prova com velocidade mais rápida (amostras CP2 $0,35 \mathrm{~mm} / \mathrm{s}$ ) o material apresentou um limite de escoamento maior chegando a sofrer uma deformação muito menor. No entanto, também foi possível concluir, 
que neste caso, o aumento da dose de radiação interferiu para que o material rompesse mais rapidamente.

Os resultados mostraram que dependendo da aplicação tecnicamente o $\mathrm{SiO}_{2}$ sem o processo de irradiação seria uma carga viável para substituir o talco em compósitos de com PA 6. 


\section{SUGESTÕES PARA TRABALHOS FUTUROS}

Análise de custo para verificação da viabiliade do uso de compósitos de PA 6 com $\mathrm{SiO}_{2}$.

Irradiação dos grãos de PA 6 com $\mathrm{SiO}_{2}$ submetidos a diferentes doses de radiação e verificar o seu desempenho no processamento por injeção medindo suas propriedades, térmicas, mecânicas e reológicas.

Verificar o efeito da radiação em compósitos de PA 6 com doses de radiação acima de 400 kGy utilizando a técnica de difração de raios $X$. 


\section{REFERÊNCIAS BIBLIOGRÁFICAS}

AMADO, R. J.; RONDÓN, L. P.; PRADA, A. L.; ARRANZ, J. C. E.; COLARTE, A. I. Formulación de cápsulas duras de Tamarindus indica L. Revista cubana de farmácia, v. 48, n. 1, p. 118-118, 2014.

BROWN, M. E. Introduction to thermal analysis: Techiniques and applications. London: Chapman and Hall, 1988.

CALLISTER, W. Ciência e engenharia de materiais: uma introdução. Rio de

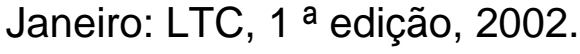

CANTO, L. B.; PESSAN, L. A. Resistência à tração, flexão e compressão. Técnicas de caracterização de polímeros. São Paulo: Editora Artliber, 2004.

CRUZ, H.; GONZALEZ, C.; JUÁREZ A.; HERRERA, M.; JUAREZ, J. Quantification of the microconstituents formed during solidification by the Newton thermal analysis 60 method. Journal of Materials Processing Technology, v. 178, n. 1-3, p.128-134, 2006.

DEDAVID, B. A.; GOMES, C. I.; MACHADO, G. Microscopia eletrônica de Varredura: Aplicações e preparação de amostras. Porto Alegre: EDIPUCRS, 2007.

DEPARTAMENTO NACIONAL DE PRODUÇÂO MINERAL Sumário mineral vl 35 ISSN 0101-2053, 2015 (DNPM, 2015). Disponível em: < http://www.dnpm.gov.br/dnpm/sumarios/sumario-mineral-2015> Acesso em: 14 fev. 2017

ERIKSSON, P. A; BOYDELL, P.; ERIKSSON, K.; MANSON, J. A. E.; ALBERTSSON, A. C. Effect of thermal oxidative aging on mechanical, chemical, and thermal properties of recycled polyamide 66, Journal of Applied Polymer Science, v. 65, p. 1619-1630, 1997. 
EVORA, M. C.; GONÇALEZ O. L.; DUTRA, R. C. L; DINIZ, M. F; WIEBECK, H.; SILVA, L. G. A. Comparação de técnicas FTIR de transmissão, reflexão e fotoacústica na análise de poliamida-6, reciclada e irradiada. Polímeros Ciência e Tecnologia, v. 12, n. 1, p. 60-68, 2002.

IONASHIRO, M. G. Fundamentos da termogravimetria, análise térmica diferencial e calorimetria exploratória diferencial. São Paulo: GIZ editorial, 2004.

KHANNA, Y. P.; KUHN, W. P. Measurement of crystalline index in ylons by DSC: complexities and recommendations. Journal of Polymer Science: Part. B, Polymer Physics, v. 35, p. 2219-2231, 1997.

MANRICH, S. Processamento de termoplásticos: Rosca única, extrusão \& matriz, injeção \& moldes. São Carlos: Artliber, 2005.

MARCZAK, R. J. Polímeros como materiais de engenharia. Porto Alegre. UFRGS, 2004.

MINATTI, J. L. Desenvolvimento de cerâmicas de mulita a partir de alumina, ácido silício e aerosil. 2009. 166p. Tese (Doutorado em Engenharia Mecânica) Universidade Estadual Paulista, Guaratinguetá. Disponível em: < http://livros01.livrosgratis.com.br/cp108481.pdf> Acesso em: 20 abr. 2017.

MOURA, S. P., Bicamadas catiônicas em silíca: adsorção e estabilidade coloidal a baixa força iônica. 2003 55p Dissertação (Mestrado em Bioquímica) - Universidade de São Paulo, São Paulo. Disponível em: $<$ www.teses.usp.br/teses/disponiveis/46/.../tde.../Dissertacao2003.pdf> Acesso: 30 mai. 2017.

MOURA, R. T., Modelagem em ensaios mecânicos de polímeros sob carregamentos quase-estático e dinâmico. 2013. 365 p. Tese (Doutorado em Engenharia Mecânica) - Universidade de São Paulo, São Paulo. Disponível em: $<$ http://www.teses.usp.br/teses/disponiveis/3/3151/tde-19072013-181611/pt-br.php > Acesso em: 12 fev. 2017.

NAGATANI, T.; SAITO, S; SATO, M.; YAMADA, M. Development of an ultra high resolution scanning electron microscope by means of a field emission source and in-lens system. Scanning Microscopy. v. 11, p. 901-909, 1987.

PAGLIOSA, C. Determinação experimental de propriedades viscoelásticas de material polimérico. 2004. 110p. Dissertação (Mestrado em Engenharia Mecânica) - Universidade Federal de Santa Catarina, Florianópolis. Disponível 
em: <https://repositorio.ufsc.br/xmlui/handle/123456789/87835> Acesso em: 22 mai. 2017

PLASTSHOW - Iniciativa Bem-Sucedida de Feira e Congresso Único Evento Polímeros: Ciência e tecnologia, v. 12, p. 2, 2002.

PERTESON, M.; ADILSON, O. S.; REITZ, G. M.; DONDOSSOLA. R; RIELLA, H. G. Utilização de análise térmica diferencial e termogravimétrica para caracterização de controle de talcos. São Pedro, 2000.

PINHEIRO, J. C. F. Perfil analítico do talco. Ministério das Minas e Energia boletim n. 22. Departamento Nacional da Produção Mineral, Rio de Janeiro, 1973.

PERKINS, W. D. Fourier Transform infrared spectroscopy. Part III. Applications. Journal of Chemical Education, v. 64, n. 12, p. A296, 1987.

ORÉFICE R. L.; PEREIRA M. M.; MANSUR H. S. Biomateriais - Fundamentos e Aplicações. São Paulo: Guanabara Koogan, 1 a edição , 2012.

SANCHES, E. A. Estudos de XRD e SAXS aplicados a polianilina e a polí(ometoxianilina. 2011. 148p. Tese (Doutorado em Ciência e Engenharia de Materiais) - Instituto de Física de São Carlos, Universidade de São Paulo, São Carlos. Disponível em: <http://www.teses.usp.br/teses/disponiveis/88/88131/tde12052011-171806/pt-br.php> Acesso em: 20 abr. 2017.

SKOOG, D. A.; HOLLER, J. F.; NIEMAN, A. T. Principios de análise Instrumental. Porto Alegre: Bookman, 5a edição, 2002.

TEIXEIRA, E. C Sobre a teoria de difração de raios - $X$ em estruturas tridimensionais. 2014. 145p. (Mestrado em Engenharia Metalúrgica, Materiais e de Minas) - Universidade Federal de Minas Gerais. Minas Gerais.

SPINACÉ, M. A. S.; PAOLI, M. A. A tecnologia da reciclagem dos polímeros, Quimica Nova, v. 28, n. 1, p. 65-72, 2005.

VASCONCELOS, E. A. F.; MEDEIROS, M. G. F.; RAFFI, N. F. N.; MOURA, T. F. A. L. Influência da temperatura de secagem e da concentração de Aerosil ${ }^{\circledR} 200$ nas características dos extratos secos por aspersão da Schinus terebinthifolius Raddi (Anacardiaceae). Revista Brasileira de Farmacognosia Brazilian Journal of Pharmacognosy, v. 15, n. 3, p. 243-249, 2005. 
WIEBECK, H.; HARADA, J. Plásticos de Engenharia. São Paulo: Artiber, 2005. 


\section{APÊNDICE A - Arruma dados parte 1}

$\% \%$ limpa tudo, apaga tudo, fecha tudo

clear all

close all

clc

$\%$ criar variaveis

Tinstron=[]; \%s

Linstron=[]; \%mm

Finstronkgf=[]; \%kgf

$\% \%$ Copia do excel e salva

\% Voce deve abrir a planilha do excel, copiar uma coluna e salvar na

$\%$ variavel desejada (duplo click na variavel abre editor de matriz do matlab)

$\%$ apos copiar, executar o comando abaixo

$\%$ save nome_do_arquivo variavel_01 variavel_02 ...

$\%$ save dados_instron_original Tinstron Linstron Finstronkgf 


\section{APÊNDICE B - Arruma dados parte 2}

$\% \%$ limpa tudo, apaga tudo, fecha tudo

clear all

close all

clc

$\% \%$ carregar variaveis originais e constantes

load dados_instron_original

$g=9.7871$;

n_fotos $=66$;

intervalo_entre_fotos $=3$;

FinstronN $=g$ * Finstronkgf;

$\% \%$ criar vetores INTERPOLADOS

Tinterp $=[0: \text { intervalo_entre_fotos:((n_fotos- } 1)^{*}$ intervalo_entre_fotos $\left.)\right]$;

$\% \mathrm{y}=\operatorname{interp} 1(\mathrm{x} 0, \mathrm{y} 0, \mathrm{x})$

Linterp $=$ interp1 $($ Tinstron,Linstron, Tinterp);

Finterp $=$ interp1 $($ Tinstron,FinstronN,Tinterp);

figure(1)

plot(Tinstron,Linstron,'rx')

hold all

plot(Tinterp,Linterp,'ob')

grid on

legend('instron','interpolado para fotos','Location', 'Northwest')

title('Extensao') 
figure(2)

plot(Tinstron,FinstronN,'rx')

hold all

plot(Tinterp,Finterp,'ob')

grid on

legend('instron','interpolado para fotos','Location','Southeast')

title('Força')

\%save nome_do_arquivo variavel_01 variavel_02 ...

save dados_instron_tratados Tinterp Linterp Finterp 


\section{APÊNDICE C - Tratamento do teste}

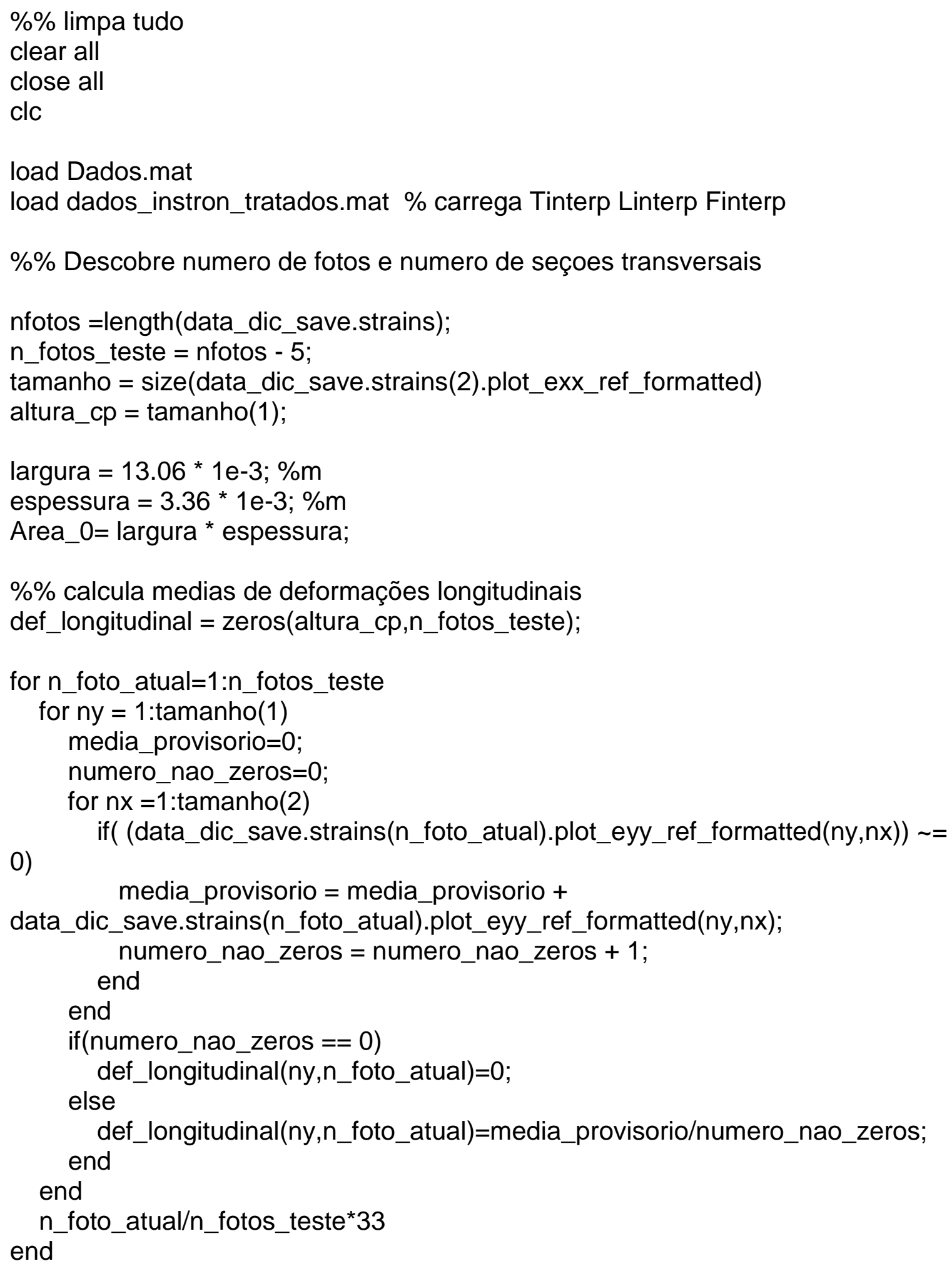




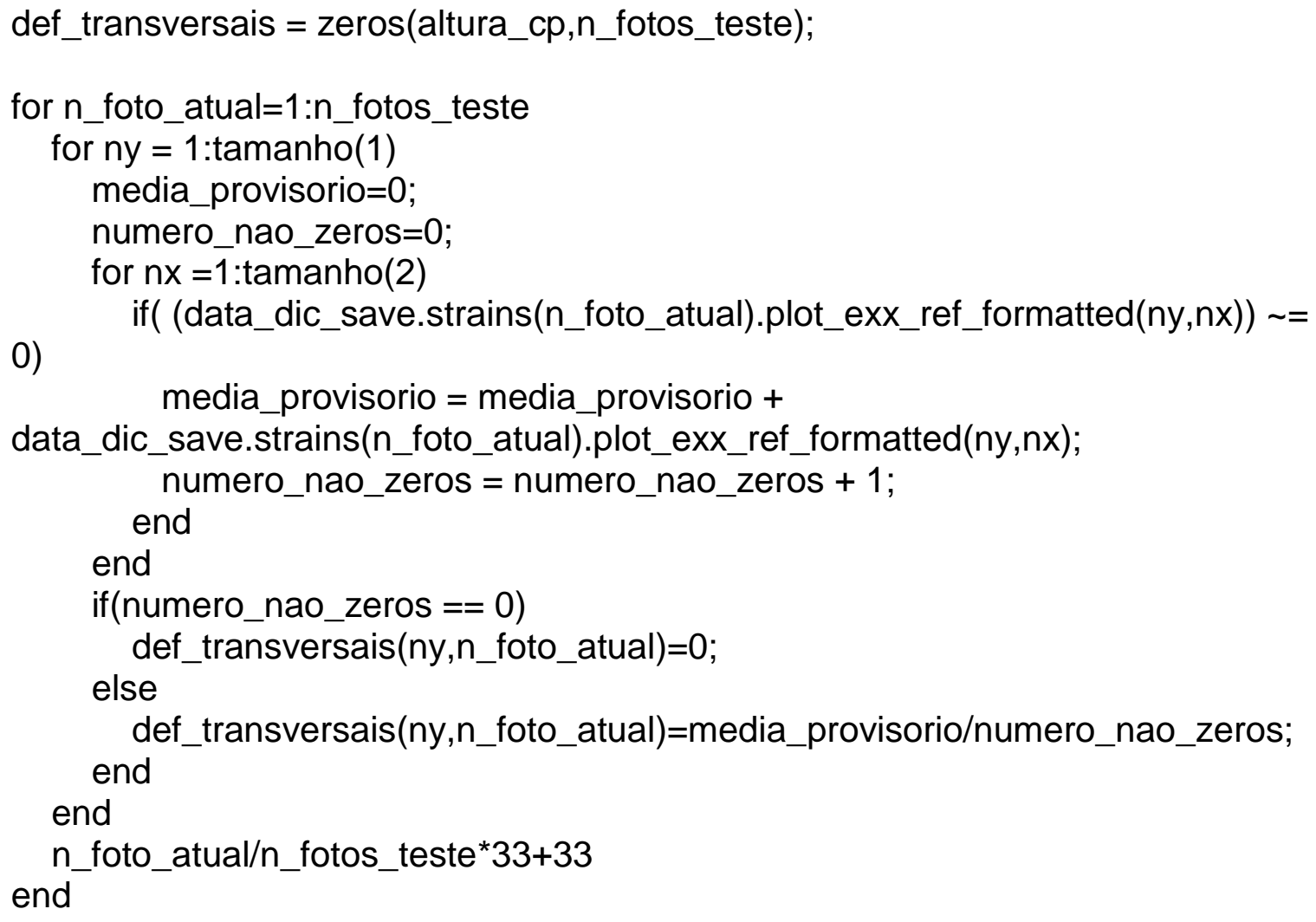

$\% \%$ calcula poisson

poisson = zeros(altura_cp,n_fotos_teste);

for $n$ foto_atual=1:n_fotos_teste

\%\% calcula a deformação logarítima

def_log = zeros(altura_cp,n_fotos_teste);

for n_foto_atual $=1$ :n_fotos_teste

for ny = $1: \operatorname{tamanho}(1)$

);

def_log $($ ny, n_foto_atual $)=0.5^{*} \log \left(2^{*}(\right.$ def_longitudinal $($ ny,n_foto_atual $))+1$

end 


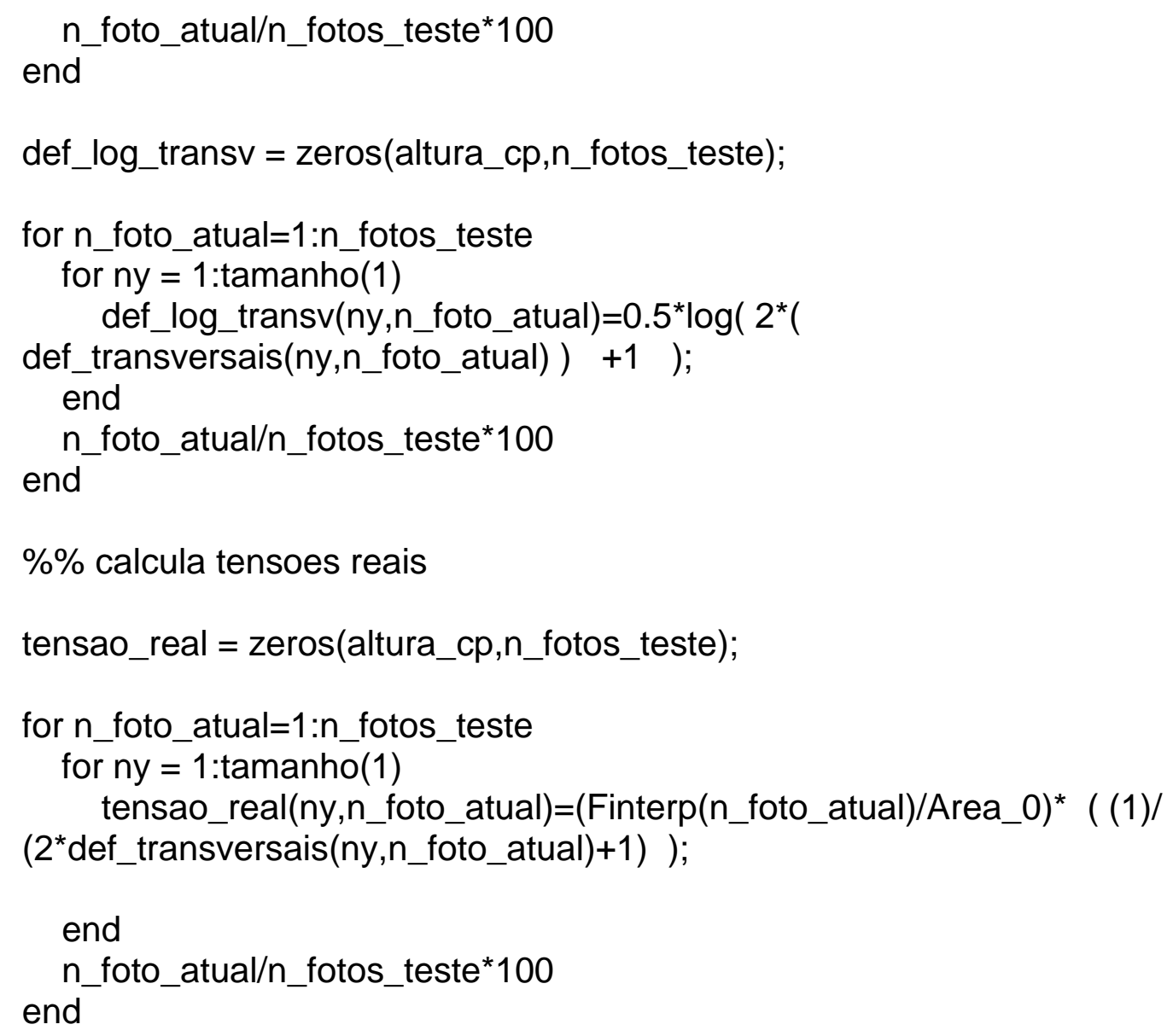

$\% \%$ PLOTAR TUDO

seccao_maxima $=233$;

seccao_minima $=42$;

$\%$ ao longo do corpo de prova

fig = figure;

fig. Units = 'centimeters';

$\%[$ left bottom width height]

fig.Position = [lllll 014 21];

fig.PaperType = 'a4';

$\%[$ left bottom width height]

fig.PaperPosition = [ $\left.\begin{array}{llll}0 & 0 & 14 & 21\end{array}\right]$;

subplot $(3,2,1)$;

for n_foto_atual $=1: \mathrm{n}$ fotos_teste

plot(def_longitudinal(seccao_minima:seccao_maxima,n_foto_atual))

hold on

end

axis([0 200004$])$

grid on

xlabel(\{'Posição da secção';' transversal (pixel)'\},'Fontsize',10)

ylabel(\{'Deformação de Green';' longitudinal $(\mathrm{mm} / \mathrm{mm})$ '\},'Fontsize',10) 
xlabel(\{'Posição da secção';' transversal (pixel)'\},'Fontsize',10)

ylabel('Tensão verdadeira (MPa)','Fontsize',10)

print('Figura_01','-djpeg');

fig2 = figure;

fig2. Units = 'centimeters';

$\%[$ left bottom width height]

fig2.Position = [llll $\left.0 \begin{array}{lll}0 & 10 & 8\end{array}\right]$;

fig2.PaperType = 'a4';

$\%[$ left bottom width height]

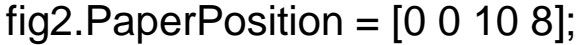

plot(def_log(190,:),tensao_real(190,:)*1e-6,'k','Linewidth',2)

hold on

for seccao_transversal=1:altura_cp

plot(def_log(seccao_transversal,:),tensao_real(seccao_transversal,:: $\left.{ }^{*} 1 \mathrm{e}-6\right)$ hold on

end

plot(def_log(190,:),tensao_real(190,:)*1e-6,'k','Linewidth',2)

$\operatorname{axis}\left(\left[\begin{array}{llll}0 & 1.1 & 0 & 100\end{array}\right)\right.$

grid on

xlabel(\{'Deformação logaritmica $(\mathrm{mm} / \mathrm{mm})$ '\},'Fontsize',11)

ylabel(\{'Tensão verdadeira (MPa)'\},'Fontsize',11)

\% legend(\{'Secção com maior deformação'\},'Location','Northwest')

print('Figura_02','-djpeg');

def_PA61200CP1 = def_log(190,:);

tens_PA61200CP1 = tensao_real $(190,:)$;

save SS_PA61200CP1 def_PA61200CP1 tens_PA61200CP1 


\section{APÊNDICE D - Faz gráfico CP1 e CP2}

$\% \%$ limpa tudo

clear all

close all

clc

$\% \%$ PLOTAR TUDO

fig_t = figure;

fig_t.Units = 'centimeters';

$\%$ [left bottom width height]

fig_t.Position $=\left[\begin{array}{llll}0 & 0 & 14 & 11.5\end{array}\right]$;

fig_t.PaperType = 'a4';

$\%$ [left bottom width height]

fig_t.PaperUnits = 'centimeters';

fig_t.PaperPosition $=\left[\begin{array}{llll}0 & 0 & 14 & 11.5\end{array}\right]$;

load SS_PA61NICP1

plot(def_PA61NICP1,tens_PA61NICP1*1e-6,'b','Linewidth',2)

clear all

hold all

load SS_PA61NICP2

plot(def_PA61NICP2,tens_PA61NICP2*1e-6,'r','Linewidth',2)

clear all

hold all

load SS_PA61200CP1

plot(def_PA61200CP1,tens_PA61200CP1*1e-6,'b:','Linewidth',2)

clear all

hold all

load SS_PA61200CP2

plot(def_PA61200CP2,tens_PA61200CP2*1e-6,'r:','Linewidth',2)

clear all

hold all

load SS_PA61300CP1

plot(def_PA61300CP1,tens_PA61300CP1*1e-6,'b--','Linewidth',2)

clear all

hold all 


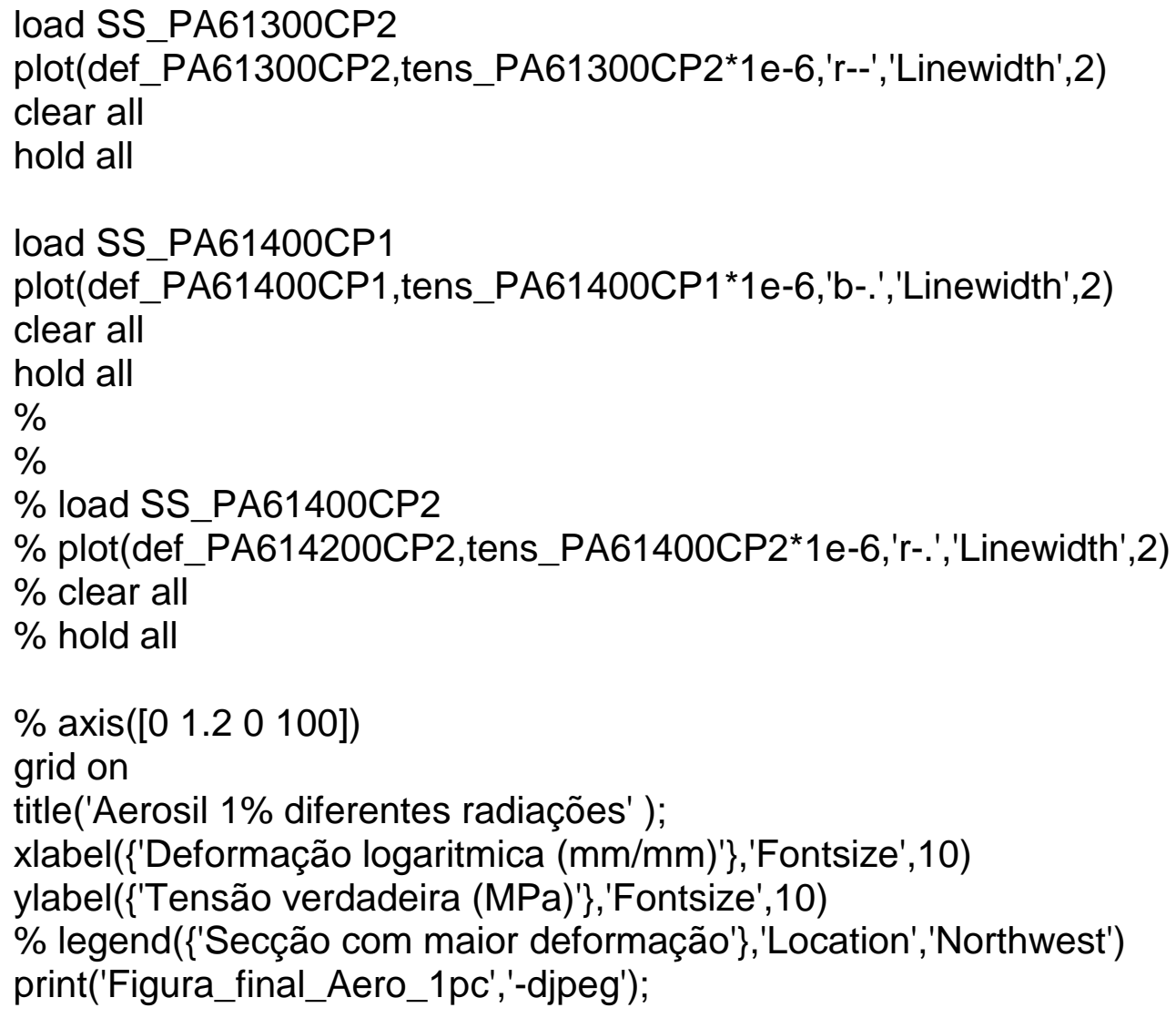


